\title{
EFFECT OF A PSYCHOPATHY DIAGNOSIS, OFFENDER GENDER, AND OFFENDER AGE ON JUROR DECISION MAKING
}

\author{
A thesis submitted to \\ the Faculty of Graduate Studies and Research \\ in Partial Fulfillment of the requirements for the degree \\ Masters of Arts
}

by

Julie Blais

Department of Psychology

Carleton University

September 2008

(C2008 Julie Blais 


$\begin{array}{ll}\begin{array}{l}\text { Library and } \\ \text { Archives Canada }\end{array} & \begin{array}{l}\text { Bibliothèque et } \\ \text { Archives Canada }\end{array} \\ \begin{array}{l}\text { Published Heritage } \\ \text { Branch }\end{array} & \begin{array}{l}\text { Direction du } \\ \text { Patrimoine de l'édition }\end{array} \\ \begin{array}{l}\text { 395 Wellington Street } \\ \text { Ottawa ON K1A 0N4 } \\ \text { Canada }\end{array} & \begin{array}{l}\text { 395, rue Wellington } \\ \text { Ottawa ON K1A 0N4 } \\ \text { Canada }\end{array}\end{array}$

Your file Votre référence ISBN: 978-0-494-43447-5 Our file Notre référence ISBN: 978-0-494-43447-5

NOTICE:

The author has granted a nonexclusive license allowing Library and Archives Canada to reproduce, publish, archive, preserve, conserve, communicate to the public by telecommunication or on the Internet, loan, distribute and sell theses worldwide, for commercial or noncommercial purposes, in microform, paper, electronic and/or any other formats.

The author retains copyright ownership and moral rights in this thesis. Neither the thesis nor substantial extracts from it may be printed or otherwise reproduced without the author's permission.
AVIS:

L'auteur a accordé une licence non exclusive permettant à la Bibliothèque et Archives Canada de reproduire, publier, archiver, sauvegarder, conserver, transmettre au public par télécommunication ou par l'Internet, prêter, distribuer et vendre des thèses partout dans le monde, à des fins commerciales ou autres, sur support microforme, papier, électronique et/ou autres formats.

L'auteur conserve la propriété du droit d'auteur et des droits moraux qui protège cette thèse. $\mathrm{Ni}$ la thèse ni des extraits substantiels de celle-ci ne doivent être imprimés ou autrement reproduits sans son autorisation.
In compliance with the Canadian Privacy Act some supporting forms may have been removed from this thesis.

While these forms may be included in the document page count, their removal does not represent any loss of content from the thesis.
Conformément à la loi canadienne sur la protection de la vie privée, quelques formulaires secondaires ont été enlevés de cette thèse.

Bien que ces formulaires aient inclus dans la pagination, il n'y aura aucun contenu manquant.

\section{Canada}




\begin{abstract}
Mock jurors $(N=247)$ read a simulated trial transcript involving a case of aggravated assault. The transcript differed in terms of diagnosis (psychopathy vs. antisocial personality disorder/conduct disorder vs. no diagnosis), age (15 vs. 30 ), and gender (male vs. female) of the defendant. The effects of these variables on decisions regarding culpability, treatment, violence, and recidivism were investigated. Results indicated that defendants described as psychopaths and as having APD/CD were more likely to be found guilty, more likely to receive higher ratings of risk for future violence, and were perceived as an increased risk to society regardless of their age and gender. In addition, youth described as psychopathic or as having conduct disorder were believed to be at risk for adult criminality. Only two specific labeling/criterion effects of psychopathy were found: young male psychopaths and adult female psychopaths were given higher ratings of risk for future criminal behaviour compared to offenders with no diagnosis. Finally, in terms of treatment, female offenders were believed to be more amenable to treatment than male offenders regardless of diagnosis and age. Implications of the findings and future directions are discussed.
\end{abstract}




\section{Acknowledgements}

I would like to thank my supervisor, Dr. Adelle Forth, for giving me the opportunity to conduct research in this field. It is with her constant feedback and great ideas that I was able to complete this project. I look forward to continuing this collaboration in the future. I would also like to thank my committee members for their time and invaluable comments.

Thank you to my friend Diane, for always knowing what to say and for making me laugh when I needed to. To Matt Dann, my partner in crime, for always being on my side no matter what, and for helping me code part of this research (I think we need a vacation). Finally, thank you to my parents for their unwavering support throughout this process. You've always been there to help me along, and you've never complained when I've had to cancel visits and miss holidays in order to work. Without you, I would not have been able to achieve my goals and to find the courage to keep going. 
Table of Contents

Page

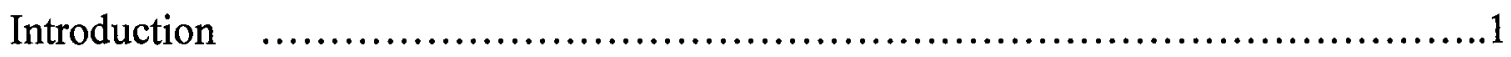

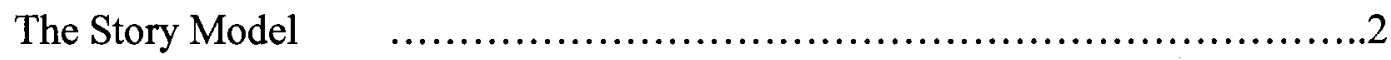

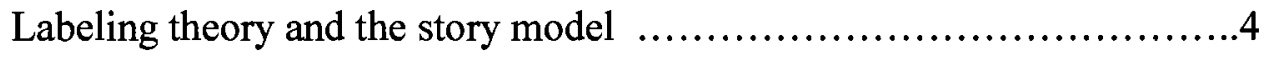

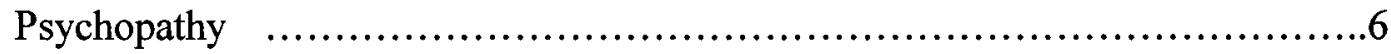

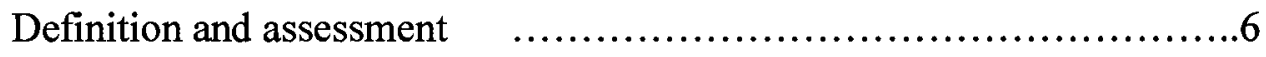

Violence and recidivism $\quad$........................................ 12

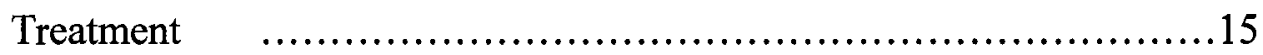

Effect of Diagnostic Labels $\quad$...............................................20

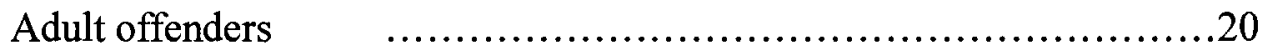

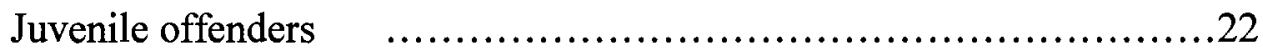

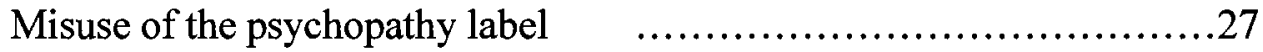

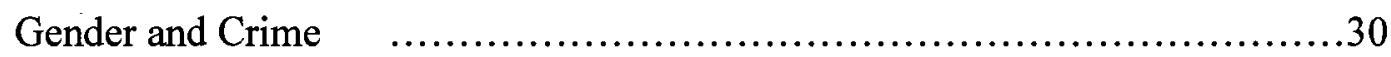

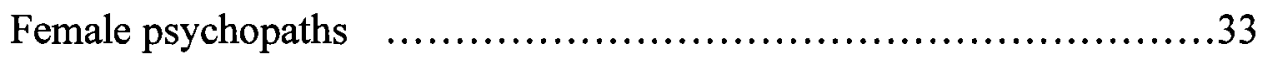

Gender and jury studies $\quad$............................................

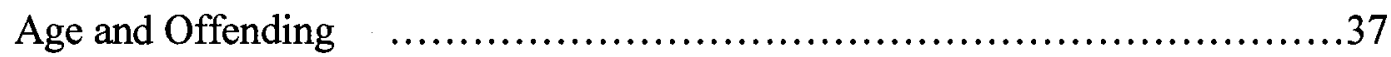

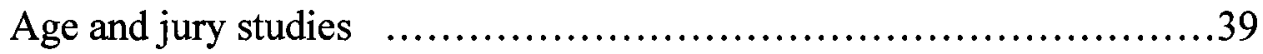

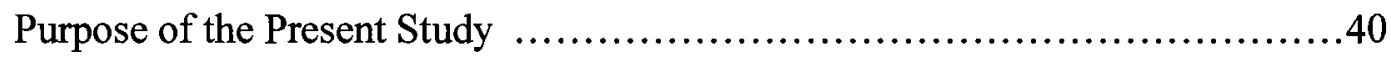

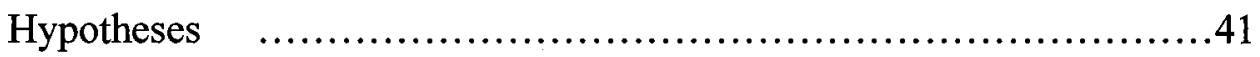

Diagnostic label $\quad$.............................................. 41

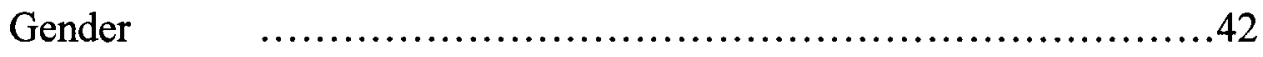


Beliefs

Method

Participants

Design .46

Materials .46

Beliefs questionnaire .46

Trial transcript .46

Demographic questionnaire .47

Credibility ratings form

Verdict and verdict confidence form .47

Proposed sentence form .48

Treatment and risk for violence questionnaire .48

Manipulation check .48

Procedure .48

Results. .50

Preliminary Analysis 50

Manipulation check

Gender 50

Credibility Ratings

Victim, defendant, and expert 
Continuous verdict

Dichotomous verdict 56

Verdict confidence

Sentencing .56

Treatment, Violence, and Recidivism.

Treatment

Violence 59

Recidivism 60

Beliefs .66

Open-ended question .70

Discussion .74

Manipulation Check .74

Mock Juror Gender .75

Effects of Diagnostic Label .76

Gender of the Defendant .84

Age of the Defendant .86

Interactions .88

Beliefs and the Story Model 89

Limitations and Future Direction .91

Conclusion and Implications .94

References 97 


\section{List of Tables}

Table 1. Mean credibility ratings for the victim, defendant, and expert witness as a function of diagnosis, age, and gender of the offender.

Table 2. Mean verdict rating as a function of diagnosis, age, and gender

of the offender

Table 3. Logistic regression predicting verdict from diagnosis, age, and

gender of the defendant.

Table 4. Mean ratings for treatment questions as a function of diagnosis, age, and gender of the offender.

Table 5. Mean ratings for the violence question and the recidivism questions as a function of diagnosis, age, and gender of the offender.

Table 6. Beliefs questionnaire assessing attitudes towards psychopathy, gender, and age.

Table 7. Correlations between the three categories of beliefs questions and credibility ratings (victim, defendant, expert), verdict, and verdict confidence for the entire sample.

Table 8. Correlations between the three categories of beliefs questions and sentence recommendation, treatment, violence and recidivism for the mock jurors who rendered a guilty verdict.

Table 9. Frequency of mock jurors' responses to an open-ended question concerning verdict reasoning.

Table 10. Frequency of the three diagnostic categories for participants who rendered not viii 
guilty and guilty verdicts............................................ 73 


\section{List of Figures}

Figure 1. Interaction plot of mean ratings of risk for future criminal acts for youth defendants defined by gender and type of diagnosis.....................64

Figure 2. Interaction plot of mean ratings of risk for future criminal acts for adult defendants defined by gender and type of diagnosis.......................65 


\section{List of Appendices}

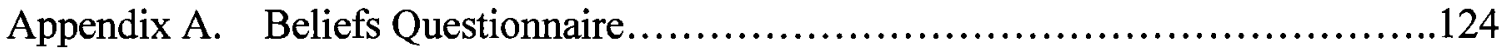

Appendix B. Court Summary..................................................126

Appendix C. Demographic Questionnaire......................................131

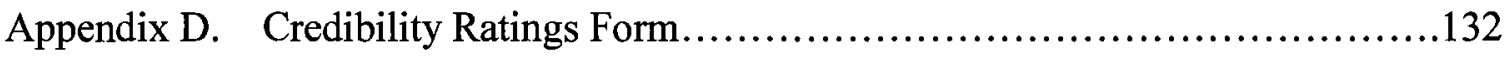

Appendix E. Verdict and Verdict Confidence Form................................133

Appendix F. Proposed Sentence Form........................................134

Appendix G. Treatment and Risk for Violence Questionnaire.......................135

Appendix H. Manipulation Check...............................................136

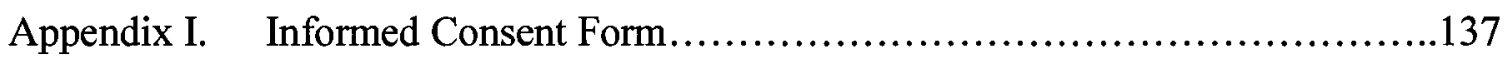

Appendix J. Debriefing Form.............................................139

Appendix K. Reasons for Verdict Decision........................................141 
Effect of a psychopathy diagnosis, offender gender, and offender age on juror decision making

Psychopathy has consistently been shown to be a risk factor for violence (Tengström, Grann, Långström, \& Kullgren, 2000), recidivism (Walters, 2003a, 2003b, 2006), and poor treatment outcomes (Hare, Clark, Grann, \& Thornton, 2000). In the past several years, research examining the applicability of the psychopathy diagnosis in children and adolescents has grown exponentially. Findings are confirming that even in a younger population, psychopathy is related to aggression (Edens, Skeem, Cruise, \& Cauffman, 2001) and recidivism (Gretton, Hare, \& Catchpole, 2004). Although some studies are also showing negative results in terms of treatment, (O’Neill, Lidz, \& Heilbrun, 2003), others have reported more positive findings indicating that youth with psychopathic features may benefit from intensive treatment (Caldwell, Skeem, Salekin, \& Van Rybroek, 2006).

Within the criminal justice system (CJS), decisions about the potential risk and culpability of an offender are often made by laypersons who may hold stereotypic views regarding psychopaths. Research examining the effect of a psychopathy diagnosis on members of the CJS has indicated that a potential biasing effect occurs for both adult (Edens, Desforges, Fernandez, \& Palac, 2004) and youth offenders (Edens, Guy, \& Fernandez, 2003). Despite these findings, recent research has shown that clinicians working with juvenile offenders are not influenced by a psychopathy label when asked about treatment (Rockett, Murrie, \& Boccaccini, 2007). The goal of the present research is to further explore the potential biasing effect a psychopathy label may have on juror decision making while exploring the mitigating or aggravating effects of factors such as 
age and gender of the offender. For example, the introduction of the Youth Criminal Justice Act (YCJA) has placed an emphasis on alternatives for youth offenders such as treatment and rehabilitation; however, do jurors still feel that youth will benefit from these alternatives if they are also described as psychopaths?

The Story Model

An important consideration when conducting jury simulation research is the theoretical model that explains how mock jurors make decisions. The following is a description of the story model proposed by Pennington and Hastie (1986) as an alternative to other flawed models commonly used in the past.

Before proposing the story model, Pennington and Hastie (1981) conducted a comprehensive review of the existing decision making models. The first model examined was the mathematical information integration model which had received support in the past (Kaplan \& Kemmerick, 1974). This model postulates that jurors give independent weight and value to both legally relevant (e.g., case facts) and irrelevant (e.g., physical appearance of defendant) components of a trial. When making decisions, the jurors then integrate all the informational cues in order to have a single unitary evaluation of guilt or lack of guilt (Kaplan \& Kemmerick, 1974). In contrast, Pennington and Hastie (1981) proposed that an adequate model must describe the cognitive representation of information instead of simply relying on the way information is integrated and calculated. They emphasized that the information integration model, and other mathematical models (e.g., Bayesian and sequential weighting), fail to capture the complexity of legal decision making. 
Unlike mathematical models, the story model hypothesizes that jurors impose a narrative structure to the evidence being presented in order to organize and facilitate their comprehension of that evidence. Jurors then use this narrative to make a pre-deliberation verdict based on the information they've acquired during the trial and on their own personal knowledge. The story model consists of three stages: story construction, verdict category establishment, and story classification (Pennington \& Hastie, 1986).

Story construction occurs during evidence presentation and after evidence presentation. Jurors incorporate the trial evidence into a plausible story of what they believed happened. Evidence presentation during a trial is often disconnected and in a question and answer format. Since it often restricts information concerning motive, emotion, and connecting events, the juror must fill in the gaps by organizing the information into an "episode schema" which characterizes the actor's goals, reasons for their actions, and the consequences of those actions (Pennington \& Hastie, 1986).

The second stage, verdict category establishment, describes the juror's understanding of the different verdicts available. This stage most likely takes place during the judge's instructions to the jury on matters of law. The juror is presented with different verdict alternatives each with its own criteria and rules of applicability. In most criminal cases, there will be several verdict alternatives with several elements that the prosecution must prove in order to have the verdict apply. The third and final stage of the story model is story classification. In this stage, the juror uses the narrative they have constructed using the evidence from the trial and their own personal knowledge to select the verdict that matches their story taking into consideration the judge's instructions. 
Several studies have validated the use of the story model in interpreting jury decision making (Pennington \& Hastie, 1986, 1988). Pennington and Hastie (1986) conducted a study using twenty-six subjects who had previously served on a jury. The subjects watched a three-hour trial re-enactment and were asked to orally describe how they had come to a decision between four verdict alternatives. In order to show support for the story model, the jurors' oral accounts must contain organizational elements consistent with the construction of a narrative (e.g., causal chains) and jurors who decided on different verdicts must have different stories. Results indicated that jurors did use elements of an "episode schema" to form a story. Results also indicated that jurors who chose different verdicts also differed in their narratives (Pennington \& Hastie, 1986).

The story model provides the necessary theoretical framework for examining the potential biasing effect of certain variables on jury decision making. For example, diagnostic labels, gender, and age of the offender all have the potential to either mitigate or aggravate the case against the offender depending on how the juror feels about the particular issue. The story model proposes that jurors use the evidence from the trial as well as personal information to construct a story and it is with the inclusion of their already existing ideas that bias can occur.

Labeling theory and the story model. One of the key principles of labeling theory is that the deviant label (i.e., psychopath) results in society treating the person as deviant (Scheff, 1966, 1972). As a consequence to that differential treatment, the person who has been labeled continues to exhibit deviant behaviour (secondary deviance). Despite the claim of some researchers that the behaviour of the individual and not the label itself leads to differential treatment (Gove, 1982; Huffine \& Clausen, 1979), others have shown 
that members of the general public will stigmatize a person labeled as mentally ill in the absence of information concerning aberrant behaviour (Link, 1987; Link, Cullen, Frank, \& Wozniak, 1987). It is more commonly believed now that aberrant behaviour leads to a particular label which then causes differential treatment resulting in more aberrant behaviour (Link \& Cullen, 1986; Mechanic, McAlpine, Rosenfield, \& Davis, 1994).

In order to understand how a label may lead to discrimination it is important to understand the difference between a stereotype and a prejudice. Stereotypes are negative beliefs about a group (e.g., dangerous, violent) whereas prejudice is the agreement with those beliefs and the formation of negative emotional evaluations as a result of that agreement (Allport, 1979; Devine, 1989, 1995). Discrimination is the behavioural reaction to a prejudice. In terms of the CJS, possible discrimination against people labeled with a mental illness has been documented (Porporino \& Motiuk, 1995; Teplin, 1984; Teplin, Abram, \& McLelland, 1994).

The story model states that during the story construction stage jurors will use information from the trial (e.g., evidence, extra-legal factors) and their own beliefs in order to form a narrative which will aid them in making decisions. When a defendant is given a label (e.g., psychopath), that label can become part of jurors' narratives. Jurors will assess their beliefs of that label and may therefore participate in discrimination if those beliefs are based on false information. Preliminary research into the portrayal of psychopaths in the media has found that they are generally depicted accurately (Stevens, 2008), therefore whether harsher decisions can be considered prejudicial will later be discussed. 
In terms of youth, the media has depicted "a class of violent, impulsive, callous, and untreatable juvenile offender" (Vidal \& Skeem, 2007, p. 481) without actually using the psychopathy label. These offenders have been called "superpredators" (e.g., Dilulio, 1995; Innes, 1997) and their depiction in the media could affect how mock jurors view a youth offender described with similar language (i.e., psychopath). Labeling youth as superpredators or psychopaths could cause discrimination since not all findings regarding adult psychopaths have been proven to apply to youth. If jurors extend their beliefs about adult psychopaths to youth defendants, they may make erroneous decisions (e.g., amenability to treatment). Regardless, if jurors' beliefs about psychopathy can be found to predict trial outcomes, then those results would validate the story model. In addition, if the reasons given for verdict outcome decisions differ between mock jurors that render a guilty verdict versus those that render a not guilty verdict, that information could also be supportive of the story model.

Psychopathy

Definition and assessment. Psychopathy is a construct used to describe distinct affective, interpersonal, and behavioural characteristics (Hare, 1991). Hervey Cleckley (1988) described the psychopath as someone who is superficially charming, dishonest, and manipulative. The psychopath engages in ego-enhancement, while being immune to negative consequences as a form of punishment. Despite these characteristics, psychopaths are also seen as lacking other signs of mental disorder (e.g., schizophrenia; Cleckley, 1988).

The assessment of psychopathy was advanced with the creation of the Psychopathy Checklist (Hare, 1980) and the Hare Psychopathy Checklist-Revised (PCL- 
R; Hare, 1991, 2003). These tools, which use semi-structured interviews and file information, make it possible to detect the personality features as well as the behavioural components of psychopathy. The PCL-R consists of 20 questions scored on a 3-point scale $(0,1$, and 2$)$. A total score of 30 or greater is indicative of psychopathy. The psychometric properties of the PCL and the PCL-R have been well established and replicated in numerous studies (Cooke \& Michie, 1997, 1999; Hare, 2003; Salekin, Rogers, \& Sewell, 1996) and in different populations such as young offenders (Forth, Hart, \& Hare, 1990) and female offenders (Hare, 2003). Through factor analysis, two correlated factors have been identified within the PCL-R (Hare, 1991, 1998; Hare et al., 1990; Harpur, Hakstian, \& Hare, 1988). Factor 1 represents the affective and interpersonal component of psychopathy while Factor 2 describes the antisocial lifestyle and behavioural patterns. Harper et al. (1988) assessed the construct validity of these two factors in the PCL. They concluded that both factors are not only valid, but measure unique elements of psychopathy. They further stated that any scale focusing on only one factor would be inadequate in the assessment of psychopathy. A four-factor structure of the PCL-R has also been proposed: Interpersonal, Affective, Lifestyle, and Antisocial factors (Hare, 2003). Subsequent research has found support for these four factors as a means of further capturing the nature of psychopathy (Neumann, Kosson, \& Salekin, 2007).

Introducing a cut-off score of 30 for the PCL-R invites criticisms as to whether psychopathy can be defined in categorical terms. Would someone scoring 29 simply be considered a non psychopath despite displaying certain psychopathic characteristics? Harris, Skilling, and Rice (2001) describe psychopaths as comprising "a discrete natural 
class of individuals (even though the boundaries of this class may be indistinct" (p. 197). It is true that although psychopathy may share similarities with other disorders (e.g., antisocial personality disorder) it has its own distinct emphasis on affective and interpersonal traits (Edens, Marcus, Lilienfeld, \& Poythress, 2006a). Harris, Rice, and Quinsey (1994) conducted one of the most influential studies in support of the taxonic structure of psychopathy. Through taxometric analyses of the PCL-R in a large sample of mentally disordered offenders, they reported that not only could a taxon be identified, but that scores as low as 20 on the PCL-R could differentiate between psychopaths and non psychopaths. This study has subsequently received many criticisms including having used an atypical sample (e.g., large number of not guilty by reason of insanity (NGRI) offenders) (Edens et al., 2006a).

Despite the attempt of other researchers to define psychopathy as a taxon (Skilling, Harris, Rice, \& Quinsey, 2002), Edens and colleagues (2006a) have instead argued that psychopathy is a dimensional construct. Using multiple taxometric procedures on PCL-R scores, the authors were unable to identify an underlying taxonic structure for psychopathy. These results support the contention that psychopathy may actually be extreme levels of personality traits that are continuously distributed (Benning, Patrick, Blonigen, Hicks, \& Iacono, 2005; Lilienfeld \& Fowler, 2006). In the legal system, distinctions are often made between offenders who are considered either psychopathic or not and important decisions (e.g., death penalty decisions in the U.S.) are rendered based on those distinctions (DeMatteo \& Edens, 2006; Walsh \& Walsh, 2006). If psychopathy is dimensional, then decisions based on taxons could be considered arbitrary (Edens et al., 2006a). 
Interest in studying psychopathy among children and adolescents has grown considerably in the last 10 years propelled by early research conducted by Frick (e.g., Frick, O'Brian, Wootton, \& McBurnett, 1994) and Lynam (1996). Extending the construct of psychopathy to include children and adolescents is argued to be beneficial in terms of finding etiological causes for psychopathy and developing prevention and intervention programs (Frick, 1998, 2002; Lynam, 1998, 2002). Despite these advantages, researchers have questioned whether psychopathy, a construct describing adult behavioural and affective attributes is applicable to children and adolescents given the transient nature of symptoms in this population (Salekin, 2002; Skeem, Monahan, \& Mulvey, 2002). Hart and colleagues argue "...if stable personality does not exist in childhood or adolescence, then surely personality disorder cannot" (Hart, Watt, \& Vincent, 2002, p. 242). Also, even if psychopathy can be applied to youth, the malleability of traits in this population is unknown. It is possible that assumptions about adult psychopaths (e.g., untreatable), which may not apply to younger populations will be extended downward to the study of youth psychopathy (Petrila \& Skeem, 2003). There is also concern over the potential labeling effect of a psychopathy diagnosis. Psychopathy as a label applied to youth "could do significant harm, particularly given that many of the adolescents to whom the label might be applied are already involved in juvenile proceedings" (Petrila \& Skeem, 2003, p. 691).

Despite these possible problems, researchers have also discovered that personality structures and disorders rarely have a sudden onset in adulthood. There is evidence to suggest a developmental and a biological component to psychopathy which would make it imperative to study the disorder among a younger population (Forth, Kosson, \& Hare, 
2003). Research examining psychopathic traits in children began with the different subtypes of conduct disorder (CD) defined by the Diagnostic and Statistical Manual of Mental Disorders (DSM-III; American Psychiatric Association, 1980); CD was divided into a "socialized" and "undersocialized" type. The "socialized" type closely resembled Factor 2 of the PCL-R in that it was characterized by deviant and antisocial behaviours and lifestyle while the "undersocialized" type, characterized by lack of affect, egocentrism, and manipulation mirrored Factor 1 of the PCL-R. The next version of the DSM, however, focused more on behavioural characteristics of $\mathrm{CD}$, moving away from concepts similar to adult psychopathy (Frick \& Ellis, 1999).

Stemming from the "undersocialized" CD group, researchers identified the interpersonal/affective psychopathy factor, calling it "callous-unemotional" (CU) traits. $\mathrm{CU}$ traits have been related to more severe and pervasive $\mathrm{CD}$, therefore prompting the assertion that the combination of $\mathrm{CU}$ traits and $\mathrm{CD}$ represents an etiological pathway to psychopathy (Barry, Frick, DeShazo, McCoy, Ellis, \& Loney, 2000; Frick \& Ellis, 1999; Lynam, 1996). In line with this pathway, numerous research studies have found relations between childhood psychopathy measures and conduct problems (high CU) in clinicalreferred samples (Christian, Frick, Hill, Tyler, \& Frazer, 1997; Frick et al., 1994), juvenile offender samples (Caputo, Frick, \& Brodsky, 1999; Kruh, Frick, \& Clements, 2005), and in the community (Frick, Cornell, Barry, Bodin, \& Dane, 2003). In terms of the stability of psychopathic characteristics, Barry, Barry, Deming, and Lochman (2008) have found that psychopathic traits in children (i.e., CU traits, conduct problems, and narcissism) are stable at three separate time points during early middle school. Similar results were also found by Frick, Kimonis, Dandreaux, and Farrell (2003). Other studies 
are reporting that youth psychopathy is also moderately stable from adolescence to adulthood (Loney, Taylor, Butler, \& Iacono, 2007; Lynam, Caspi, Moffitt, Loeber, \& Stouthamer-Loeber, 2007; Lynam, Loeber, \& Stouthamer-Loeber, 2008). Finally, research has demonstrated that CU traits and antisocial behaviour have both environmental correlates (e.g., negative parenting characteristics) and a strong genetic influence (Larsson, Viding, \& Plomin, 2008; Viding, Blair, Moffitt, \& Plomin, 2005). The development of the Hare Psychopathy Checklist: Youth Version (PCL: YV; Forth et al., 2003) has given researchers the tool necessary for studying psychopathy in youth populations. The PCL: YV was developed from the Hare Psychopathy ChecklistRevised (PCL-R; Hare, 1991, 2003). Certain similarities between the scales include their ability to measure interpersonal, affective, antisocial, and behavioural aspects of psychopathy, as well as their comparable assessment procedures (expert-rater, multisource information needed for a diagnosis). The PCL: YV excludes certain items from the PCL-R that are largely inapplicable to youth populations such as questions relating to marital relationships and work history. The scale was also modified to take into account normal fluctuations in behaviour associated with adolescence. Studies have supported the validity and reliability of using the PCL: YV to study psychopathy in children and adolescents (Corrado, Vincent, Hart, \& Cohen, 2004; Dolan \& Rennie, 2006; Forth et al., 2003). Studies that have evaluated the factor structure of the PCL: YV have also reported a two-factor model similar to the one found with adult offenders (Brandt, Kennedy, Patrick, \& Curtin, 1997; Forth, 1995). Factor 1 describes the interpersonal and affective components and Factor 2 describes the deviant behavioural 
features. Neumann, Kosson, Forth, and Hare (2006) have also supported the three-factor model (interpersonal, affective, and antisocial dimensions) of psychopathy in youth.

Violence and recidivism. Since psychopaths represent $15-25 \%$ of the federal inmate population, it is not surprising that psychopathy is a risk factor for future dangerousness and violent recidivism (Salekin et al., 1996; Tengström et al., 2000). In an early study, Hare and Jutai (1983) found that $18 \%$ of charges to offenders scoring high on the original PCL (Hare, 1980) were for violence compared to $9 \%$ for offenders scoring low on the PCL. Porter, Birt, and Boer (2001) found that offenders scoring high on the PCL-R (Hare, 1991) committed a mean 7.32 nonsexual violent crime compared to the mean 4.52 for low scorers. The researchers also concluded that this difference was evident over three decades, indicating that psychopathic offenders commit more violent crimes throughout the length of their criminal careers.

Closely related to violence, is the relationship between psychopathy and recidivism. There is pressure within the CIS to make appropriate and accurate decisions concerning the release and supervision of offenders into the community (Douglas, Vincent, \& Edens, 2006). Several meta-analyses have attempted to summarize the known literature on psychopathy and its relationship to violent and general recidivism. Salekin et al. (1996) reported mean effect sizes (Cohen's $d$ ) of .55 for violent and non-violent recidivism (10 studies); however this meta-analysis has been accused of contaminating the results by including both community and institutional studies (Lipsey \& Wilson, 2001). Hemphill, Hare, and Wong (1998) conducted a meta-analysis using only community based studies and reported weighted correlations of .27 for general recidivism, .27 for violent recidivism, and .23 for sexual recidivism. They also noted that 
Factor 2 (antisocial behavioural pattern) of the PCL-R (Hare, 1991) was more predictive of general recidivism than was Factor 1 (affective-interpersonal dimension).

Gendreau, Goggin, and Smith (2002) conducted a meta-analysis (57 studies) exploring the utility of both the PCL-R and the Level of Service Inventory-Revised (LSIR; Andrews \& Bonta, 1995) in predicting offender risk. Gendreau et al. reported a weighted effect size of .23 for general recidivism and .21 for violent recidivism for the PCL-R. They also reported considerable heterogeneity in the observed effect sizes. The authors expressed concern in using the PCL-R as a risk assessment tool and reported larger effect sizes for general and violent recidivism for the LSI-R $(\Phi=.37$ and .26 respectively). Walters (2003a) explored the utility of the PCL-R in predicting future criminal outcomes. He reported a weighted point biserial correlation of .26 for general recidivism (33 studies). He also reported that Factor 2 showed higher predictive relations for general and violent recidivism $(r=.32$ and .26$)$ than Factor $1(r=.15$ and .18$)$. Factor 2 of the PCL-R has also been found to be more predictive of general and violent recidivism in institutional samples (Walters, 2003b). In a more recent meta-analysis, Leistico, Salekin, DeCoster, and Rogers (2008) reported that higher total PCL scores and factor scores were related to antisocial conduct. They also reported that Factor 2 scores were more strongly related with antisocial conduct than were Factor 1 scores. Results from meta-analyses have clearly shown a relationship between psychopathy and future criminality; however, the heterogeneity of effect sizes also suggests that this relationship could be moderated by other variables (Douglas et al., 2006).

With an increased interest in juvenile violence in general and having research that clearly shows a link between violence and adult psychopathy, discovering a relationship 
between psychopathic youth and violence is of considerable interest. Gretton et al. (2004) used the PCL: YV (Forth et al., 2003) to investigate the relationship between youth psychopathy and recidivism during a 10-year follow-up period. Participants were 157 adolescent males (ages 12 to 18 ) who had confessed to or been convicted of one or more crimes and were awaiting sentencing. Using archival file information, the PCL: YV was retrospectively coded for each participant. Results indicated that both factors of the PCL: YV were correlated to violent recidivism, whereas only Factor 2 was correlated with general recidivism. The PCL: YV was not correlated to sexual recidivism. High PCL: YV was also indicative of a shorter length of time before the first violent re-offence took place. Finally, the relationship between high PCL: YV scores and violent recidivism remained even after controlling for conduct disorder, age at first offence, and history of violent and non-violent offending (Gretton et al., 2004). Edens and Cahill (2007) explored criminal recidivism in an ethnically diverse sample of youthful offenders $(N=$ 75) for a follow-up period of approximately 10 years. Unlike the results reported by Gretton et al. (2004), Edens and Cahill did not find a significant relationship between the PCL: YV and general and violent recidivism. The authors caution in making preliminary conclusions, stating that further research is needed in order to fully understand the relationship between ethnicity, psychopathy, and violence.

Edens, Campbell, and Weir (2006b) conducted a meta-analysis exploring the relationship between youth psychopathy and criminal recidivism. The sample consisted of 21 published and unpublished studies exploring recidivism among male and female offenders and across different ethnicities. Results indicated a significant relationship between psychopathy and general $\left(r_{w}=.24\right)$ and violent $\left(r_{w}=.25\right)$ recidivism. 
Psychopathy was not predictive of sexual recidivism. The authors also reported considerable heterogeneity among the effect sizes possibly explained by the gender and ethnic composition of the samples (Edens et al., 2006b). Edens and Campbell (2007) conducted a meta-analysis exploring the relationship between psychopathy and institutional misconduct (15 studies). Misconduct was divided into three types: total, aggressive, and physical. Results indicated that mean weighted effect sizes were consistent for total, aggressive, and physical misconduct $\left(r_{w}=.24, .25\right.$, and .28 respectively). The authors also reported considerable heterogeneity for mean effect sizes associated with aggressive and physical misconduct (Edens \& Campbell, 2007).

Overall, it appears that there is a relationship between psychopathy and general and violent recidivism for both adult and youth offenders. It is important to note, however, that considerable heterogeneity in effect sizes was reported in several different meta-analyses. This indicates that other variables may moderate the relationship between psychopathy and recidivism.

Treatment. One of the important questions laypersons face when dealing with decisions concerning psychopathic offenders is whether these offenders can benefit from treatment. The clinical literature addressing this issue has been pessimistic. Early reports claimed that not only would psychopaths not benefit from treatment but they also lacked the emotional bond necessary to make treatment possible (Cleckley, 1941, 1988). One of the treatments thought to be beneficial for psychopaths was therapeutic communities. The belief was that the type of social milieu provided by therapeutic communities might help change the personality characteristics and behaviours of psychopathic offenders (Hare, 1970). Although some early studies showed promise for this approach to treatment 
(Barker \& Mason, 1968; Copas, O’Brian, Roberts, \& Whiteley, 1984), Rice, Harris, and Cormier's (1992) evaluation of an intensive therapeutic community provided less promising evidence. Rice et al. (1992) compared recidivism rates for 146 treated offenders and 146 non-treated offenders. Results indicated that compared to offenders who received no treatment, treatment was associated with lower recidivism for the nonpsychopathic offenders and higher recidivism for the psychopathic offenders. Several studies on therapeutic communities have shown similar negative treatment results for psychopathic offenders (Hobson, Shine, \& Roberts, 2000; Ogloff, Wong, \& Greenwood, 1990).

Cognitive-behavioural treatments (e.g., relapse prevention programs) focusing on an offender's criminogenic needs, have also been recommended for the treatment of psychopaths (Andrews \& Bonta, 1994; Serin \& Kuriychuk, 1994). Hare et al. (2000) conducted a review of a cognitive-behavioural program with results indicating that treated offenders scoring high on Factor 1 of the PCL-R had higher rates of recidivism than non-treated offenders also scoring high on Factor 1. Seto and Barbaree (1999) originally reported that sex offenders with high PCL-R scores and favorable ratings by therapists conducting the treatment were more likely to reoffend. After re-analyzing the data using a better outcome database, however, Barbaree (2005) found no interaction between PCL-R scores and treatment behaviour. Langton, Barbaree, Harkins, and Peacock (2006) explored the effect psychopathy might have on the treatment responses of 418 sex offenders who had undergone a cognitive-behavioural treatment in prison (average 5 year follow-up). Results indicated that higher PCL-R scores were related to 
negative behaviours in treatment and predicted serious recidivism. Ratings of response to treatment did not predict recidivism for this sample.

With differing opinions concerning the relationship between psychopathy and treatment outcomes, it is important to mention research that has attempted to summarize the known literature. D'Silva, Duggan, and McCarthy (2004) conducted a review of 24 studies evaluating the treatment outcomes for psychopathic offenders. The goal of this review was to discover if treatment does in fact negatively impact psychopaths as has been suggested by previous studies. In order to identify the studies with an appropriate design, the authors set the following inclusion criteria: appropriate control group, focus on treating psychopathy, appropriate outcome variables, and adequate length of followup. Of the 24 studies, D'Silva et al. found that only three met the inclusion criteria; however the authors further concluded that these three studies had significant methodological flaws (e.g., retrospective file review, small sample size, and incomplete reporting). D'Silva et al.'s review demonstrated that the apparent inverse relationship between high psychopathy and treatment response has not been shown when methodological issues are taken into account and is therefore invalid. Salekin (2002) also reviewed 42 treatment studies and concluded that therapeutic pessimism regarding psychopathic offenders has little scientific basis. He claims there are three main problems found in the treatment literature to date: (1) disagreement regarding the characteristics of psychopathy, (2) lack of understanding of the etiology of psychopathy, and (3) few empirical evaluations of the psychopathy/treatment relationship with even fewer followup studies. 
Studies describing the behaviours of youth psychopaths in treatment programs have shown conflicting results. Rogers, Vitacco, Cruise, Sewell, and Neumann (2002) examined the relationship between psychopathy and treatment outcomes in a sample of 82 adolescent offenders treated for substance abuse in a state hospital. High psychopathic youth (as measured by the Psychopathy-Screen scale of the Survey of Attitudes and Life Experiences; Rogers et al., 2002) had a higher number of behavioural problems and lower ratings from the staff on level of improvement at time of discharge. Similarly, O’Neill et al. (2003) found that PCL:YV (Forth et al., 2003) scores for 64 male adolescents being treated for substance abuse were negatively correlated with program participation, attendance, staff ratings of clinical improvement, and positively correlated with recidivism one year after the program. Other studies have shown positive correlations between youth psychopathy and number of physical and verbal aggressive acts during a treatment program (Spain, Douglas, Poythress, \& Epstein, 2004) and with treatment noncompliance (Falkenbach, Poythress, \& Heide, 2003). Overall, it appears that psychopathic youth are more difficult to treat and are more likely to be disruptive in a treatment setting.

Caldwell et al. (2006) conducted a study comparing the treatment outcomes of 141 juvenile offenders scoring high on the PCL: YV (Forth et al., 2003). Two groups were identified: those undergoing treatment at the Mendota Juvenile Treatment Centre (MJTC) and those receiving standard treatment from a juvenile correction institution (JCIs). The MJTC offers a treatment program aimed at helping the most behaviourally disturbed adolescents held in a correctional facility. It emphasizes social skills development and the acquisition of appropriate social bonds in order to remove antisocial 
associations and activities (Sherman, 1993). Data concerning treatment response was collected during a 2-year follow-up period and revealed that a smaller percentage of the MJTC group generally recidivated compared to the JCI group (57\% and $78 \%$ respectively). The JCI group was also twice more likely to violently recidivate in the community than the MJTC group (21\% and 49\%). The authors concluded that treatments similar to that offered at the MJTC could result in lower rates of serious recidivism among juvenile offenders scoring high on the PCL: YV.

A recent study by Caldwell, McCormick, Umstead, and Van Rybroek (2007) explored the treatment progress of 86 delinquent boys also from the MJTC. Treatment progress was assessed using behavioural rating scales and indices of institutional misconduct (e.g., misconducts requiring intervention). Caldwell et al. (2007) reported that PCL: YV (Forth et al., 2003) scores were predictive of institutional maladjustment and aggression before treatment. Despite finding that the high psychopathy youth were more difficult to treat, the authors reported that they did show a positive response to treatment. More specifically, PCL: YV scores no longer predicted behavioural ratings and institutional misconducts at the end of the treatment program. After a four-year follow-up period, violent recidivism was no longer predicted by initial PCL: YV scores. The main limitation of this and previous studies mentioned is that the treatments being assessed are not designed to specifically reduce psychopathic features.

Although the adult literature concerning psychopathy and treatment outcomes is quite pessimistic, many of these studies have been fraught with poor methodology. Preliminary studies on youth psychopathy have been more promising indicating that some treatment interventions may help reduce recidivism and institutional misconduct. It 
is now important to assess whether laypersons within the CJS make decisions that are consistent with the psychopathy literature.

Effect of Diagnostic Labels

Adult offenders. It has been argued that "the [psychopathy] label may drive decision making in the legal setting in a more punitive direction" (Petrila \& Skeem, 2003, p. 691). Empirical research examining this potential biasing effect has only begun to surface in recent years. In an early study, Guy and Edens (2003) wanted to distinguish between different types of risk assessment instruments (clinical opinion, actuarial assessment, or ratings of psychopathy) in order to examine the impact on potential jurors' attitudes towards the defendant. Participants (172 undergraduate students) were presented with a mock transcript from a commitment trial for a violent sexual predator. The researchers manipulated type of risk assessment method (psychopathy vs. clinical opinion vs. actuarial) and level of actual risk (high risk for future violence vs. low risk for future violence). After taking gender of the potential juror into account, results indicated that women in the psychopathy condition were more likely to vote for commitment and give higher ratings of dangerousness than men in the same condition. No differences between genders were found for the other risk assessment conditions. The authors concluded that a defendant described as a "high risk psychopath" was judged more harshly, but only by female jurors. Gender is usually found to confound results when the offence being described is sexual in nature (Guy \& Edens, 2003, 2006).

Edens et al. (2004) conducted a study evaluating the effects of a mental disorder diagnosis on mock jurors' decisions in order to discover if biasing effects were specifically related to psychopathy or psychosis in general. The researchers manipulated 
the mental disorder variable by placing 238 undergraduate students in one of three mental disorder conditions (psychopathy, psychosis, or no disorder) and one of two violence conditions (high or low). The information was presented in the form of court transcripts describing the crime and the prosecution and defence's arguments from the sentencing hearing. In the psychopathy condition, the students read a description of the defendant consistent with Factor 1 items of the PCL-R. In the psychosis condition, the defendant was described using criteria from the DSM-IV (American Psychiatric Association, 1994) diagnosis of schizophrenia. Specific labels were never used.

Results indicated that students in the psychopathy condition rated the defendant as a higher risk for future dangerousness than students in the no disorder condition. The same pattern was found in the psychosis condition and there was no significant difference between the psychosis and the psychopathy manipulation. The authors concluded that mock jurors may be biased by descriptions of a mental disorder in general, and not specifically psychopathy. In terms of the risk manipulation, students rated the defendant higher on future dangerousness if he was placed in the high risk/ no psychosis condition compared to the low risk/ no psychosis condition. However, there were no significant differences between risk levels in the psychopathy or psychosis conditions. These results indicate that including evidence of a mental disorder may convince jurors that the defendant is at risk for future dangerousness even when presented with evidence that describes the defendant as a low risk.

Edens, Colwell, Desforges, and Fernandez (2005) conducted another study in an attempt to replicate the previous findings. Using the same design, 203 undergraduate students completed the questionnaire concerning their perceptions of a defendant's risk 
for future violence and their preference for the death penalty. Once again, the researchers found that the psychopathy group rated the defendant significantly higher on future dangerousness and there was no difference between the psychosis and psychopathy groups. In terms of sentencing, students were more likely to support the death penalty if the defendant was described as a psychopath compared to both the psychosis and nonpsychosis groups. Results also indicated that the mental disorder variable predicted the preference for the death penalty beyond the respondents' assessment of dangerousness. From these results, the researchers concluded that using the PCL-R as a risk assessment tool in the sentencing phase of capital trials can bias the jury to favor the death penalty even though very little evidence exists concerning psychopaths' future violence if sent to life imprisonment. It is important to note that this study took place in the United States; Canada no longer has a death penalty.

Juvenile offenders. Edens et al. (2003) conducted one of the first studies examining the potential biasing effect of psychopathy traits using juvenile offenders. Undergraduate students $(N=360)$ read a newspaper article which described a death row inmate who was appealing his sentence due to the fact that he had committed the crime during his adolescence. Researchers manipulated the presence or absence of a psychopathy diagnosis by inserting a description of the defendant as exhibiting traits consistent with Factor 1 of the PCL-R, or exhibiting traits not consistent with a diagnosis of psychopathy (e.g., trustworthy). Participants answered questions regarding three main categories: sentencing, rehabilitation, and general beliefs about juvenile violence.

Participants also rated whether they believed the defendant exhibited psychopathic traits independent of the research condition they were assigned. Participants in the 
psychopathic traits condition were more likely to support the death penalty (U.S. study) and less likely to support treatment options for the defendant, despite being presented with mitigating factors such as a history of sexual abuse. Across the treatment conditions, if the participants described the defendant as having psychopathic traits, they were more likely to support the death penalty. Based on these results, the researchers concluded that simply describing a defendant as possessing psychopathic traits could bias mock jurors towards harsher penalties without explicitly using the psychopathy label.

In order to examine the potential biasing effects of diagnostic labels versus diagnostic criterion, Murrie, Cornell, and McCoy (2005) conducted a study using juvenile probation officer (JPO) recommendations. Juvenile probation officers read vignettes which manipulated the presence of diagnostic labels (psychopathy, conduct disorder, no diagnosis) and diagnostic criterion (antisocial behavioural history and psychopathic personality traits) in order to examine general labeling effects, specific labeling effects, and criterion effects. JPOs answered a questionnaire regarding their recommendations for the type of service the youth should receive (supervision, transfer to adult court etc.) and whether they believed the youth would commit future crimes.

Results indicated that using the labels themselves did not produce significant differences, but that describing the youth as possessing the specific traits related to the diagnostic labels was much more influential. More specifically, JPOs supported harsher decisions when the youth were described as having a history of antisocial behaviour. JPOs also found that the youth displaying psychopathic personality traits were more likely to commit future crime and to become adult criminals when compared to the no criterion group. Results indicated very little evidence for specific labeling effects with 
JPOs having similar recommendations for both the conduct disordered and psychopathic offenders. A general labeling effect was found with JPOs more likely to recommend psychological services for youth with a diagnosis (conduct disorder or psychopathy) than for youth without a diagnosis. Overall, the researchers concluded that the criteria that underlie labels may be more biasing than the labels themselves.

Murrie, Boccaccini, McCoy, and Cornell (2007) replicated the findings of the previous research using a national sample of judges $(N=326)$. Like JPOs, judges were not negatively affected by the labels presented (conduct disorder or psychopathy) but rather by the diagnostic criteria. Judges prescribed more serious sanctions when the youth was described as having a history of antisocial behaviour and they also believed the youth to be at risk for future violence and adult criminality. The presence of psychopathic personality traits was less influential, however, judges were still less likely to recommend the least punitive sanction for these youths. Judges were also more likely to expect future violence and adult criminality if the youth were described as having psychopathic traits. These results support the conclusion that diagnostic labels are less influential than the criteria that underlie them.

Vidal and Skeem (2007) investigated the effects of psychopathy, abuse, and ethnicity on JPOs' decision making and supervision strategies. Using a 2 (psychopath/ non-psychopath) $\times 2$ (severe abuse/ no abuse) $\times 2$ (African American/ Caucasian) design, a significant effect was found for the psychopathy and abuse variables but not for ethnicity. More specifically, JPOs believed that psychopathic offenders (criteria and label were mentioned) were slightly less likely to adhere to a treatment program and be amenable to that treatment. They also believed that psychopathic offenders and offenders 
with an abuse history were at greater risk for future dangerousness. JPOs were likely to recommend secure placement for both psychopathic and abused offenders however they also recommended intensive supervision for psychopathic youth. Finally, JPOs were more likely to expect supervision difficulties from both abused and psychopathic youth however they would adopt a control-oriented approach when dealing with psychopathic youth and a care-oriented approach with the abused offenders. Interestingly, no interaction was found between the psychopathy and abuse history variables indicating that JPOs do not differentiate psychopaths into sub-types.

Rockett et al. (2007) examined the potential biasing effect of psychopathy on the recommendations of clinicians working in the juvenile justice setting. The authors manipulated three variables: history of antisocial behaviour (substantial vs. minimal), psychopathic traits (present vs. absent), and diagnostic label (psychopathy, conduct disorder, no diagnosis). Clinicians $(N=109)$ were asked about their recommendations for psychological services, the likelihood that the youth would benefit from treatment, the future violence risk of the youth, and the likelihood that the youth would become an adult offender. Results indicated that psychopathy traits and the label itself had no effect on clinicians' views regarding treatment. The psychopathy label did result in higher perceptions of violence risk, however this effect was no longer evident when the youth was also described as having a substantial history of antisocial behaviour. Psychopathy traits resulted in higher ratings for future violence and for the likelihood of adult criminality. The authors concluded that clinicians are more responsive to psychopathic traits than are other members of the CJS. 
Finally, Jones and Cauffman (2008) assessed the effect of psychopathy in a sample of 100 judges from juvenile and adult courts. Each judge read a scenario where the details of the crime itself remained unchanged: two males, aged fifteen, were involved in an assault on one another. There were four scenarios in total which manipulated the presence/absence of psychopathy information: 1) no mental health information present, 2) the defendant is labeled a psychopath but no other information given - label condition, 3) defendant described as a psychopath without a label - trait condition, and 4) both the label and the traits of psychopathy were given. Judicial decision making was assessed on four dependant variables: culpability, amenability to treatment, dangerousness, and restrictiveness. Results indicated no significant differences across the four scenarios for culpability. Defendants described in the label and traits condition were recommended for more restrictive placements and were perceived as less amenable to treatment than the no disorder condition. In terms of dangerousness, those described in the trait condition, label condition, and the traits and label condition were perceived as more dangerous than those in the no disorder condition. After controlling for dangerousness, the effect of psychopathy on placement recommendations was no longer significant, indicating that perceived restrictiveness operates through the perception of dangerousness of the youth (Jones \& Cauffman, 2008).

Research concerning the possible biasing effect of a psychopathy diagnosis has just begun to emerge. It is clear that an effect of psychopathy does occur, however, whether the effect can be considered a bias or good discernment is still unclear. One of the main limitations of these studies is that employing vignettes can rarely capture the complexity of an actual court case. 
Misuse of the psychopathy label. After reviewing the empirical literature on psychopathy and its subsequent effect on members of the CJS, one might be tempted to ask whether harsher sanctions for psychopathic offenders can really be considered a bias. If the research reveals that psychopathy is a risk factor for violence (Tengström et al., 2000) and recidivism (Walters, 2003a, 2003b, 2006) should these offenders not be given more severe sanctions in the interest of public safety? Is the literature on diagnostic labels actually revealing effective decision making on the behalf of the CJS? The problem lies not in the actual use of a diagnostic label, but rather in its misuse. The potential problem with introducing a psychopathy diagnosis in the court system occurs when the label is misused and inappropriate conclusions concerning the defendant are drawn.

Edens (2001) explored the misuse of the PCL-R in the United States court system by presenting two case studies. The first case concerned a defendant convicted of multiple murders. The prosecution sought to include the defendant's PCL-R score during the penalty phase of the trial in order to secure the death penalty. The argument was that the defendant, having achieved the diagnosis of psychopath, was likely to pose a significant threat to fellow inmates. Edens (2001), however, claims that although some studies have found a strong correlation between the PCL-R and violent disciplinary infractions and base rates of institutional violence (Forth et al., 1990) others have failed to replicate these findings (for a review see Edens et al., 2001). In this case, PCL-R evidence may be inappropriate in deciding whether an offender should be put to death or sentenced to life imprisonment. In terms of the present case, the defence was successful in suppressing the use of the PCL-R score and the defendant was sentenced to life without parole. 
The second case explored by Edens (2001) concerned the testimony of a psychiatrist during the trial of a man charged with several counts of sexual assault. The psychiatrist claimed that due to the absence of certain risk factors (i.e., psychopathy) the defendant was unlikely to have committed the crimes. Unfortunately, several problems with regards to the administration and reporting of the PCL-R were present: 1) the expert witness did not have adequate information to administer the PCL-R, 2) only fractions of the test were reported during the testimony, and 3) the expert witness drew erroneous conclusions concerning the results (e.g., the witness claimed that a lack of psychopathic traits made it unlikely that the defendant would engage in incestuous acts). After several hours of deliberation, the defendant was found not guilty. These two cases demonstrate that evidence concerning psychopathy can and is misused in the court system. Conclusions are drawn that may not accurately reflect the current literature and the PCL$\mathrm{R}$ itself can be administered incorrectly.

Zinger and Forth (1998) conducted a review of expert testimony on the diagnosis of psychopathy in Canadian criminal proceedings. The goal of this review was to examine whether the expert testimony met the highest standards and was indeed based on empirical literature concerning psychopathy. In Canada, a psychopathy diagnosis has been used to justify life imprisonment (e.g., R. v. Schultz, 1987), to justify the transfer of youth offenders to adult court (e.g., R. v. G. R., 1994), and to increase the length of a parole ineligibility period (e.g., $R . v$. Kasparek, 1994). It is evident that in the majority of cases, a psychopathy diagnosis results in harsher sanctions for the defendant, but is the evidence presented accurate? In terms of actual assessment practices within Canadian courts, it appears that the most popular assessment method is clinical opinions or clinical 
opinions paired with a structured diagnosis (e.g., Antisocial Personality Disorder) both of which are not as effective as the PCL-R. Even so, the use of the PCL-R to assess psychopathy in the courtroom can also be fraught with difficulties. For example, there have been cases where conflicting testimony is presented concerning the actual PCL-R score (e.g., R. v. L.M.T., 37 versus "low 20s"), discrepancies that may be due to insufficient training or bias on the part of the evaluator. In two instances, the PCL-R was administered and scored using only file information, a practice that can only be done properly if adequate information is available (Serin, 1993).

Zinger and Forth (1998) explored the use of a psychopathy diagnosis in predicting violent recidivism. They reported that in general, psychopathy evidence is presented in categorical terms (e.g., psychopath vs. non-psychopath) however research has shown that the different factors of psychopathy relate differently to violent and general recidivism (Walters, 2003b; Serin, 1996; Walsh \& Kosson, 2008). Therefore, the authors contend that evidence should be presented as dimensional in order to ensure the accuracy of the information and to avoid judicial misunderstandings. Finally, expert witnesses have stated that psychopaths are essentially untreatable which has invariably resulted in more severe dispositions for offenders (e.g., R. v. Newman, 1989; R. v. C.-T., 1991). It is widely argued within the treatment literature that the lack of treatment amenability may actually be the result of inappropriate treatment rather than offender resistance (for a review see D'Silva et al., 2004). Zinger and Forth's (1998) review demonstrates that not only is expert testimony on psychopathy being used in Canadian criminal courts but also that it does not always reflect the empirical research on the assessment, prediction, and treatment of psychopathy. 
The use of psychopathy evidence in the courtroom has increased tremendously with the large majority of cases involving assessments of risk for general and sexual violence (DeMatteo \& Edens, 2006; Walsh \& Walsh, 2006). Although instances of misuse have been reported, DeMatteo and Edens (2006) also state that in the majority of cases PCL-R evidence is relevant to the legal question at hand and conclusions drawn are both valid and reflective of the available research on psychopathy. Despite this claim, the authors caution that "clinicians who choose to use [the PCL-R] should be forthcoming about the limits of its relevance to the question being addressed" (p. 233). It is clear that it is not the use of the PCL-R that is the issue, but rather its misuse in the CJS that can cause prejudicial outcomes for defendants.

\section{Gender and Crime}

Historically, female offenders have not been the focus of research examining crime. One of the reasons is that female offenders do not commit crime at the same rate as male offenders. In $2006-2007,6.2 \%$ of admissions to federal custody were for female offenders (Public Safety Canada, 2007). There are also differences in the types of crime committed; men are more likely to serve sentences for violent crimes and women are more likely to serve sentences for drug related offences (Chesney-Lind \& Pasko, 2004). There are several characteristics that female offenders share with their male counterparts: they tend to be younger (e.g., early 30 s), less educated, and on social assistance. Unlike male offenders, female offenders are more likely to be victims of physical and sexual abuse, have higher rates of mental disorder, engage in self-injurious behaviour, and have less extensive criminal histories (Chesney-Lind \& Pasko, 2004). 
Female offenders may also be treated differently by members of the CJS. For example, police officers have been found to associate law-breaking with male offenders more so than with female offenders (Horn \& Hollin, 1997; Young, 1991). Horn and Hollin (1997) reported that both police officers and civilians believed female offenders to be more reliable and responsible. They also believed that females turn to crime because of external reasons and not because of personal characteristics. Sentences also tend to be shorter for female offenders than for male offenders. For example, in $2007,92 \%$ of women were given a sentence of six months or less compared to $85 \%$ of men (Public Safety Canada, 2007). O'Neil (1999) proposed the "chivalry" theory in an attempt to explain the differential sentences received by women. This theory states that the criminal justice system is male-dominated and views female offenders as fragile and in need of protection from harsh treatment. Closely related is the "paternalism" theory which imposes a parent-child like relationship between the justice system and female offenders. In this case, the female offender is the child who cannot be held fully accountable for her actions (O’Neil, 1999). These theories may be more applicable to Caucasian offenders, since it is widely cited that there is an overrepresentation of female Aboriginal offenders in the CJS (Correctional Service Canada, 2001). Finally, social control theory postulates that women receive lighter sentences because they require less formal social control due to their inherent bond with other individuals (e.g., families and children; Nagel \& Johnson, 1994).

In contrast to these theories of crime, other studies that have controlled for legal factors such as prior offences have failed to find any differences between the treatment of male and female offenders (Clarke \& Koch, 1980; Dannefur \& Schutt, 1982; Horowitz \& 
Pottieger, 1991; Teilmann \& Landry, 1981). Horowitz and Pottieger (1991) evaluated the handling of serious delinquent youths during the arrest, adjudication, and disposition stages of the justice system. After controlling for race, type of offence, arrests, and number of adjudications certain gender differences were found, most noticeably at the arrest stage. Although there was a higher likelihood of repeat arrests for females, the authors believed that it was due to the visibility and nature of the crime females were most likely arrested for: prostitution. Females were also more likely to be found at the adjudication stage, however, again, prostitution is more likely to be adjudicated than other crimes committed by males. The authors concluded that although some gender differences were significant, there are explanations for these differences that do not involve a gender bias.

Increasing the ambiguity of the gender bias literature, other studies have reported that female delinquents are treated more harshly at different stages of the CJS (ChesneyLind \& Sheldon, 1997; MacDonald \& Chesney-Lind, 2001; Sheldon \& Horvath, 1986; Stahl, 1998). In a multiyear analysis, MacDonald and Chesney-Lind (2001) examined the effect of gender as it related to three separate issues: 1) whether a case was officially petitioned, 2) whether a case resulted in the finding of delinquency at the adjudication hearing, and 3) whether a case resulted in a formal disposition. Results indicated that at the early stages of the court process (e.g., petition and adjudication) there were no gender differences in how delinquents were handled; however, gender did matter when delinquents got passed the initial stages. More specifically, female delinquents were given harsher sanctions during formal dispositions for relatively minor offences such as 
running away from home. Therefore, it appears that whether a gender bias does or does not occur may depend on the different stages of the CJS.

Female psychopaths. Women often experience higher rates of internalizing problems such as depression while men are more likely to have externalizing problems such as antisocial personality and aggression (Robins \& Regier, 1991). One explanation for these differences is that there is underlying cognitive and biological differences between males and females (Hankin \& Abramson, 2001) which may also help to explain differential rates of psychopathy. The prevalence rate for psychopathy among male offender samples ranges from $15 \%$ to $30 \%$ when the standard PCL-R cut-off score of 30 is used (Vitale, Smith, Brinkley, \& Newman, 2002). Although some studies have reported similar base rates of psychopathy in incarcerated women as is found in men (3231\%; Louth, Hare, \& Linden, 1998; Strachan, 1993), others have shown lower rates for psychopathy in women. Vitale et al. (2002) reported a range of $9 \%$ to $23 \%$ in female offender samples and Hare (2003) reported a base rate as low as 7.5\%. Other studies using mean scores for males and females have found that women also have lower mean PCL-R scores than men (Weiler \& Widom, 1996; Rutherford, Cacciola, Alterman, \& McKay, 1996).

A few studies have attempted to test the generalizability of the two-factor model of psychopathy across gender. Salekin, Rogers, and Sewell (1997) used exploratory factor analysis of the PCL-R (Hare, 1991) and discovered that although the two-factor model was applicable to women, the PCL-R items did not load on the factors in the same way as they did in men. Several items (e.g., impulsivity, poor behavioural controls) cross loaded on both Factor 1 and 2 and other items (e.g., failure to accept responsibility, 
revocation of conditional release) failed to load onto either factor. O'Connor (2001) found similar results using confirmatory factor analysis of the PCL-R in a sample of federal female prisoners. It has been suggested that the differences in factor structure between men and women is actually a reflection of the limitations of the original twofactor model. Warren et al. (2003) conducted an examination of the original two-factor model (Harpur, Hare, \& Hakstian, 1989) as well as the three-factor model proposed by Cooke and Michie (2001), and the four-factor model proposed by Hare (2003). Confirmatory factor analyses revealed that the best fit to the data (sample of 138 female inmates) was represented by the three-factor model; the four-factor model was also found to be a better fit than the original two-factor model.

Research has also examined the different ways in which psychopathy may be manifested in women as opposed to men. An early study by Lilienfeld (1992), postulated that certain disorders more commonly seen in women such as borderline personality disorder (BPD) and histrionic personality disorder (HPD) may actually be female manifestations of psychopathy. More recently, Hamburger, Lilienfeld, and Hogben (1996) found that college men showed higher associations between Psychopathic Personality Inventory (PPI; Lilienfeld \& Andrews, 1996) scores and antisocial personality disorder while women showed a higher relationship between PPI scores and HPD. However, these findings have not always been replicated (Cale \& Lilienfeld, 2002; Wilson, Frick, \& Clements, 1999). In terms of emotional reactivity, it appears that the findings for women parallel those found for men; Factor 1 of the PCL-R is associated with reduced negative emotional reactivity and low levels of anxiety while Factor 2 is 
associated with increased negative emotionality and aggression (Patrick, 1994; Verona, Patrick, \& Joiner, 2001).

Very few studies to date have evaluated the predictive validity of the PCL-R for female offenders. Salekin, Rogers, Ustad, and Sewell (1998) examined the ability of the PCL-R to predict recidivism in a sample of 78 female offenders during a 14-month follow-up period. Results indicated that total PCL-R scores were not significantly related to recidivism $(r=.20, n s)$. The researchers also discovered that contrary to what is reported with male offenders, Factor 1 scores were significantly correlated to recidivism $(r=.26, p<.05)$ while Factor 2 scores showed no significance to recidivism for female offenders $(r=.14, n s)$. Finally, Salekin et al. (1998) reported high rates of falsenegatives: of the women who recidivated, $90 \%$ had not been classified as a psychopath, and of the women who did not recidivate, $9 \%$ had been classified as psychopaths. The authors concluded that the PCL-R was a 'moderate to poor' predictor of recidivism in female offenders.

In another study on psychopathy and recidivism, Loucks and Zamble (2000) included a wide range of variables in their analysis which were grouped into four categories: 1) social, personal, and criminal history; 2) history of maladaptive behaviour, including drug, and alcohol use; 3) history of abuse — physical, sexual, and psychological; and 4) personality, ability, and emotional functioning. Using multiple regression analysis, the authors examined the relationship between these variables and recidivism for 80 women offenders for a follow-up period of 38 months. Results indicated that psychopathy was the most important predictor of recidivism (i.e., releases and readmissions). The authors concluded that psychopathy is a strong predictor of recidivism 
in serious offenders regardless of gender. One limitation of this analysis is that the individual contribution of psychopathy is not known because the results were not disaggregated by predictor variable.

In a more recent study, Richards, Casey, and Lucente (2003) examined the predictive validity of PCL-R on 404 female offenders undergoing in-prison treatment for substance abuse. Results indicated that psychopathy scores were significantly associated with poor treatment response, removal for noncompliance, violent and disruptive rule violations, and avoidance of urinalysis testing. A sample from this initial group $(n=239)$ was also evaluated post-release for a mean period of 13.9 months. During this period approximately $30 \%$ of the women were charged with a new offence and total psychopathy scores were found to negatively correlate to number of charge-free days $(r=$ $-.24, p<.01)$. Regression analyses also revealed that Factor 1 scores significantly predicted new charges (i.e., one-point increase above the group mean associated with $11 \%$ increase in probability of a new arrest; Richards et al., 2003).

Research on psychopathy in women continues to grow. It appears that similarities in psychopathy across genders exist as well as important differences. Although most of the research has focused on testing the applicability of concepts developed with male psychopaths to female psychopaths, new research should begin to develop theories that explain the unique experience of psychopathy in women.

Gender and jury studies. Research examining the effect of gender on mock juries has commonly manipulated the gender of the victim or the gender composition of the jury itself. An early study by Ackerman, McMahon, and Fehr (1984) examined the effect of defendant gender on juries' sentencing decisions. The researchers used a mock transcript 
of a child abuse case where the defendant was described as either a woman or a man and found that jurors suggested longer sentences for male defendants than for female defendants. However, this study used adolescent mock jurors, therefore it is still unknown if this result would be replicated in adults.

More recently, an Australian study by Forster Lee et al. (2004) manipulated the presence of victim impact statements (VIS) and gender of the offender. Results indicated that when there was not a VIS, the male defendant received a harsher sentence; however, when there was a VIS the female defendant received a harsher sentence than the male defendant. Mock jurors also reported more anger towards the female defendant with the inclusion of the VIS. The research described previously on labeling effects has only used descriptions of male offenders. Age and Offending

The Youth Criminal Justice Act (YCJA) is the current Canadian legislation dealing with young offenders. Enacted in 2003, the YCJA has three main objectives: prevent youth crime, provide consequences to behaviours while encouraging personal responsibility, and focus on rehabilitation and reintegration into the community. The YCJA encourages police officers to find extrajudicial measures to dealing with youth crime such as warnings and treatment referrals (Youth Criminal Justice Act, 2002, s. 10). The YCJA has also given judges more options in terms of sentencing including giving a reprimand, issuing an attendance or supervision order, and implementing rehabilitative custody (Youth Criminal Justice Act, 2002, s. 42). Under the YCJA, it is no longer possible to transfer youth offenders to adult court; instead, if found guilty, a judge can apply an adult sentence to a juvenile offender (Youth Criminal Justice Act, 2002, s. 61). 
Age plays an important role in descriptions of criminal behaviour. For example, adolescence has been shown to be a period of heightened risk for antisocial behaviour (Moffitt, 1993). Young offenders are often categorized into those who began offending in childhood (childhood onset) and those who began offending in adolescence (adolescent onset). These two pathways are important in determining the future trajectories of antisocial behaviour. Research has generally shown that early childhood onset of antisocial behaviour is related to more serious and persistent criminality later in life (Fergusson \& Woodward, 2000; Loeber \& Farrington, 2000). Offenders following the adolescent onset trajectory are more likely to desist in early adulthood compared to childhood onset offenders; however some offenders beginning criminality in adolescence will continue this offending into adulthood (Moffitt, Caspi, Rutter, \& Silva, 2002).

There are certain individual and social risk factors that may increase the likelihood that a child or adolescent will develop antisocial or criminal tendencies. For example, biological factors such as parental history of Attention-Deficit Hyperactivity Disorder (ADHD) or behavioural problems can increase risk in children (Cohen, Adler, Kaplan, Pelcovitz, \& Mandel, 2002). Also, there is a relationship between the use of drugs or alcohol during pregnancy and risk for future behavioural problems (Cohen et al., 2002). Finally, childhood temperament can be an individual risk factor. Children described as being difficult to soothe or impulsive are at risk for future disruptive behaviour (Farrington, 1995). In terms of familial risk factors, parental behaviour and parenting style can affect the future behavioural disposition of children. Parents who are harsh and inconsistent in their disciplinary actions increase the likelihood that their child will exhibit behavioural problems (Dekovic, 1999). Other factors such as low 
socioeconomic status, large family size, and parental mental health problems can act as risk factors (Frick, 1994; Patterson, Reid, \& Dishion, 1998). Social risk factors can be found within the school environment. Young children who socialize with aggressive peers are at risk of developing externalizing behaviours (Laird, Jordan, Dodge, Petit, \& Bates, 2001). Social disapproval and feelings of rejection in children who already exhibit aggressive behaviour can also lead to more serious behavioural problems (Rudolph \& Asher, 2000).

Even though research has shown a relationship between age and increased risk for criminality, statistics indicate that the rate at which youths are charged with various crimes (e.g., assault and theft) has actually declined in recent years (Statistics Canada, 2006). Despite these results, juvenile offending remains a topic of much speculation for the public. Media portrayals of crime out of control have helped fuel a public fear towards violent and criminal youth (Jackson, 2004; MacDonald, 1995; Muncie, 1999). Sprott (1999) surveyed over 1,000 Canadians in order to examine gender differences in punitive beliefs concerning offenders. Results indicated that women were more likely to report high levels of fear and beliefs that crime was increasing. Interestingly, women were harsher than men in the sentences recommended for specific cases (descriptions of a youth/ adult first-time offender charged with breaking and entering), unless the offender was a youth. Attitudes towards youth crime are diverse in the general population (Sims \& Johnston, 2004) and it is therefore important to assess the impact that age could have on a layperson's decision making process in the courtroom.

Age and jury studies. There are very few published mock jury studies manipulating age of the defendant. Higgins, Heath, and Grannemann (2007) found no 
effect of defendant age on jurors' verdicts and perceptions of offender responsibility; however the authors described the defendant as being either 22 or 65 years old. Bergeron and McKelvie (2004) examined the effect of defendant age (20 vs. 40 vs. 60 years old) on mock jurors' sentencing decisions. They concluded that defendants that were 20 and 60 years old received more lenient sentences. To date, there have been no studies manipulating the presence of both age of offender (youth vs. adult) and psychopathy. Purpose of the Present Study

The present study investigated the impact of diagnostic labels and criteria, gender, and age of the offender on mock jurors' decisions about culpability, sentencing, and treatment amenability. Working within the framework of the story model, jurors' prior beliefs about the variables were assessed in order to gain better insight into the factors that contribute to decision making. The first variable, diagnostic criteria, consisted of three separate levels: psychopathy, antisocial personality disorder or conduct disorder (APD/CD; depending on the age of the offender), and no diagnosis. Descriptions of each diagnosis were used as well as the labels themselves based on findings that using labels alone does not usually provide significant results (Murrie et al., 2005, 2007). Also, antisocial personality disorder or conduct disorder was used to assess the validity of past research indicating a biasing effect for any diagnosis and not specifically for psychopathy (Edens et al., 2005; Edens et al., 2004). A description of antisocial personality was used when the offender was described as an adult, and conduct disorder was used when the offender was described as an adolescent.

The second variable, gender, was manipulated by changing the trial transcript to include either a male defendant with a male victim, or a female defendant with a female 
victim. Ackerman et al. (1984) found that gender was a mitigating factor in mock jurors' sentencing decisions; therefore, the goal was to see if the presence of psychopathic traits would negate the potential mitigating effect of gender.

The final variable, age, had two levels: adult (30 years old) and early adolescent (15 years old). It was felt that the ages were far enough apart to create two distinct categories of offenders. Also, early adolescence was chosen since it is possible to assign adult sentences in accordance with the Youth Criminal Justice Act (2002).

Findings from this study help to determine if laypersons' beliefs about how different types of offenders should be treated by the CJS are consistent with the findings available on actual violence risk and treatment outcomes. It was also important to assess the influence of diagnostic labels given their increased use in the CJS. More specifically, differential treatment of offenders labeled as psychopaths could be detrimental if the label is misused and incorrect. There is also a gap in the literature concerning the potential mitigating or aggravating effects of offender age and gender; therefore this study explored how these variables were related to the outcome measures. Finally, this was the first Canadian study exploring the effect of psychopathy information on potential jurors' perceptions of psychopathic offenders.

\section{Hypotheses}

Diagnostic label

1. Mock jurors would assign higher ratings of guilt to offenders described as psychopathic and offenders described as having antisocial personality or conduct disorder compared to offenders with no diagnosis. 
2. Mock jurors would recommend harsher sentences to offenders described as psychopathic and offenders described as having antisocial personality or conduct disorder compared to offenders with no diagnosis.

3. Mock jurors would be less positive towards recommending treatment and actual treatment benefit of psychopathic and antisocial personality/conduct disorder offenders than with the no diagnosis offender find offenders

4. Mock jurors would rate psychopathic and antisocial personality/conduct disorder offenders as a higher risk for future violence and criminality.

\section{Gender}

5. Mock jurors would assign lower ratings of guilt for female offenders than for male offenders.

6. Mock jurors would assign less punitive sanctions to female offenders than to male offenders.

7. Mock jurors would be more positive towards recommending treatment and actual treatment benefit of female offenders than of male offenders.

8. Mock jurors would rate female offenders as a lower risk for future violence and criminality compared to male offenders.

Age

9. Mock jurors would assign lower ratings of guilt to the young offender compared to the adult offender.

10. Mock jurors would assign less punitive sanctions to the young offender compared to the adult offender. 
11. Mock jurors would be more positive towards recommending treatment and actual treatment benefit of the young offender compared to the adult offender.

12. Mock jurors would rate the young offenders as a lower risk for future violence and criminality compared to male offender.

\section{Interactions}

13. Mock jurors would assign higher ratings of guilt to offenders described as psychopathic and offenders described as having antisocial personality compared to offenders with no diagnosis for adult and male offenders but not for youth and female offenders.

14. Mock jurors would recommend harsher sentences to offenders described as psychopathic and offenders described as having antisocial personality compared to offenders with no diagnosis for adult and male offenders but not for youth and female offenders.

15. Mock jurors would be less positive towards treatment recommendations and amenability of psychopathic and antisocial personality offenders than with the no diagnosis offender for adult and male offenders but not for youth and female offenders.

16. Mock jurors would be give higher ratings of future risk and criminality to psychopathic and antisocial personality offenders than with the no diagnosis offender for adult and male offenders but not for youth and female offenders.

\section{Beliefs}


17. Mock jurors' beliefs would be correlated with outcome variables of a similar nature (e.g., a question regarding treatment amenability would be related to the outcome variable concerning treatment). 
Method

\section{Participants}

Two hundred and ninety-five participants (121 men and 167 women, 7 declined to respond) were recruited from the first year psychology undergraduate pool at Carleton University and from the community through an email campaign. Participants were given the option to complete a paper copy of the study $(n=131)$ or an online version $(n=164)$. Participants $(M=23.45, S D=8.76$, Range: $18-61$ years $)$ were required to be 18 years of age and be citizens of Canada to more closely resemble eligible jurors. The majority (77\%) of participants were Caucasian and forty-seven percent indicated English as their only language (24\% were bilingual in English and French). Participants consisted mostly of students (82\%) and ninety-nine percent had achieved a high-school diploma.

A total of forty-eight participants were eliminated because they either failed to correctly respond to the manipulation check questions relating to the independent variables and to the charge (questions 1,2 , and 5) $(n=42)$ and/or failed to respond to one or more of the questionnaires $(n=6)$. Therefore, the total number of participants included in the analysis was two hundred and forty-seven (95 men and 145 women, 7 declined to respond). Of these participants $(M=23.74, S D=9.059$, Range: $18-61$ years $)$ seventynine percent were Caucasian and forty-eight percent indicated English as their only language (24\% were bilingual in English and French). The majority of these participants were students (80\%) and ninety-nine percent had achieved a high-school diploma. Course credit was given to participants from the first year psychology pool, and a chance to win $\$ 100$ dollars (name entered in draw) was given as an incentive to other participants not eligible for extra course credit. 


\section{Design}

A 3 (Diagnostic label/criteria: psychopathy vs. antisocial personality disorder or conduct disorder vs. no diagnosis) $\times 2$ (Gender: male vs. female) $\times 2$ (Age: 30 vs. 15 years old) between-subjects factorial design was used. Dependent variables included ratings of guilt, ratings of future dangerousness, severity of sentence (if found guilty), treatment amenability, and overall perceptions of psychopathic, female, and youth offenders.

Materials

Beliefs Questionnaire. Participants answered questions concerning their beliefs about offenders diagnosed as psychopaths, female offenders, and youth offenders on a 7point Likert scale (1- Strongly Disagree to 7- Strongly Agree) (Appendix A). Questions included beliefs about treatment, violence, and recidivism.

Trial transcript. There were twelve different versions of a simulated trial transcript (see Appendix B) describing a case of aggravated assault where the defendant was claiming self-defence. The facts were as follows: Mr./Mrs. Marlowe and Mr./Mrs. Pullman met in an alley to discuss a disagreement concerning infidelity. An altercation takes place which leaves Mr./Mrs. Marlowe stabbed several times. The transcript consisted of opening statements by the Crown and Defence followed by the questioning and cross-examination of Mr./Mrs. Pullman and Mr./Mrs. Marlowe. Mr./Mrs. Pullman claimed that $\mathrm{Mr}$./Mrs. Marlowe became enraged and started choking him/her. In selfdefence, Mr./Mrs. Pullman grabbed a piece of glass and stabbed him/her. Mr./Mrs. Marlowe claimed that Mr./Mrs. Pullman started the altercation and stabbed him/her purposely, not in self-defence. The transcript then described an interview of Mr./Mrs. 
Pullman conducted by a court appointed clinical psychologist and finally, the judge's charge to the jury.

The transcript differed in terms of age of the defendant, gender of the defendant, and diagnostic label/criteria. This was accomplished by changing names and gender pronouns throughout the transcript and through the psychologist's statement. The defendant's age (15 vs. 30 ) was stated by the judge and the defendant. The gender (male vs. female) of the defendant was evident through the names and gender pronouns used. The clinical psychologist provided a description of the defendant using terminology consistent with the diagnoses chosen (psychopathy, antisocial personality disorder or conduct disorder, no diagnosis) as well as the labels themselves.

Demographic questionnaire. Participants completed several demographic questions including age, gender, ethnicity, education level, and language fluency (Appendix C).

Credibility ratings form. The participants answered questions concerning their beliefs of how convincing each testimony was (defendant, victim, expert) on a 7-point Likert scale (1- Not at All to 7- Extremely) (Appendix D).

Verdict and verdict confidence form. Participants indicated the degree to which they found the defendant guilty on a 7-point Likert scale (1- Not at all Guilty to 7Definitely Guilty). Participants were then asked to make a dichotomous choice between Not Guilty and Guilty (Appendix E). Both methods were used in order to increase the sensitivity in finding statistical differences and to maintain external validity. Participants also gave a rating regarding their confidence in their decision on a 7-point Likert scale (1- 
Not Confident at All to 7- Extremely Confident). Finally, participants answered an openended question concerning the elements that helped them make their decision.

Proposed sentence form. Participants were asked to choose a sentence ranging from 1-2 years to 10-14 years in accordance with the Canadian Criminal Code (1985). If the defendant was also described as a young adolescent, participants decided whether to impose the adult sentence or whether to impose an alternative sentence proposed by the Youth Criminal Justice Act (2002) (Appendix F).

Treatment and risk for violence questionnaire. Participants responded to questions concerning potential treatment recommendations and amenability, risk for future violence, and general recidivism of the offender on a 7-point Likert scale (1- Not at All to 7- Extremely) (Appendix G).

Manipulation check. Participants answered five multiple choice questions concerning certain elements of the trial transcript in order to ensure that they had read and understood the transcript. Questions concerned 1) age of the defendant, 2) diagnosis provided, 3) detail about the altercation, 4) the type of weapon used and 5) defendant's charge (Appendix H).

Procedure

Participants were given the option to complete the survey in paper format or through an online survey system. For the paper format, participants were run in small groups of 1-5 people in an assigned room. The participants were randomly assigned to one of the twelve possible treatment conditions. The participants were told that there were numerous scenarios and they must therefore answer their questions independently. Before beginning the study, each participant was instructed to read and sign the informed 
consent form (Appendix I). At this point, they were also told that participation was voluntary and that they could leave at any time without penalty. The consent form was then collected and kept separate from the study envelopes in order to ensure complete anonymity and confidentiality. Participants were instructed to pretend that they were actual jurors on a criminal case. They read the court transcript and responded to the Beliefs Questionnaire, the Demographic Questionnaire, the Credibility Ratings Form, the Verdict and Verdict Confidence Form, the Proposed Sentence Form, the Treatment and Risk for Violence Questionnaire, and finally the Manipulation Check. Upon completing the questionnaire, the participants were told to read the Debriefing Form (Appendix I) carefully and to take it with them upon leaving. The entire session lasted between 30 and 45 minutes.

The online survey consisted of all the same elements as the paper format. Participants were told via email that they could stop the survey at any time without penalty. 


\section{Results}

\section{Preliminary Analysis}

Manipulation check. Manipulation checks (multiple choice questions) were administered in order to assess whether the participants understood the trial transcript and could correctly identify the variables of interest. Questions relating to the age of the defendant, the diagnosis given, and the charge were analyzed for accuracy ( 2 filler questions relating to the location of the altercation and the weapon used were discarded). Ninety-six percent $(n=282)$ of participants were able to correctly identify the age of the defendant in their respective condition ( 15 vs. 30 ). For diagnosis, ninety percent of participants were able to identify the diagnosis given by the expert witness in their condition $(n=265)$, meaning that thirty participants failed to identify the proper diagnosis. Ninety-six percent $(n=282)$ of participants correctly identified the charge of aggravated assault. Only one participant failed to answer the manipulation check questions. Given the high number of incorrect responses for diagnosis, this participant was not included in subsequent analyses. In total, forty-one participants were eliminated for incorrectly responding to one or more of the three manipulation check questions.

Gender. In order to control for the possible confound of mock juror gender (given the unbalanced number of female to male mock jurors) preliminary analyses were conducted assessing the effect of gender on all dependent variables. Previous research examining the effect of jury demographic composition have found that jurors tend to be more lenient to defendants most like themselves (e.g., a majority female jury will more likely convict a male defendant; Fischer, 1997; Schutte \& Hosch, 1997). Also, Guy and Edens (2003) had previously found an effect of mock juror gender on decision making. A 
univariate analysis of variance (ANOVA) revealed a significant main effect of gender for the continuous variable of verdict confidence, $F(1,238)=4.40, p=.04$, partial $\eta^{2}=.02$. Specifically, female mock jurors were less confident in their verdict decision $(M=4.59$, $S D=1.34)$ than male mock jurors $(M=4.96, S D=1.35)$. The only other gender difference occurred with one of the violence questions. Female mock jurors were less likely to believe that the defendant was at risk for future violence $(M=4.25, S D=1.15)$ than male mock jurors $(M=4.69, S D=1.08), F(1,119)=4.56, p=.04$, partial $\eta^{2}=.04$. Due to these findings, gender was controlled for in subsequent analyses involving these dependant variables.

\section{Credibility Ratings}

Victim, defendant, and expert. A 3 (diagnosis; psychopathy vs. antisocial personality/conduct disorder vs. no disorder) $\times 2$ (age of defendant; 15 vs. 30 years $) \times 2$ (gender of defendant; female vs. male) between-subjects multiple analysis of variance (MANOVA) was conducted on mock jurors' ratings of the credibility of the victim, defendant, and expert witness. A significant main effect of gender was found for the credibility of the expert witness, $F(1,235)=10.94, p=.04$, partial $\eta^{2}=.02$. Significant main effects of diagnosis were found for the credibility of the victim, $F(2,235)=4.89, p$ $=.01$, partial $\eta^{2}=.04$, the defendant, $F(2,235)=13.98, p<.001$, partial $\eta^{2}=.12$, and the expert witness, $F(2,235)=3.69, p=.03$, partial $\eta^{2}=.03$. No other main effects or interactions were significant. In terms of gender, mock jurors found the expert witness to be more credible when the defendant was female $(M=5.02, S D=1.47)$ than when the defendant was male $(M=4.60, S D=1.74)$. 
Post hoc comparisons using Tukey's HSD indicated a significant difference in mean victim credibility ratings between the psychopathy and no disorder groups $(p=$ .01). No significant differences in mean credibility ratings of the victim were found for the other two groups (antisocial/conduct disorder vs. psychopathy, $p=.19$; antisocial/conduct disorder vs. no disorder, $p=.41)$. When the defendant was described as a psychopath, mock jurors found the victim to be more credible $(M=3.94, S D=1.34)$ than when the defendant was described as having no disorder $(M=3.31, S D=1.27)$. Mean credibility ratings for the defendant were significantly different between the psychopathy and no disorder conditions $(p<.001)$ and between the antisocial/conduct (APD/CD) and no disorder conditions $(p=.001)$. No significant difference was found between psychopathy and $\operatorname{APD} / \mathrm{CD}(p=.43)$. When the defendant was described as a psychopath or as APD/CD, mock jurors were less likely to find his/ her story credible ( $M$ $=3.85, S D=1.31 ; M=4.10, S D=1.22$ respectively) compared to the defendant described as having no disorder $(M=4.83, S D=1.25)$. These results indicate that the diagnosis presented did affect how mock jurors interpreted the events that took place even though the events in both cases remained unchanged.

Mean credibility ratings of the expert witness were significantly different between the psychopathy and no disorder groups $(p=.01)$. No other significant differences in mean credibility ratings of the expert witness were found. Mock jurors rated the expert witness as less credible when he was describing psychopathy symptoms $(M=4.49, S D=$ 1.68) compared to the description of no disorder $(M=5.16, S D=1.49)$. This is an interesting finding considering that the psychopathy diagnosis proposed by the expert 
witness influenced ratings of credibility for the defendant and the victim. A summary of these findings can be found in Table 1.

\section{Juror Verdicts}

Continuous verdict. A 3 (diagnosis; psychopathy vs. antisocial personality/conduct disorder vs. no disorder) $\times 2$ (age of defendant; 15 vs. 30 years) $\times 2$ (gender of defendant; female vs. male) between-subjects ANOVA was conducted on mock jurors' guilty ratings of the defendant. A significant main effect was found for type of diagnosis, $F(2,235)=17.88, p<.001$, partial $\eta^{2}=.13$. No other main effects or interactions were significant. Tukey's HSD indicated significant mean differences in verdict ratings between the psychopathy and no disorder groups $(p<.001)$ and between the APD/CD and no disorder groups $(p<.001)$. Consistent with the hypothesis for type of diagnosis there were no differences in mean verdict ratings between the psychopathy and antisocial/conduct disorder groups. Also confirmed was that when the defendant was described as a psychopath or as having an antisocial personality/conduct disorder, mock jurors gave higher guilty ratings $(M=4.64, S D=1.33 ; M=4.28, S D=1.45$ respectively) than when the defendant was described as having no disorder $(M=3.38, S D=1.47)$. See Table 2 for a summary of the results of mean verdict ratings as a function of diagnosis, age, and gender of the defendant. 
Table 1

Mean (SD) credibility ratings for the victim, defendant, and expert witness as a function of diagnosis, age, and gender of the offender

Verdict Ratings $\quad$ Victim Defendant Expert

Diagnosis

Psychopathy

Antisocial personality/conduct disorder

No disorder

Age

15 years

30 years

Gender

Male

Female
$3.94(1.34) \quad 3.85(1.31) \quad 4.49(1.68)$

$3.57(1.31) \quad 4.10(1.22) \quad 4.73(1.65)$

$3.31(1.27) \quad 4.83(1.25) \quad 5.16(1.49)$

$3.69(1.30) \quad 4.43(1.22) \quad 4.81(1.69)$

$3.50(1.35) \quad 4.13(1.41) \quad 4.80(1.56)$

$3.59(1.24) \quad 4.33(1.21) \quad 4.60(1.74)$

$3.60(1.42) \quad 4.23(1.44) \quad 5.02(1.47)$ 
Table 2

Mean (SD) verdict rating as a function of diagnosis, age, and gender of the offender

\section{Verdict Ratings}

Diagnosis

Psychopathy

Antisocial personality/conduct disorder

No disorder

Age

15 years

30 years

Gender

Male

Female
$4.64(1.37)$

$4.28(1.45)$

$3.38(1.47)$

$4.02(1.52)$

$4.12(1.51)$

$3.96(1.44)$

$4.19(1.59)$ 
Dichotomous verdict. Logistic regression analysis was performed to predict the probability that a participant would choose a guilty verdict $(0=$ not guilty and $1=$ guilty $)$. The predictor variables were diagnosis, age, and gender of the defendant. All interactions between the variables were included and all variables were simultaneously entered into the model. A test of the full model was significant, $\chi^{2}(11, N=247)=45.13, p<.001$, and the Hosmer and Lemeshow test revealed a good fit between the data and the model (goodness of fit $\chi^{2}=0, d f=8, p=1.0$ ). The Wald test of significance revealed that only psychopathy and APD/CD diagnoses reliably predicted a guilty verdict. The odds ratio for diagnosis indicates that, holding all other variables constant, a defendant described as a psychopath is 7.5 times more likely to elicit a guilty verdict than when the defendant has no disorder, and an APD/CD defendant is 9 times more likely to elicit a guilty verdict than in the no disorder condition. The results from the logistic regression are presented in Table 3.

Verdict confidence. A 3 (diagnosis; psychopathy vs. antisocial personality/conduct disorder vs. no disorder) $\times 2$ (age of defendant; 15 vs. 30 years) $\times 2$ (gender of defendant; female vs. male) between-subjects analysis of covariance (ANCOVA) was conducted on mean verdict confidence ratings while controlling for mock juror gender. No significant main effects or interactions were found.

\section{Sentencing}

The participants who rendered a guilty verdict $(n=125)$ were assessed in terms of the sentence recommendations made. In order to compare both adult and youth sentences together the youth category was collapsed to create a five-point Likert scale (1- least severe to 5- most severe) matching that of adult offenders. 
Table 3

Logistic regression predicting verdict from diagnosis, age, and gender of the defendant

\begin{tabular}{|c|c|c|c|c|c|}
\hline Variables & $\beta$ & $S E$ & Wald & Sig. $(p)$ & $\begin{array}{c}\text { Odds } \\
\text { ratio }\end{array}$ \\
\hline \multicolumn{6}{|l|}{ Diagnosis } \\
\hline Psychopathy & 2.01 & .71 & 8.07 & .004 & 7.47 \\
\hline $\mathrm{APD} / \mathrm{CD}$ & 2.19 & .73 & 9.01 & .003 & 8.96 \\
\hline No disorder ${ }^{\mathrm{a}}$ & $0^{*}$ & & & & \\
\hline \multicolumn{6}{|l|}{ Age } \\
\hline 15 years & .12 & .70 & .03 & .862 & 1.13 \\
\hline 30 years $^{\mathrm{a}}$ & $0 *$ & & & & \\
\hline \multicolumn{6}{|l|}{ Gender } \\
\hline Female & .34 & .68 & .24 & .623 & 1.40 \\
\hline Male $^{\mathrm{a}}$ & $0 *$ & & & & \\
\hline \multicolumn{6}{|l|}{ Interactions $^{\mathbf{b}}$} \\
\hline Age by Gender & -.74 & 1.00 & .55 & .459 & .48 \\
\hline Diagnosis(1) by Gender & -.34 & .97 & .12 & .729 & .71 \\
\hline Diagnosis(2) by Gender & -1.37 & .97 & 1.99 & .159 & .26 \\
\hline Diagnosis(1) by Age & -.87 & .96 & .83 & .362 & .42 \\
\hline Diagnosis(2) by Age & -.95 & .98 & .94 & .332 & .39 \\
\hline $\begin{array}{l}\text { Diagnosis(1) by Age by } \\
\text { Gender }\end{array}$ & 1.97 & 1.41 & 1.95 & .162 & 7.16 \\
\hline $\begin{array}{l}\text { Diagnosis(2) by Age by } \\
\text { Gender }\end{array}$ & 2.42 & 1.38 & 3.06 & .080 & 11.23 \\
\hline
\end{tabular}


More specifically, youth (absolute discharge), youth (discharge with conditions), and youth (fine not to exceed \$1000) were coded as 1 ; youth (community service), youth (probation not more than 2 years) and youth (240 hours in non-residential program) were coded as $2 ;$ youth (custody order less than 2 years) and adult (1-2 years) were coded as 3; adult 3-4 years and adult 5-6 years were coded as 4; adult 7-8 years and adult 10-14 years were coded as 5.

A 3 (diagnosis; psychopathy vs. antisocial personality/conduct disorder vs. no disorder) $\times 2$ (age of defendant; 15 vs. 30 years $) \times 2$ (gender of defendant; female vs male) between-subjects ANOVA was conducted on mean sentence recommendations. Main effect of age was significant, $F(1,113)=23.14, p<.001$, partial $\eta^{2}=.04$. No other main effects or interactions were found. Mock jurors gave higher mean ratings to youth defendants $(M=2.79, S D=0.97)$ than to adult defendants $(M=1.89, S D=0.91)$. This finding should be interpreted cautiously due to the collapsing of the youth sentences to fit a 5-point Likert scale. For adults, mock jurors were likely to recommend between 1 to 4 years in prison. For youth, the same is true: jurors believed that either 1-2 years of custody in a youth detention centre or 1-2 years imprisonment was appropriate for the crime committed.

When the youth data was analyzed separately (i.e., without collapsing across youth sentences) there were no significant main effects of diagnosis, $F(2,55)=1.79, p=$ .18 , partial $\eta^{2}=.06$, or gender, $F(1,55)=0.60, p=.44$, partial $\eta^{2}=.01$, on sentence recommendations. The same is true for the adult data: diagnosis, $F(2,58)=0.32, p=.73$, partial $\eta^{2}=.01$; gender, $F(1,58)=0.02, p=.90$, partial $\eta^{2}=.00$. There was no interaction between diagnosis and gender for either the adult or youth data. 
Treatment, Violence, and Recidivism

Treatment. A 3 (diagnosis; psychopathy vs. antisocial personality/conduct disorder vs. no disorder) $\times 2$ (age of defendant; 15 vs. 30 years) $\times 2$ (gender of defendant; female vs. male) between-subjects MANOVA was conducted on mean ratings for the questions relating to treatment: 1) How likely are you to recommend treatment? 2) How likely is it that the defendant will benefit from treatment? 3) How useful would treatment aimed at reducing violence be? 4) How useful would treatment aimed at reducing criminal behaviour be? Significant main effects of gender were found for question $2, F(1$, $113)=5.21, p=.02$, partial $\eta^{2}=.04$ and question $3, F(1,113)=5.87, p=.02$, partial $\eta^{2}=$ .05 . No other main effects or interactions were significant for the treatment questions. In terms of gender, mock jurors rated female defendants as more likely to benefit from treatment $(M=5.09, S D=1.08)$ than male defendants $(M=4.62, S D=1.20)$. Jurors also believed that a treatment aimed at reducing violence would be more beneficial for female defendants $(M=5.20, S D=1.12)$ than male defendants $(M=4.74, S D=1.25)$. A summary of these findings can be seen in Table 4.

Violence. A 3 (diagnosis; psychopathy vs. antisocial personality/conduct disorder vs. no disorder) $\times 2$ (age of defendant; 15 vs. 30 years) $\times 2$ (gender of defendant; female vs. male) between-subjects ANCOVA was conducted on mean ratings of risk for future violence while controlling for the effect of juror gender. A significant main effect of diagnosis was found, $F(2,108)=6.81, p<.01$, partial $\eta^{2}=.11$. No other main effects or interactions were significant. In terms of diagnosis, simple post hoc contrasts revealed that jurors rated psychopathic $(p<.001)$ and $\operatorname{APD} / \mathrm{CD}(p<.01)$ defendants as a higher 
risk for future violence $(M=4.67, S D=1.10 ; M=4.55, S D=1.10$ respectively) when compared to the no disorder group $(M=3.59, S D=1.10)$. See Table 5 for a summary.

Recidivism. A 3 (diagnosis; psychopathy vs. antisocial personality/conduct disorder vs. no disorder) $\times 2$ (age of defendant; 15 vs. 30 years $) \times 2$ (gender of defendant; female vs. male) between-subjects MANOVA was conducted on mean ratings for the following questions regarding recidivism: 1) How high is the risk for future criminal behaviour? 2) How likely is it that the defendant poses a risk to society? There was a significant main effect of diagnosis for question $1, F(2,113)=11.08, p<.001$, partial $\eta^{2}$ $=.16$, and question $2, F(2,113)=12.00, p<.001$, partial $\eta^{2}=.18$. No other main effects were significant. Tukey's HSD showed significant differences between the psychopathy and no disorder conditions $(p<.001)$ and between the APD/CD and no disorder conditions $(p<.01)$ for question number 1 . The same pattern of results was observed for question number 2: psychopath vs. no disorder $(p<.001)$; APD/CD vs. no disorder $(p=$ $.001)$. There were no differences between the psychopathy and APD/CD conditions. More specifically, mock jurors gave higher mean ratings of risk for future criminal behaviour for the psychopathy $(M=4.48, S D=1.37)$ and $\mathrm{APD} / \mathrm{CD}(M=4.12, S D=$ 1.11) groups than for the no disorder group $(M=3.05, S D=0.10)$. Mock jurors also gave higher ratings of risk to society for psychopathic $(M=4.44, S D=1.25)$ and APD/CD $(M$ $=4.08, S D=1.24)$ defendants compared to the no disorder condition $(M=2.95, S D=$ 1.05). See Table 5 for a summary. 
Table 4

Mean (SD) ratings for treatment questions as a function of diagnosis, age, and gender of the offender

Variables Treatment Questions

$\begin{array}{llll}\mathrm{T} 1 & \mathrm{~T} 2 & \mathrm{~T} 3 & \mathrm{~T} 4\end{array}$

Diagnosis

$\begin{array}{lllll}\text { Psychopathy } & 5.87(1.45) & 4.72(1.22) & 4.87(1.29) & 4.63(1.26) \\ \text { APD/CD } & 5.88(1.27) & 4.88(1.11) & 5.12(1.07) & 4.82(1.03) \\ \text { No disorder } & 5.09(1.72) & 5.18(1.10) & 4.91(1.27) & 4.36(1.53)\end{array}$

Age

$\begin{array}{lllll}15 \text { years } & 5.87(1.41) & 4.89(1.23) & 5.05(1.30) & 4.82(1.34) \\ 30 \text { years } & 5.61(1.50) & 4.84(1.10) & 4.91(1.11) & 4.50(1.11)\end{array}$

Gender

$\begin{array}{llll}\text { Male } & 5.46(1.50) \quad 4.62(1.20) \quad 4.74(1.25) \quad 4.57(1.28)\end{array}$

$\begin{array}{llll}\text { Female } & 6.00(1.37) & 5.09(1.08) & 5.20(1.12)\end{array} \quad 4.73(1.19)$

Note. $\mathrm{T} 1$ = How likely to recommend treatment; T2 = How likely to benefit from treatment; $\mathrm{T} 3=$ How useful treatment at reducing violence would be; $\mathrm{T} 4=\mathrm{How}$ useful would treatment for reducing criminal behaviour be. 
Table 5

Mean (SD) ratings for the violence question and the recidivism questions as a function of diagnosis, age, and gender of the offender

Violence $\quad$ Recidivism $1 \quad$ Recidivism 2

Diagnosis

Psychopathy

$\mathrm{APD} / \mathrm{CD}$

No disorder

Age

15 years

30 years

Gender

Male

Female
$4.67(1.10)$

4.55 (1.06)

$3.59(1.05)$

$4.43(1.08)$

$4.43(1.20)$

$4.42(1.10)$

$4.44(1.18)$
4.48 (1.37)

$4.12(1.11)$

$3.05(1.00)$

$2.95(1.05)$

$4.44(1.25)$

4.08 (1.24)

$4.20(1.34)$

3.89 (1.29)

$3.89(1.20)$

4.05 (1.32)

4.05 (1.24)

4.13 (1.30)

4.03 (1.39)

Note. Violence $=$ Likelihood for future violence; Recidivism $1=$ Likelihood to commit future criminal acts; Recidivism 2 = Likelihood to pose risk to society. 
The main effect for the question relating to risk for future criminal behaviour (Recidivism question 1) was qualified, however, by a significant diagnosis by age by gender interaction, $F(2,113)=3.50, p=.03$, partial $\eta^{2}=.06$. Simple comparisons revealed a significant effect of diagnosis for young males, $F(2,113)=5.15, p=.01$ (Figure 1) and for adult females, $F(2,113)=3.47, p=.04$ (Figure 2). Simple simple comparisons were used to test the contrast between psychopathy vs. no disorder (contrast 1) and APD/CD vs. no disorder (contrast 2). A reduced alpha level $(\alpha=.025)$ was calculated using a Bonferroni correction to control for an inflated Type I error rate. Results indicated that contrast 1 was significant for both youth males $(p<.01)$ and adult females $(p=.02)$. No other significant differences were found. More specifically, mock jurors gave higher mean risk ratings for future criminal behaviour to youth male psychopaths $(M=5.27, S D=1.35)$ compared to youth males with no disorder $(M=2.67$, $S D=1.21)$. Higher risk ratings were also given to adult female psychopaths $(M=4.36$, $S D=1.60)$ compared to adult females with no disorder $(M=3.14, S D=0.69)$.

The youth data was isolated in order to conduct an ANOVA for the following question: How likely is it that the defendant will become an adult criminal? Only the main effect of diagnosis was significant, $F(2,55)=5.26, p=.01$, partial $\eta^{2}=.06$. Tukey's HSD revealed significant differences between the psychopathy and no disorder conditions $(p<.01)$ and between the CD and no disorder conditions $(p=.02)$. Psychopathic youth $(M=4.50, S D=1.40)$ and conduct disordered youth $(M=4.24, S D=$ 1.20) were rated as more likely to become adult criminals when compared to youth with no disorder $(M=3.10, S D=0.99)$. Again, no significant differences were found between the psychopathy and $\mathrm{CD}$ conditions. 


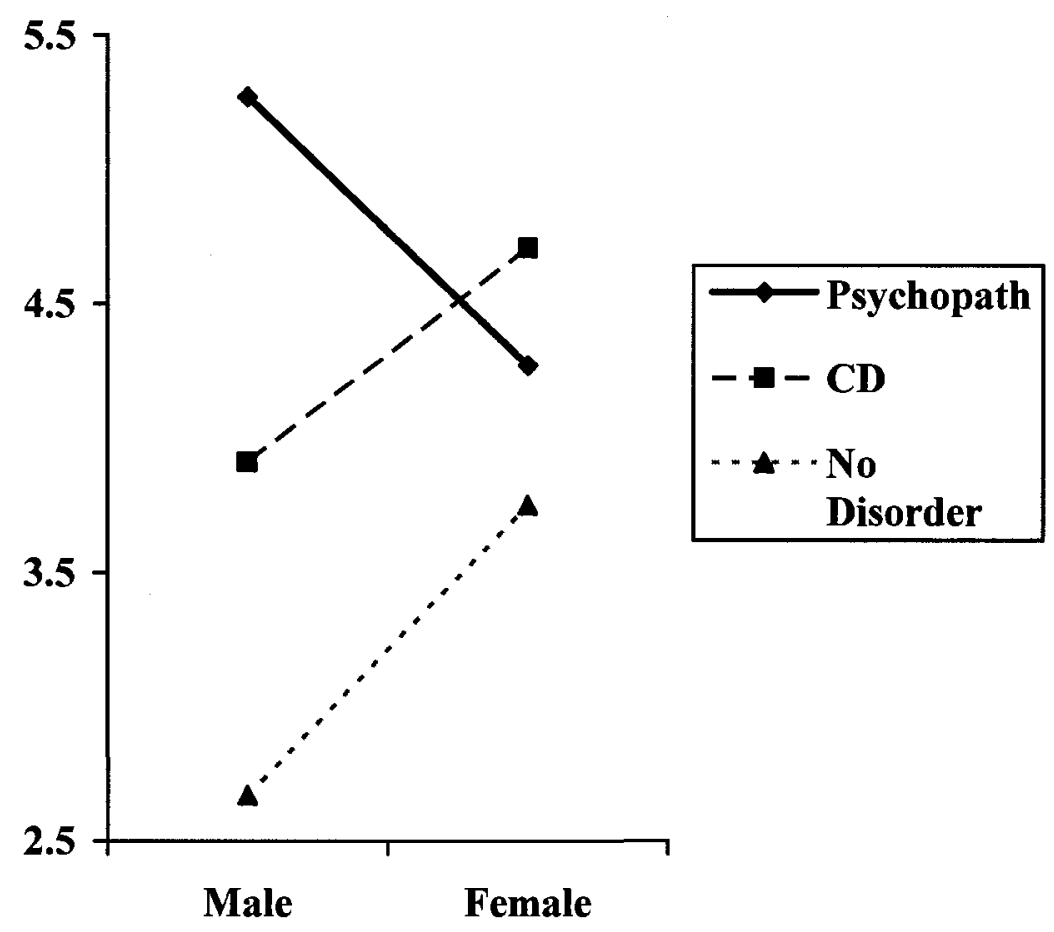

Figure 1. Interaction plot of mean ratings of risk for future criminal acts for youth defendants defined by gender and type of diagnosis 


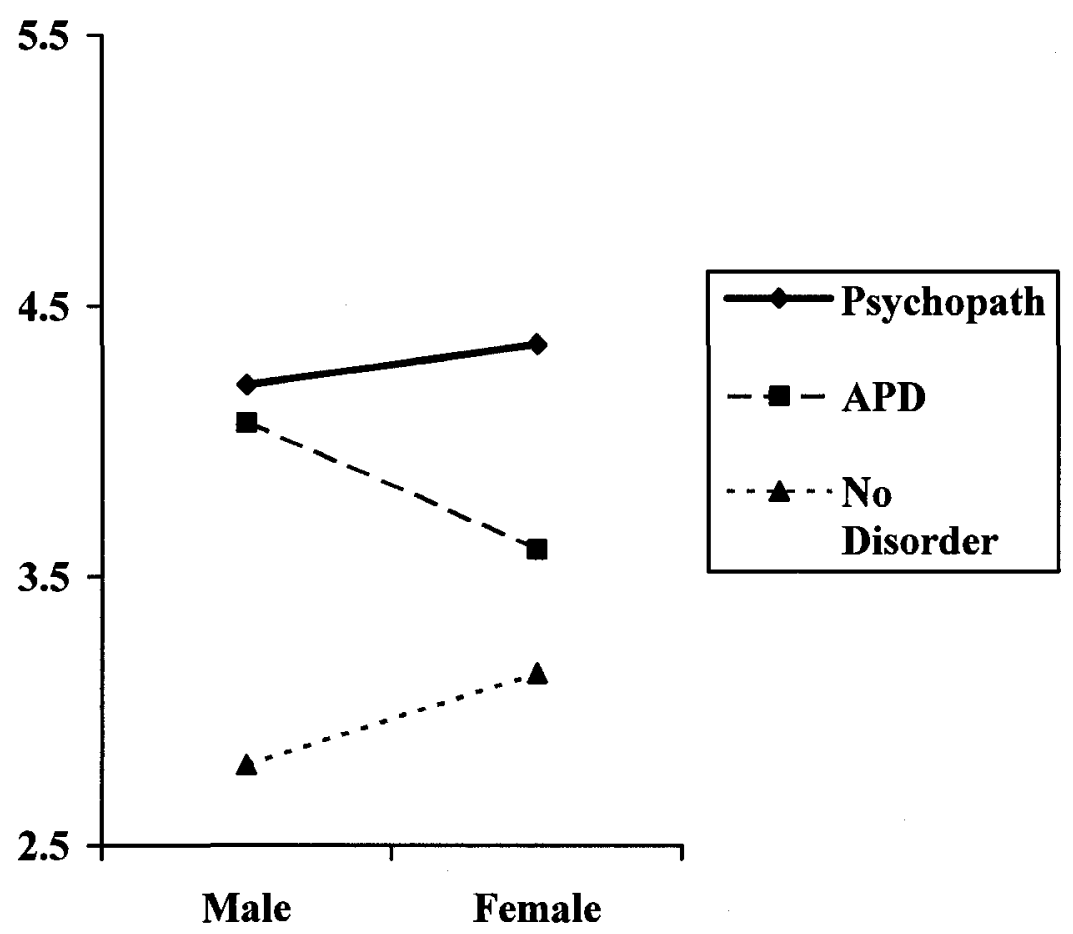

Figure 2. Interaction plot of mean ratings of risk for future criminal acts for adult defendants defined by gender and type of diagnosis 
Beliefs

Beliefs were assessed using fourteen questions relating to different types of offenders, treatment, violence, and recidivism. The questions were grouped in order to create three separate categories: psychopathy, gender, and age (Table 6). Table 7 shows correlations between the three categories and credibility ratings (victim, defendant, expert), verdict, and verdict confidence for the entire sample $(N=247)$. Credibility of the victim was significantly and positively related to questions regarding the gender of the offender. This finding indicates that higher ratings of victim credibility were related to more negative views towards male offenders. Credibility of the expert witness was positively related to the psychopathy category. (i.e., more negative views towards psychopaths were related to higher credibility ratings for the expert witness). Continuous verdict was also positively and significantly related to the psychopathy category. Therefore, more negative views towards psychopaths were related to higher ratings of guilt for the defendant.

Table 8 shows correlations between the three categories of beliefs questions and the remainder of the dependant variables for mock jurors who rendered guilty verdicts ( $n$ $=125$ ). Sentence recommendation was significantly and positively related to the gender category. Therefore more negative views towards male offenders were related to higher sentence recommendations. Recidivism question 2 (i.e., how likely does defendant pose risk to society) was significantly and positively related to the psychopathy category. Therefore, more negative views towards psychopaths were related to higher ratings of risk. 
Table 6

Beliefs questionnaire assessing attitudes towards psychopathy, gender, and age

$$
\text { Questions }
$$

Psychopathy

1. Individuals who are diagnosed as psychopaths are more likely to commit crimes

2. Individuals who are diagnosed as psychopaths are more likely to be violent.

3. Individuals who are diagnosed as psychopaths do not benefit from treatment.

4. Adolescents diagnosed as psychopaths will maintain that diagnosis into adulthood.

5. Psychopaths released from prison will likely reoffend again.

Gender

6. Men are more likely to commit crimes than women.

7. Men are more likely to be violent than women.

8. Male offenders are less likely to benefit from treatment than female offenders.

9. Adolescent male offenders are more likely to continue offending into adulthood than female adolescent offenders.

10. Male offenders released from prison are more likely to reoffend than female offenders released from prison.

Age

11. Youth offenders are more violent than adult offenders.

12. Youth offenders do not benefit from treatment.

13. Youth offenders in general will continue offending into adulthood.

14. Youth offenders released from custody pose a significant risk to society. 


\section{Table 7}

Correlations between the three categories of beliefs questions and credibility ratings (victim, defendant, expert), verdict, and verdict confidence for the entire sample $(N=$ 247)

Psychopathy Gender Age

\begin{tabular}{lccc} 
Credibility (Victim) & .06 & $.20^{* *}$ & .10 \\
Credibility (Defendant) & -.07 & -.01 & -.04 \\
Credibility (Expert) & $.14^{*}$ & .04 & -.03 \\
Verdict (Continuous) & $.15^{*}$ & .11 & .06 \\
Verdict (Confidence) & .05 & -.01 & .01 \\
\hline
\end{tabular}

${ }^{*} p \leq .05 ;{ }^{*} p \leq .01$ 
Table 8

Correlations between the three categories of beliefs questions and sentence recommendation, treatment, violence and recidivism for the mock jurors who rendered a guilty verdict $(N=125)$

Psychopathy Gender Age

\begin{tabular}{lccc} 
Sentence & .10 & $.18^{*}$ & -.08 \\
$\mathrm{~T} 1$ & .14 & .04 & .04 \\
$\mathrm{~T} 2$ & -.08 & -.09 & -.01 \\
$\mathrm{~T} 3$ & -.09 & -.02 & -.02 \\
$\mathrm{~T} 4$ & -.03 & .03 & .03 \\
Violence & .11 & .14 & -.01 \\
$\mathrm{R} 1$ & .14 & .16 & .01 \\
$\mathrm{R} 2$ & $.26 * *$ & .12 & .12 \\
\hline
\end{tabular}

${ }^{*} p \leq .05 ;{ }^{* *} p \leq .01$ Note.

Note. $\mathrm{T} 1$ = How likely to recommend treatment; $\mathrm{T} 2=$ How likely to benefit from treatment; T3 = How useful treatment at reducing violence would be; T4 = How useful would treatment for reducing criminal behaviour be; $\mathrm{R} 1=$ Likelihood to commit future criminal acts; R2 = Likelihood to pose risk to society. 
Finally, in order to evaluate the question concerning the risk for adult criminality, the youth data for participants who rendered a guilty verdict was analyzed separately $(n=$ 61). Beliefs concerning psychopathy were significantly and positively related to the risk question $(r=.41, p=.001)$ as were beliefs concerning the gender of the offender $(r=.27$, $p=.03)$. Therefore, more negative views towards psychopaths and male offenders resulted in higher ratings of risk for adult criminality.

A logistic regression was conducted on verdict choice (0- not guilty and 1- guilty) with the fourteen beliefs questions as predictors. The overall model was not significant, $\chi^{2}(14, N=247)=14.50, p=.41$. Results indicated, however, that question 6 was the only significant predictor of verdict while holding all other predictors constant (Wald = $6.53, p=.01, \operatorname{Exp}(\mathrm{B})=1.37)$. The odds ratio revealed that a one-point increase in the question relating to recidivism of male offenders resulted in the odds of rendering a guilty verdict increasing by a factor of 1.37 . When the three categories (i.e., psychopathy, gender, and age) were used in the model, there were no significant predictors of verdict choice.

Open-ended question. The open-ended question relating to the reasoning of the verdict was analyzed for frequency of responses in order to gain a better insight into the factors that lead to mock jurors' decisions. Two independent raters blind to the verdict outcomes and to the conditions were given a random sample of 50 ( $20 \%$ of the sample) cases to code for frequency of responses. The raters then compiled their responses into one master list eliminating any redundant responses and keeping all others (Appendix K). Another random sample of 50 cases was generated and each rater used the newly formed master list to code the cases. There was sufficient inter-rater reliability between these 
cases (Cronbach's alpha $=.83$; Intraclass correlation of absolute agreement $=.70)$ to validate the codebook used. Table 9 summarizes the most frequently given responses. In both types of verdicts it appears that the most frequently stated factor in decision making was the doctor's testimony. Table 10 displays the frequencies of the three diagnostic categories for participants who rendered both types of verdicts. The no diagnosis category had a higher frequency in the not guilty verdicts, whereas psychopathy and $\mathrm{APD} / \mathrm{CD}$ made up the majority of the guilty verdicts. 
Table 9

Frequency (\%) of mock jurors' responses to an open-ended question concerning verdict reasoning

Class of Responses

Frequency $(\%)^{\mathrm{a}}$

Not Guilty $(n=118)^{\mathrm{b}}$

Doctor's testimony

Self-defence

Not proven beyond a reasonable doubt

Disbelief of victim's statement

Not enough evidence

Victim initiated confrontation

Guilty $(n=117)^{\mathrm{b}}$

Doctor's testimony

Level of forced used

Didn't call for an ambulance

Disbelief in defendant's statement

Defendant was an aggressive person

\footnotetext{
${ }^{a}$ Percentages are not meant to add to 100 because some participants gave more than one response.

${ }^{\mathrm{b}}$ Sample sizes are lower than originally stated (not guilty $n=122$; guilty $n=125$ ) because 4 cases were missing from the not guilty group and 8 cases were missing from the guilty group.
} 
Table 10

Frequency (\%) of the three diagnostic categories for participants who rendered not guilty and guilty verdicts

Diagnostic Category $\quad$ Frequency (\%)

Not Guilty $(n=122)$

Psychopathy $26(21)$

$\mathrm{APD} / \mathrm{CD}$ $30(25)$

No Diagnosis

$66(54)$

Guilty $(n=125)$

Psychopathy

54 (43)

APD/CD

49 (39)

No Diagnosis

22 (18) 


\section{Discussion}

The primary goal of this study was to assess the effect of diagnostic labels, gender, and age on mock jurors' perception of guilt, treatment amenability, recidivism, and violence. A secondary goal was to gain preliminary insight into the specific factors that lead to decision making and to assess the relationship between decisions and preexisting beliefs in accordance with the story model theory. Psychopathy evidence is presented in the courtroom with growing frequency therefore, assessing what effect it may have on members of the CJS is of vital importance. Does this evidence influence jurors' decisions and to what extent can that influence be considered negative?

\section{Manipulation Check}

The manipulation check questions relating to the age of the defendant and the charge showed a relatively high accuracy rate of ninety-six percent. In terms of age, it is possible that some of the answer choices were too similar to cause a distinction (e.g., 12, 15,30 , or 32). However, upon closer inspection, it was revealed that the participants who could not accurately identify the age of the defendant were also more likely to incorrectly identify the diagnosis given $(n=9)$, indicating that these participants did not read the transcript accurately in general. The same can be seen for the participants that failed to accurately identify the charge: eight of the thirteen participants also failed to identify the proper diagnosis. In fact, incorrect responses for the diagnosis question resulted in the majority of the excluded cases $(n=30)$. It is possible that the participants did not accurately read the diagnostic information because it was placed at the end of the trial transcript, and was not mentioned at the beginning (as were the other independent 
variables). The partial transcript was a few pages long and some participants may have tired of reading.

The major limitation of the manipulation check questions was the absence of a question assessing the gender of the defendant. Gender pronouns were used throughout the trial transcript and throughout the various questionnaires that followed (i.e., defendant was referred to as he/she throughout all of the questionnaires and the manipulation check). Although a manipulation check question would have assured that this variable was salient to the participants, inspection of the open-ended questions revealed the appropriate use of gender pronouns by the participants (e.g., participants in the female conditions described the defendant using feminine pronouns).

\section{Mock Juror Gender}

Although past studies have found that men and women can differ in verdict choice and severity of sanctions given (Guy \& Edens, 2006; Schutte \& Hosch, 1997) mock juror gender was not part of the main investigation of the current study. Gender differences are seen in cases involving crimes against women and young girls, most notably those that are sexual in nature. In these cases, women are more likely to hold positive views towards the victim and are subsequently more likely to convict a male defendant (Bottoms, Davis, \& Epstein, 2004; Guy \& Edens, 2003, 2006; Quas, Goodman, \& Jones, 2003). Since the crime in the present study was neither sexual in nature nor involving crimes against women or children, gender was investigated as a possible confound and not as a main variable of study. Mock juror gender was found to affect two outcome variables, verdict confidence and risk for future violence. Female jurors were less confident in their verdict decisions than male defendants. Studies 
examining gender differences in confidence ratings have generally found that females give themselves lower ratings when the task set before them is difficult and when inadequate feedback is given in terms of their performance (Lenney, 1977, 1981; Mednick \& Thomas, 1993; Hyde, 2004). The trial transcript presented in this study was ambiguous and therefore, deciding guilt or innocence was a difficult task. Also, at no time during the study were the participants given feedback on their performance.

Female mock jurors also rated the defendant as less likely to be at risk for future violence. As noted above, women usually display harsher views towards male defendants in cases involving sex offenders. Although the present case was not sexual in nature, it is still unexpected that women gave the defendant lower risk ratings. This finding must be replicated before appropriate conclusions can be drawn. Due to these significant results, mock juror gender was entered as a covariate in the analysis of verdict confidence and ratings of violence risk.

Effects of Diagnostic Label

Diagnostic label affected ratings of credibility for the victim, defendant, and expert witness. Mock jurors were clearly affected by the doctor's testimony since they rated the defendant as less credible when he/she was described and labeled as a psychopath and they found the victim to be more credible in the psychopathy condition as well. This finding is contrasted against the fact that the credibility of the expert witness was lower in the psychopathy condition. This is an interesting finding considering the obvious effect of this same testimony on the credibility of the other two testimonies. Studies have shown that mock jurors are more likely persuaded by male expert witnesses when the complexity of the testimony is high (Schuller, Terry, \& McKimmie, 2005) and 
when the expert's credentials are well established (Cooper, Bennett, \& Sukel, 1996). In order to increase the credibility ratings of the expert witness, these two conditions will have to be met in future studies. When coding the open-ended question regarding verdict decision, a few jurors did say that the testimony of Dr. Richards seemed incomplete and bias towards the defendant. Although these statements were made by only a few jurors, perhaps they are indicative of the possible mistrust of expert testimony and a lack of information in the present scenario.

Consistent with first hypothesis, mock jurors gave the defendant significantly higher guilt ratings when they were diagnosed as psychopathic compared to no disorder. Only one study has previously investigated the effect of psychopathy on perceived culpability of the defendant, and it found no significant effect of label or criterion (Jones \& Cauffman, 2008). The main reason for this conflicting result is that the information presented to the judges in Jones and Cauffman's study was much less ambiguous than the information given in the present study. For example, the authors' scenario stated that both parties involved in the altercation and numerous witnesses agreed that the defendant not only began the assault but also did most of the punching. The scenario also included information concerning the defendant's past appearances before the court. Because of the lack of ambiguity in the scenario provided, Jones and Cauffman (2008) were less able to appropriately assess the effect of diagnosis on ratings of culpability.

The hypothesis regarding the verdict differences between APD/CD and no disorder was also confirmed: APD/CD defendants were given higher guilt ratings compared to no disorder defendants demonstrating that the effect of the diagnostic label does not solely apply to psychopathy. This finding is consistent with past research 
examining the specific labeling effect of psychopathy vs. psychosis (Edens et al., 2004, 2005) and psychopathy vs. conduct disorder (Murrie et al., 2005, 2007). Members of the CJS do not differentiate between psychopathy and descriptions of other mental or personality disorders. In terms of the dichotomous verdict choice, both psychopathy and $\mathrm{APD} / \mathrm{CD}$ were reliable predictors of a guilty verdict.

It is true that the description of both psychopathy and $\mathrm{APD} / \mathrm{CD}$ share similarities and it may difficult for laypersons to understand the subtle differences of these disorders considering the volume of research dedicated to making that distinction (Hare, Hart, \& Harpur, 1991; Lilienfeld, 1994; Rogers, Salekin, Sewell, \& Cruise, 2000; Widiger, Corbitt, \& Millon, 1992). On the other hand, the factors that are most important to decision making may lie in the similarities of the disorders and not in their differences. For example, psychopathy and $\mathrm{APD} / \mathrm{CD}$ are related to violence and dangerousness and it may be those factors that are contributing to the decision verdict. Jones and Cauffman (2008) did find that after controlling for dangerousness, the effect of psychopathy on judges' recommendations was no longer significant.

Studies examining the effect of diagnosis on sentence recommendations provide conflicting results. Murrie and his colleagues $(2005,2007)$ reported that JPOs showed no difference in the recommendations they would give in terms of commitment and incarceration based on psychopathy information in two separate studies. On the other hand, psychopathy information has resulted in harsher recommendations in terms of likelihood of commitment (Guy \& Edens, 2006), secure placement and supervision (Vidal \& Skeem, 2007), and support for the death penalty (Edens et al., 2003, 2005). Diagnostic labels/criteria did not affect sentence recommendations in the present study. 
This finding could possibly be explained by the relatively small number of cases in some of the sentence options. For example, only 2 of the mock jurors chose the harshest sentence available (i.e., 10-14 years). It appears that the nature of the crime described (i.e., aggravated assault) only warranted an average sentence term between $1-4$ years ( $M$ $=2.33$ ) for the jurors who rendered a guilty verdict. Therefore, the lack of a significant effect of diagnostic criteria on sentence recommendation could be due to poor manipulation of the crime in question.

In the present study, four treatment questions were assessed: 1) How likely are you to recommend treatment? 2) How likely is it that the defendant will benefit from treatment? 3) How useful would a treatment aimed at reducing violence be? 4) How useful would a treatment aimed at reducing criminal behaviour be? Type of diagnosis did not have a significant effect on any of the treatment questions. In terms of treatment recommendation, past research has shown both an increased likelihood of recommendation due to diagnostic information (Murrie et al., 2005, 2007) and no effect of diagnosis at all (Edens et al., 2003; Rockett et al., 2007; Vidal \& Skeem, 2007). These results demonstrate that psychopathic individuals are not denied treatment by members of the CJS as past research has suggested (Steinberg, 2002) which could be considered encouraging. On the other hand, if we adopt a risk-and-needs perspective (Andrews, Bonta, \& Hoge, 1990; Andrews, Zinger, Hoge, \& Bonta, 1996), we would likely recommend more treatment to individuals who possess more criminal risk factors and are considered higher-risk offenders. In this case, psychopaths, who are more likely to be violent and to recidivate, should be given more treatment efforts (Simourd \& Hoge, 2000). 
In terms of treatment benefit or amenability, the literature is again divided; studies have shown both a decreased perception of treatment amenability as a result of diagnostic information (Jones \& Cauffman, 2008; Vidal \& Skeem, 2007) and no effect at all (Murrie et al., 2005, 2007; Rockett et al., 2007). The question of whether members of the CJS believe that psychopaths are amenable to treatment is an important one in terms of identifying potential discrimination. Although the relationship between psychopathy and violence and recidivism is widely accepted, the popular opinion that psychopaths cannot be treated is still debated. Two studies have summarized the treatment literature to date and found that the inverse relationship between psychopathy and treatment response has little scientific value once methodological issues are controlled (D'Silva et al., 2004; Salekin, 2002). Therefore, any negative decisions stemming from the belief that psychopaths are not amenable to treatment should be considered discriminatory. Although there are very few real-life studies examining the use of psychopathy evidence in the courtroom, those that do exist show that this evidence is being used to make decisions regarding risk for future violence, sentence recommendations, dangerous offender hearings, and transfers to adult court (DeMatteo \& Edens, 2006; Walsh \& Walsh, 2006; Zinger \& Forth, 1998). If psychopaths are believed to be untreatable, this information could influence all of the above decisions and may result in human rights abuses.

Consistent with the fourth hypothesis, diagnosis did, however, significantly affect ratings of risk for future violence. Again, there was no difference between psychopathy and APD/CD diagnoses, and both defendants in these conditions were considered a higher risk for violence than defendants with no diagnosis. The relationship between 
psychopathy and violence has consistently been shown in the literature examining simulated diagnoses (Edens et al., 2004; Murrie et al., 2007) and with research examining actual psychopathy in various populations (Edens et al., 2001; Tengström et al., 2000). Of course, the question then becomes, if psychopaths are more likely to be violent, shouldn't members of the CJS take this into consideration when making decisions? Psychopathy has been shown to predict violence in adults and adolescents (Edens et al., 2007; Gendreau et al., 2002; Leistico et al., 2008; Walters, 2003a, 2003b) therefore, if the PCL$\mathrm{R}$ is properly administered and the evidence presented in court is of the highest standard, the answer is yes. Of course, caution must also be issued; there have been instances where the PCL-R has not been properly administered in which case, grave injustices can occur (DeMatteo \& Edens, 2006; Edens, 2001). Given the seriousness of the consequences to the offender when psychopathy evidence is introduced, it is necessary that all factors (e.g., risk and protective factors) are considered before predicting future violence (Leistico et al., 2008).

A similar pattern of results was also seen for the following question: How likely is it that the defendant poses a risk to society? The psychopathy and APD/CD diagnoses resulted in higher ratings of risk. There were no significant differences between psychopathy and APD/CD. Research examining the effect of diagnostic labels on perceptions of risk and dangerousness has found that the mention of a diagnosis increases risk perceptions (Edens et al., 2005; Jones \& Cauffman, 2008; Vidal \& Skeem, 2007). The relationship between psychopathy and general recidivism has also been demonstrated in numerous offender populations (Gendreau et al., 2002; Hemphill et al., 1998); however, Factor 2 of the PCL-R has been known to be a better predictor than Factor 1 
(Hare, 1991; Leistico et al., 2008). In terms of psychopathy and APD, Wormith and colleagues (2008) have examined the validity of both the PCL-R and the diagnostic criteria for APD in predicting recidivism. Both measures were highly correlated with one another with Factor 2 of the PCL-R accounting for the majority of the shared variability. Both measures also significantly predicted the recidivism of 61 offenders during a 10 year follow-up period. The authors reported that the differences between using the PCL$\mathrm{R}$ and the APD criteria in predicting recidivism were minimal (Wormith, Olver, Stevenson, \& Girard, 2008). With this information, it is not surprising that mock jurors did not differentiate between a diagnosis of psychopathy and antisocial personality/ conduct disorder.

In real-life cases, the PCL-R has been used to make decisions regarding the risk an offender could pose to society (Zinger \& Forth, 1998) and again it is not necessarily bad to introduce psychopathy evidence to make these decisions. The risk for injustice lies in the misuse of this evidence, for example if the person is incorrectly assessed as psychopathic. A recent study has shown that there is poor interrater reliability between clinicians retained by the defence and the prosecution in legal proceedings. These results suggest that clinicians are biased towards the side that retained them for the evaluation (Murrie, Boccaccini, Johnson, \& Janke, 2008). It is clear that before psychopathy evidence can be used to make appropriate decisions concerning the potential risk of an offender, the court must ensure that the evidence being presented is both valid and reliable.

Before discussing the effects of age in general, there was one last question of particular interest for the effect of diagnosis: How likely is it that the defendant will 
become an adult criminal? Results indicated that mock jurors believed that the criminal activity of both psychopathic youth and those with conduct disorder would persist into adulthood. These results are consistent with other studies examining the opinions of clinicians (Rockett et al., 2007), juvenile court judges (Murrie et al., 2007), and juvenile POs (Murrie et al., 2005; Vidal \& Skeem, 2007).

Studies examining the stability of psychopathy across time are growing in number. These studies are confirming that psychopathy is moderately stable from childhood to early adolescence (Barry et al., 2008; Frick et al., 2003) and from adolescence to early adulthood (Loney et al., 2007; Lynam et al., 2007; Lynam et al., 2008). Since mock jurors believed that youth psychopaths were more likely to commit crimes as adults, it is important to discover if, in addition to being stable across time, psychopathy features in youth predict adult criminality. Gretton et al. (2004) reported that the risk for violence in early adulthood was greater among those who had high PCL: YV scores as adolescents. Despite the long follow-up period (i.e., 10 years), this study was not truly prospective and therefore is subject to the limitations of retrospective designs (e.g., artificially inflated correlations). Edens and Cahill (2007) failed to find any relationship between youth psychopathy and adult recidivism (violent or general) in a multiethnic sample. This study was also retrospective and was limited by a small sample size $(N=76)$. In a purely prospective design (i.e., 130 children and adolescents followed during a 3-4 year span), Salekin (2008) used four separate measures of psychopathy to assess whether youth psychopathy could predict adult recidivism. Results indicated that psychopathy in early adolescence was predictive of general and violent recidivism during a critical transition period into adulthood. These results remained even after controlling 
for a number of other variables related to offending (e.g., demographics, family factors, delinquency). Salekin (2008) concluded that there appears to be stability in offending for psychopathic individuals. Despite these findings, caution must be taken when assuming that psychopathic youth will offend in adulthood since this research is only beginning to emerge.

\section{Gender of the Defendant}

Gender of the defendant had a very limited effect on the majority of the outcome variables. In terms of credibility, mock jurors were more likely to find the expert witness credible when he was describing a female defendant. We can only speculate as to the reasons for this outcome since there has not been research examining the relationship between the credibility of an expert witness and the gender of the person being described. Perhaps mock jurors are more likely to believe that a diagnosis is responsible for the behaviour of the female offender because it is rare to hear of females committing such violent crimes (Chesney-Lind \& Pasko, 2004) and in fact females commit less violent offences than males (Public Safety Canada, 2007).

The most notable gender difference occurred for the following treatment questions: How likely is it that the defendant will benefit from treatment? How useful would a treatment aimed at reducing violence be? Female defendants were rated as more likely to benefit from treatment and more likely to be amenable to treatment aimed at reducing violence. Studies of program effectiveness often use male only samples, or fail to examine the results by gender, therefore not as much is known concerning the effectiveness of treatment programs for female offenders (Bloom, 2000; Kendall, 1998; Koons, Burrows, Morash, \& Bynum, 1997). In a qualitative study, Koons et al. (1997) 
reviewed correctional programs for female offenders and identified a list of treatment needs related to successful treatment outcomes. These included substance abuse education, parenting and life skills, and victimization issues. In a meta-analysis on treatment effectiveness for female offenders, Dowden and Andrews (1999) reported that the principles of risk (higher level of service for offenders with higher risk), need (program must target criminogenic needs), and general responsivity (cognitivebehavioural therapy) resulted in successful treatment programs; however the number of studies in this meta-analysis $(N=26)$ was small compared to meta-analyses on male offenders. Covington and Bloom (2007) have argued that men and women are qualitatively different and thus have different treatment needs; treatment programs should therefore reflect these differences.

Despite the research attempting to assess the effectiveness of gender specific programs, there does not appear to be evidence suggesting that female offenders would more likely benefit from treatment compared to male offenders. In fact, there is considerable evidence demonstrating that appropriate treatment interventions can effectively reduce general and violent recidivism in male offenders (Andrews et al., 1996; Dowden \& Andews, 2000; Lipsey, 1995; Lösel, 1996). It appears that mock jurors' beliefs about female offenders and treatment could constitute discrimination against male offenders if male offenders are subsequently denied the same treatment opportunities. If treatment interventions are rooted in the "what works" literature and take into account the unique needs of both female and male offenders, there is no reason to believe that female offenders would be more amenable to those interventions than male offenders. 
The present study revealed no significant interaction between psychopathy and gender for the majority of the outcome measures. Psychopaths were viewed more harshly in terms of verdict and risk for future violence and dangerousness regardless of whether the defendant was male or female. The majority of research supporting the relationship between psychopathy and violence and recidivism has been conducted on male samples. Only three studies to date have examined the predictive validity of the PCL-R for female offenders (Loucks \& Zamble, 2000; Richards et al., 2003; Salekin et al., 1998). Although Loucks and Zamble and Richards et al. found that PCL-R scores were predictive of recidivism, Salekin et al. reported contrasting results to studies conducted on male offenders. More specifically, total PCL-R scores and Factor 2 scores were unrelated to recidivism. In addition, the authors reported high false-negative rates indicating that the PCL-R may not be the best risk assessment tool for female offenders. If expert witnesses use PCL-R evidence for female offenders assuming that the literature for male offenders is applicable, then injustices may occur. There is simply not enough evidence to support the same conclusions regarding recidivism and violence in both male and female psychopaths.

Age of the Defendant

Age of the defendant was included mainly to assess differences between adult and youth psychopathy. The only significant effect of age occurred for the sentence recommendation. Youth defendants were more likely to receive harsher sentences than adult defendants. Due to the fact that youth sentences were collapsed into a 5-point Likert scale (in order to compare them to adult sentences) these results must be interpreted with caution. Adult defendants were given a mean sentence range of 1-4 years whereas youth 
defendants were given a mean sentence which included 2 years in a juvenile facility and 2 years in an adult facility. When youth and adult sentences were examined separately, no significant effects of diagnosis or gender were found. One thing is clear, however; mock jurors did not consider the least punitive sanctions available for youth defendants. Whereas the enactment of the YCJA has placed a focus on rehabilitation and reintegration into society, it is possible that laypersons are still being influenced by media portrayals of youth crime out of control (Jackson, 2004; MacDonald, 1995; Muncie, 1999). Perhaps this public fear is contributing to harsher sanctions for youth offenders. Of course, it must also be considered that the crime described in the present transcript (e.g., aggravated assault) was deemed too serious to forego incarceration.

Important to mention is the lack of a significant interaction between psychopathy and age for the majority of the outcome measures. Psychopathic offenders were more likely to be found guilty and were given higher ratings of risk for future violence and dangerousness regardless of whether the defendant was a youth. It is true that youth psychopathy is related to aggression (Edens \& Campbell, 2007) and recidivism (Gretton et al., 1994) however whether appropriate treatment interventions could attenuate this relationship is still under investigation (Caldwell et al., 2006). Current research is also investigating the role of moderating factors (e.g., delinquent peers, socioeconomic status) and whether targeting these factors could reduce psychopathy in youth (Lynam et al., 2008). In order for members of the CJS to make appropriate decisions concerning psychopathic offenders, it seems imperative that they consider the offender's age. Not all findings concerning adult psychopathy can be extended to youth psychopathy (e.g., treatment amenability) and any decisions that do not consider the differences between 
these offenders could be deemed erroneous. When coding for the open-ended question concerning verdict decision, only three mock jurors mentioned that they considered the age of the defendant when making decisions.

\section{Interactions}

The only significant interaction occurred for the question concerning risk for future criminal behaviour. Although a significant main effect of diagnosis was found, there was also a significant diagnosis by age by gender interaction. For this particular question it appears that diagnosis is most relevant for youth male offenders and for adult female offenders. More specifically, in both cases, psychopaths were rated as a higher risk for future criminal behaviour than defendants with no disorder. Unlike previous results, there was no significant difference between the $\mathrm{APD} / \mathrm{CD}$ and no diagnosis conditions.

Although gender, age, and diagnosis have never been included in a single study, some simulation studies have used young male offenders in their scenarios. Two such studies reported that youth male psychopaths were judged as being a higher risk for future criminal behaviour than defendants with no disorder (Murrie et al., 2005; Vidal \& Skeem, 2007). The relationship between youth psychopathy and recidivism is also evident in offender populations (Edens et al., 2006b; Gretton et al., 1994). Mock jurors' beliefs that youth male offenders diagnosed as psychopaths are more likely to commit future crimes than non-psychopathic youth male offenders are not without scientific merit. Problems arise when offenders are incorrectly given a psychopathy label; it is in this situation that injustices will occur (Petrila \& Skeem, 2007). 
It is interesting that the significant interaction also involved adult female psychopaths. This is the first finding in this study to differentiate between male and female psychopathy. In this case, female psychopaths were viewed as more likely to commit crime than female offenders with no disorder. Considering the few studies that have examined the predictive validity of the PCL-R in female offender samples, this judgment may be premature. Whereas some studies have found psychopathy to be predictive of recidivism for female offenders (Loucks \& Zamble, 2000; Richards et al., 2003), Salekin et al. (1998) reported that total PCL-R scores did not predict recidivism for this population. There is simply not enough evidence to date to conclude that female psychopaths are at a higher risk for recidivism than other female offenders (Salekin et al., 1998).

\section{Beliefs and the Story Model}

According to the story model, mock jurors incorporate evidence presented during a trial with their own beliefs in order to create a plausible narrative for what has taken place (Pennington \& Hastie, 1986). They then use this information to choose the verdict option that best matches their narrative. In the present analysis, the details of the crime itself were purposely ambiguous in order to emphasize the testimony provided by Dr. Richards and to force mock jurors to rely on pre-existing beliefs concerning the different types of offenders presented. Pre-existing beliefs were assessed using fourteen questions presented before the trial transcript. Beliefs questions were combined to form three separate categories: 1- psychopathy, 2- gender, and 3- age. Correlational analyses revealed that there were relationships between the beliefs questions and certain outcome variables. Negative beliefs towards male offenders were related to higher credibility 
ratings for the victim whereas negative beliefs towards psychopaths were related to higher credibility ratings for the expert witness. Negative views towards psychopaths were also related to higher ratings of guilt. Among the mock jurors who rendered guilty verdicts, negative views towards male offenders were related to more severe sentence recommendations. Negative views towards psychopaths were related to ratings of higher risk (i.e., pose a threat to society). For participants assigned to the youth category, negative views towards psychopaths and male offenders were related to higher ratings of risk to commit adult crimes. These preliminary correlations are consistent with the majority of the findings of this study and indicate that extralegal factors, such as preexisting beliefs, may affect certain decisions made by mock jurors.

In order to validate the story model, Pennington and Hastie (1986) presented participants with a trial re-enactment and asked them to orally describe how they had come to their verdict decisions. If the story model accurately describes mock juror decision making, then it is expected that reasons for verdict outcomes will follow a narrative structure and those narratives will differ between participants who render different verdicts (Pennington \& Hastie, 1986). Although the present analysis did not analyze responses for narrative structure, it did ask that the jurors give reasons for their verdict choices (Appendix K). It is assumed that given the ambiguous nature of the crime itself, jurors would rely on their own knowledge and on the expert testimony in order to make decisions.

Although this analysis is qualitative and exploratory, the results that emerged are those that you would expect if the story model is correct. The reason with the greatest frequency for both guilty and not guilty verdicts was the testimony of Dr. Richards. In the 
case of the guilty verdicts, $82 \%$ percent had received testimony about psychopathy or $\mathrm{APD} / \mathrm{CD}$. In the not guilty group, this number was reduced to $46 \%$. It is possible that the evidence presented by the expert witness creates a lens through which the mock jurors then view the facts of the case. Other than expert testimony participants who rendered different verdicts showed drastically different reasons for that verdict. Those who rendered a not guilty verdict were more likely to believe that the defendant acted in selfdefence. Also, these mock jurors seemed to follow the judge's instructions in that reasonable doubt should result in a verdict of not guilty. On the other hand, mock jurors who rendered a guilty verdict were more likely to focus on the excessive nature of the force used. They were also more concerned that the defendant had not called for help after the incident. These differences are indicative of the different narratives that are formed during the story construction stage of the story model. Indeed, they mirror the results found by Pennington and Hastie (1986) in that participants who rendered different verdicts gave different reasons for that verdict choice. In order to further validate the story model, future studies could utilize both individual and group deliberations in order to more accurately simulate a trial. Analysis of the deliberations themselves would also be necessary in order to ensure that mock jurors utilize organizational elements consistent with narratives.

\section{Limitations and Future Direction}

The first limitation of the current study is the medium used - partial trial transcript. Although short transcripts allow for the manipulation of key variables and the maintenance of internal validity, it does so at the cost of external validity. It is impossible to capture the complexities of an actual court case with such a limited medium. Related to 
this limitation is the lack of group decision making as would be found in actual court cases. Some researchers have claimed that juries are less likely to be influenced by legally irrelevant factors compared to single jurors (Kaplan \& Miller, 1978; Kerwin \& Shaffer, 1994). More recently, Kerr and colleagues $(1996,1999)$ have shown that whether a juror vs. a jury is more susceptible to irrelevant information depends on a variety of other factors (e.g., task, group, and group member factors). More specifically, juries may be less susceptible to biasing information when the probability of conviction is either very high or very low. In terms of correct understanding of the judge's instructions, jury deliberations only reduce error rates when a majority of the jurors begin with a correct understanding of the law. Otherwise, jury deliberations may help to solidify erroneous beliefs and information (Diamond \& Levi, 1996).

In light of this information, future studies could attempt to utilize both juror and jury deliberations in order to add to the current literature on decision making. It would be interesting to discover how jurors vs. juries interpret biasing information when the trial transcript itself is ambiguous. Such studies could also examine the effect of expert witness testimony on juror vs. jury deliberations.

Another limitation of the current study is the information that is contained within the transcript. The facts of the case were purposely made ambiguous in order to increase the salience of the variables under investigation. However, a large number of participants who rendered a not guilty verdict indicated "not proven beyond a reasonable doubt" and "not enough evidence" as primary reasons for that verdict. It is possible that regardless of the variables under investigation, these jurors chose a not guilty verdict because the transcript was simply too ambiguous. Also, considering the decisions rendered in terms 
of sentencing, it is possible that the crime committed did not allow for sentence variability. It would be beneficial in the future to run a small pilot study in order to evaluate the effects of the trial transcript. Also, future studies should manipulate the type of offence committed in order to further investigate its impact on jury decision making.

Although the present study did not utilize a pilot study, a manipulation check questionnaire was included. Unfortunately, a large number of participants incorrectly identified one of the key variables (i.e., diagnosis) and were subsequently removed from the analysis. It is possible that the diagnostic information was less salient to mock jurors since it was presented only once during the trial transcript and was placed at the end of the transcript. It is also possible that mock jurors lack the same level of motivation to attend to the relevant trial information compared to actual jurors since there are no real consequences to their decisions (Diamond, 1997). Future studies will have to ensure that information relating to relevant variables is presented numerous times throughout the trial transcript. It is also possible that offering additional incentives could increase juror motivation.

The present study gathered information from the university and from the community in the hopes of comparing the two samples. Unfortunately, the majority of participants were students (80\%) and such a comparison was not possible. There are very few studies that have examined whether a mock jury, comprised mostly of students, can accurately capture the nature of real-life juries. This concern is important since university students rarely participate in actual juries (Bray \& Kerr, 1982). In a review of this literature, Bornstein (1999) summarized that although some studies have found undergraduates to be more lenient in their decisions (e.g., Berman \& Cutler, 1996; Simon 
\& Mahan, 1971) the majority of research has reported no significant differences between students and the general population (e.g., Finkel \& Duff, 1991; Narby \& Cutler, 1994; Schuller \& Hastings, 1996).

Finally, the current analysis contained a brief questionnaire concerning mock jurors' beliefs about different types of offenders. Very few studies have examined the portrayal of psychopathy in the media and it would be interesting to further investigate how mock jurors' decisions are shaped by their pre-existing notions of psychopathy. One recent content analysis has revealed that although some features of psychopathy are generally accurately depicted in newspapers and on the internet, this is not true of the treatment literature; psychopaths are constantly depicted as untreatable (Stevens, 2008). Future studies could also attempt to develop a scale to assess pre-existing beliefs concerning different types of offenders.

\section{Conclusion and Implications}

The current study is an extension of previous studies examining the effect of diagnostic information on the decisions rendered by members of the CJS. More specifically, whereas past research has focused on only one type of offender (e.g., adult or youth males) this study aimed to generalize findings to different types of offenders. Results indicated that defendants described as psychopaths and as having APD/CD were more likely to be found guilty, more likely to receive higher ratings of risk for future violence, and were perceived as an increased risk to society regardless of their age and gender. In addition, youth described as psychopathic or as having conduct disorder were believed to be at risk for adult criminality. Only two specific labeling/criterion effects of psychopathy were found: young male psychopaths and adult female psychopaths were 
given higher ratings of risk for future criminal behaviour than offenders with no diagnosis. Finally, in terms of treatment, female offenders were believed to be more amenable to treatment than male offenders regardless of diagnosis given.

The results of this study have clear implications for the way diagnostic evidence is presented in court. In the trial transcript provided, there was no distinction made between total psychopathy scores and factor scores (e.g., Factor 1 vs. Factor 2), yet the information provided was enough for mock jurors to give harsher ratings for these defendants. This is alarming considering that the two factors of the PCL-R have been found to predict general and violent recidivism differently (Walsh \& Kosson, 2008), especially when comparing male and female offenders. Any testimony in a real court of law that fails to make these distinctions could prejudice members of the CJS into making harsh recommendations. Also, in light of the debate on the taxonic structure of psychopathy, it may be inappropriate to present evidence that claims a defendant is a psychopath or is not. Psychopathy evidence should be presented as a dimension in order to reflect different degrees of psychopathy (Zinger \& Forth, 1998).

Another implication of these findings is the lack of consideration for the age and gender of the defendant. This study revealed that mock jurors did not consider these factors for the majority of the outcome variables when a negative diagnosis was given. Unfortunately, these decisions do not necessarily reflect the state of the current literature on female and youth psychopathy. If expert testimony draws the same conclusions regarding female and youth psychopaths as they do for male psychopaths, then those conclusions may be erroneous. It is therefore important that the validity of psychopathy 
evidence is thoroughly explored before testimony is giving as to its relevance to a particular case. 


\section{References}

Ackerman, A. M., McMahon, P. M., \& Fehr, L. A. (1984). Defendant characteristics and judgment behaviours of adolescent mock jurors. Journal of Youth and Adolescence, 13, 123-130.

Allport, G. W. (1979). The nature of prejudice. New York: Doubleday. (Original work published 1954).

American Psychiatric Association. (1980). Diagnostic and statistical manual of mental disorders (3rd ed.). Washington, DC: Author.

American Psychiatric Association. (1994). Diagnostic and statistical manual of mental disorders (4th ed.). Washington, DC: Author.

Andrews, D. A., \& Bonta, J. (1994). The psychology of criminal conduct. Cincinnati, OH: Anderson.

Andrews, D. A., \& Bonta, J. (1995). LSI-R: The Level of Service Inventory-Revised. Toronto, Canada: Multi-Health Systems.

Andrews, D. A., \& Bonta, J., \& Hoge, R. D. (1990). Classification for effective rehabilitation: Rediscovering psychology. Criminal Justice and Behavior, 17, 1952.

Andrews, D. A., Zinger, I., Hoge, R. D., \& Bonta, J. (1996). Does correctional treatment work? A clinically relevant and psychologically informed meta-analysis. In D. F. Greenberg (Ed.), Criminal careers (Vol. 2, pp. 437-472). Brookfiled, VT: Dartmouth Publishing Company Limited. 
Barbaree, H. E. (2005). Psychopathy, treatment behavior, and recidivism: An extended follow-up of Seto and Barbaree. Journal of Interpersonal Violence, 20, 11151131.

Barker, E. T., \& Mason, M. H. (1968). Buber behind bars. Canadian Psychiatric Association Journal, 13, 61-72.

Barry, T. D., Barry, C. T., Deming, A. M., \& Lochman, J. E. (2008). Stability of psychopathic characteristics in childhood: The influence of social relationships. Criminal Justice and Behavior, 35, 244-262.

Barry, C. T., Frick, P. J., DeShazo, T. M., McCoy, M. G., Ellis, M., \& Loney, B. R. (2000). The importance of callous-unemotional traits for extending the concept of psychopathy to children. Journal of Abnormal Psychology, 109, 335-340.

Benning, S. D., Patrick, C. J., Blonigen, D. M., Hicks, B. M., \& Iacono, W. G. (2005). Estimating facets of psychopathy from normal personality traits: A step toward community epidemiological investigations. Assessment, 12, 3-18.

Bergeron, C. E., \& McKelvie, S. J. (2004). Effects of defendant age on severity of punishment for different crimes. The Journal of Social Psychology, 144, 75-90.

Berman, G. L., \& Cutler, B. L. (1996). Effects of inconsistencies in eyewitness testimony on mock-juror decision making. Journal of Applied Psychology, 81, 170-177.

Bloom, B. (2000). Beyond recidivism: Perspectives on evaluations of programs for female offenders in community corrections. In M. McMahon (Ed.), Assessment to assistance: Programs for women in community corrections (pp. 107-138). Lanham, MD: American Correctional Association.

Bornstein, B. H. (1999). The ecological validity of jury simulations: Is the jury still out? Law and Human Behavior, 23, 75-92. 
Bottoms, B. L., Davis, S. L., \& Epstein, M. A. (2004). Effects of victim and defendant race on jurors' decisions in child sexual abuse cases. Journal of Applied Social Psychology, 34, 1-33.

Brandt, J. R., Kennedy, W. A., Patrick, C. J., \& Curtin, J. J. (1997). Assessment of psychopathy on a population of incarcerated adolescent offenders. Psychological Assessment, 9, 429-435.

Bray, R. M., \& Kerr, N. L. (1982). Methodological considerations in the study of the psychology of the courtroom. In N. L. Kerr \& R. M. Bray (Eds.), The psychology of the courtroom (pp. 287-323). New York: Academic Press

Caldwell, M. F., McCormick, D. J., Umstead, D., \& Van Rybroek, G. J. (2007). Evidence of treatment progress and therapeutic outcomes among adolescents with psychopathic features. Criminal Justice and Behavior, 34, 573-587.

Caldwell, M. F., Skeem, J., Salekin, R., \& Van Rybroek, G. (2006). Treatment response of adolescent offenders with psychopathy features: A 2-year follow-up. Criminal Justice and Behavior, 33, 571-596.

Cale, E. M., \& Lilienfeld, S. O. (2002). Histrionic personality disorder and antisocial personality disorder: Sex-differentiated manifestations of psychopathy? Journal of Personality Disorders, 16, 52-72.

Caputo, A. A., Frick, P. J., \& Brodsky, S. L. (1999). Family violence and juvenile sex offending: Potential mediating roles of psychopathic traits and negative attitudes toward women. Criminal Justice and Behavior, 26, 338-356.

Chesney-Lind, M., \& Pasko, L. (Eds.) (2004). The female offender. ( $2^{\text {nd }}$ ed). Thousand Oaks, CA: Sage Publications. 
Chesney-Lind, M., \& Sheldon, R. G. (1997). Girls, delinquency, and juvenile justice ( $2^{\text {nd }}$ ed.). Pacific Grove, CA: Brooks/Cole.

Christian, R. E., Frick, P. J., Hill, N. J., Tyler, L., \& Frazer, D. R. (1997). Psychopathy and conduct problems in children: II. Implications for subtyping children with conduct problems. Journal of the American Academy of Child and Adolescent Psychiatry, 36, 233-241.

Clarke, S. H., \& Koch, G. C. (1980). Juvenile court: Therapy and crime control, and do lawyers make a difference? Law and Society Review, 14, 263-308.

Cleckley, H. (1941). The mask of sanity. St. Louis, MO: Mosby.

Cleckley, H. (1988). The mask of sanity: An attempt to clarify some issues about the socalled psychopathic personality (5 $5^{\text {th }}$ ed.). Augusta, GA: Emily S. Cleckley.

Cohen, A. J., Adler, N., Kaplan, S. J., Pelcovitz, D., \& Mandel, F. S. (2002). Interactional effects of marital status and physical abuse on adolescent psychopathology. Child Abuse and Neglect, 26, 277-288.

Cooke, D. J., \& Michie, C. (1997). An item response theory analysis of the Hare Psychopathy Checklist-Revised. Psychological Assessment, 9, 3-14.

Cooke, D. J., \& Michie, C. (1999). Psychopathy across cultures: North America and Scotland compared. Journal of Abnormal Psychology, 108, 58-68.

Cooke, D. J., \& Michie, C. (2001). Refining the construct of psychopathy: Towards a hierarchical model. Psychological Assessment, 13, 171-188.

Cooper, J., Bennett, E. A., \& Sukel, H. L. (1996). Complex scientific testimony: How do jurors male decisions? Law and Human Behavior, 20, 379-394.

Copas, J. B., O'Brian, M., Roberts, J., \& Whiteley, J. S. (1984). Treatment outcome in 
personality disorder: The effect of social psychological and behavioural variables. Personality and Individual Differences, 5, 565-573.

Corrado, R. R., Vincent, G. M., Hart, S. D., \& Cohen, I. M. (2004). Predictive validity of the Psychopathy Checklist: Youth Version for general and violent recidivism. Behavioural Sciences and the Law, 22, 5-22.

Correctional Service Canada (2001). Retrieved December 29 2007 from http://www.csc-scc.gc.ca/text/prgrm/correctional/abissues/know/4 e.shtml.

Covington, S. S., \& Bloom, B. E. (2007). Gender responsive treatment and services in correctional settings. Women \& Therapy, 29, 9-33.

Criminal Code, R. S. C. 1985.

Dannefer, D., \& Schutt, R. K. (1982). Race and juvenile justice processing in court and police agencies. American Journal of Sociology, 87, 1113-1132.

Dekovic, M. (1999). Risk and protective factors in the development of problem behavior during adolescence. Journal of Youth and Adolescence, 28, 667-685.

DeMatteo, D., \& Edens, J. F. (2006). The role and relevance of the Psychopathy Checklist-Revised in court: A case law survey of U.S. courts (1991-2004). Psychology, Public Policy, and Law, 12, 214-241.

Devine, P. G. (1989). Stereotypes and prejudice: Their automatic and controlled components. Journal of Personality and Social Psychology, 56, 5-18.

Devine, P. G. (1995). Getting hooked on research in social psychology: Examples from eyewitness identification and prejudice. In G. G. Brannigan \& M. R. Merrens (Eds.), The social psychologists: Research adventures (pp. 161-184). New York: McGraw-Hill. 
Diamond, S. S. (1997). Illuminations and shadows from jury simulations. Law and Human Behavior, 21, 561-571.

Diamond, S. S., \& Levi, J. N. (1996). Improving decisions on death by revising and testing jury instructions. Judicature, 79, 224-232.

Dilulio, J. J. (1995). Crime in America: It's going to get worse. Reader's Digest, 55-60.

Dolan, M. C., \& Rennie, C. E. (2006). Reliability and validity of the Psychopathy Checklist: Youth Version in a UK sample of conduct disordered boys. Personality and Individual Differences, 40, 65-75.

Douglas, K. S., Vincent, G. M., \& Edens, J. F. (2006). Risk for criminal recidivism: The role of psychopathy. In C. J. Patrick (Ed.), Handbook of psychopathy (pp. 533554). New York, NY: The Guilford Press.

Dowden, C., \& Andrews, D. A. (1999). What works for female offenders: A metaanalytic review. Crime \& Delinquency, 45, 438-452.

Dowden, C., \& Andrews, D. A. (2000). Effective correctional treatment and violent reoffending: A meta-analysis. Canadian Journal of Criminology, 42, 449-467.

D'Silva, K., Duggan, C., \& McCarthy, L. (2004). Does treatment really make psychopaths worse? A review of the evidence. Journal of Personality Disorders, $18,163-177$.

Edens, J. F. (2001). Misuses of the Hare Psychopathy Checklist-Revised in court: Two case examples. Journal of Interpersonal Violence, 16, 1082-1093.

Edens, J. F., \& Cahill, M. A. (2007). Psychopathy in adolescence and criminal recidivism in young adulthood: Longitudinal results from a multiethnic sample of youthful offenders. Assessment, 14, 57-64. 
Edens, J. F., \& Campbell, J. S. (2007). Identifying youths at risk for institutional misconduct: A meta-analysis of the Psychopathy Checklist measures. Psychological Services, 4, 13-27.

Edens, J. F., Campbell, J. S., \& Weir, J. M. (2006b). Youth psychopathy and criminal recidivism: A meta-analysis of the Psychopathy Checklist measures. Law and Human Behavior, 31, 53-75.

Edens, J. F., Colwell, L. H., Desforges, D. M., \& Fernandez, K. (2005). The impact of mental health evidence on support for capital punishment: Are defendants labeled psychopathic considered more deserving of death? Behavioural Sciences and the Law, 23, 603-625.

Edens, J. F., Desforges, D. M., Fernandez, K., \& Palac, C. A. (2004). Effects of psychopathy and violence risk testimony on mock juror perceptions of dangerousness in a capital murder trial. Psychology, Crime \& Law, 10, 393-412.

Edens, J. F., Guy, L. S., \& Fernandez, K. (2003). Psychopathic traits predict attitudes toward a juvenile capital murderer. Behavioural Sciences and the Law, 21, 807828.

Edens, J. F., Marcus, D. K., Lilienfeld, S. O., \& Poythress, N. G. (2006a). Psychopathic, not psychopathic: Taxometric evidence for the dimensional structure of psychopathy. Journal of Abnormal Psychology, 115, 131-144.

Edens, J. F., Skeem, J. L., Cruise, K. R., \& Cauffman, E. (2001). Assessment of "juvenile psychopathy" and its association with violence: A critical review. Behavioural Sciences and the Law, 19, 53-80. 
Falkenbach, D., Poythress, N., \& Heide, K. M. (2003). Psychopathic features in a juvenile diversion population: Reliability and predictive validity of two self-report measures. Behavioural Sciences and the Law, 21, 787-805.

Farrington, D. P. (1995). Psychosocial influences on the development of antisocial personality. In G. Davies, S. Lloyd-Bostock, M. McMurran, \& C. Wilson (Eds.), Psychology, law, and criminal justice: International developments in research and practice (pp. 424-444). Oxford, England: Walter De Gruyter.

Fergusson, D. M., \& Woodward, L. J. (2000). Educational, psychosocial, and sexual outcomes of girls with conduct problems in early adolescence. Journal of Child Psychology and Psychiatry, 41, 779-792.

Finkel, N. J., \& Duff, K. B. (1991). Felony-murder and community sentiment: Testing the Supreme Court's assertions. Law and Human Behavior, 15, 405-429.

Fischer, G. J. (1997). Gender effects on individual verdicts and on mock jury verdicts in a simulated acquaintance rape trial. Sex Roles, 36, 491-501.

Forster Lee, L., Fox, G. B., Forster Lee, R., \& Ho, R. (2004). The effects of a victim impact statement and gender on juror information processing in a criminal trial: Does the punishment fit the crime? Australian Psychologist, 39, 57-67.

Forth, A. E. (1995). Psychopathy in adolescent offenders: Assessment, family background, and violence. Issues in Criminological \& Legal Psychology, 24, 4244.

Forth, A. E., Hart, S. D., \& Hare, R. D. (1990). Assessment of psychopathy in young male offenders. Psychological Assessment, 2, 342-344. 
Forth, A. E., Kosson, D. S., \& Hare, R. D. (2003). The Psychopathy Checklist: Youth Version. Toronto, ON, Canada: Multi-Health Systems.

Frick, P. J. (1994). Family dysfunction and the disruptive behavior disorders: A review of recent empirical findings. Advances in Clinical Child Psychology, 16, 203-226.

Frick, P. J. (1998). Callous-unemotional traits and conduct problems: Applying the twofactor model of psychopathy to children. In D. J. Cooke, A. E. Forth, \& R. D. Hare (Eds.), Psychopathy: Theory, research and implications for society (pp. 161187). Boston: Kluwer.

Frick, P. J. (2002). Juvenile psychopathy from a developmental perspective: Implications for construct development and use in forensic assessments. Law and Human Behavior, 26, 247-253.

Frick, P. J., Cornell, A. H., Barry, C. T., Bodin, S. D., \& Dane, H. E. (2003). Callousunemotional traits and conduct problems in the prediction of conduct problem severity, aggression, and self-report of delinquency. Journal of Abnormal Child Psychology, 31, 457-470.

Frick, P. J., \& Ellis, M. (1999). Callous-unemotional traits and subtypes of conduct disorder. Clinical Child and Family Psychology Review, 2, 149-168.

Frick, P. J., Kimonis, E. R., Dandreaux, D. M., \& Farell, M. S. (2003). The 4 year stability for psychopathic traits in non-referred youth. Behavioural Sciences and the Law, 21, 713-736.

Frick, P. J., O’Brian, B. S., Wootton, J. M., \& McBurnett, K. (1994). Psychopathy and conduct problems in children. Journal of Abnormal Psychology, 103, 700-707. 
Gendreau, P., Goggin, C., \& Smith, P. (2002). Is the PCL-R really the "unparalleled" measure of offender risk? A lesson in knowledge cumulation. Criminal Justice and Behavior, 29, 397-426.

Gove, W. R. (1982). Labeling theory's explanation of mental illness: An update of recent evidence. Deviant Behavior, 3, 307-327.

Gretton, H. M., Hare, R. D., \& Catchpole, R. E. H. (2004). Psychopathy and offending from adolescence to adulthood: A 10-year follow-up. Journal of Consulting and Clinical Psychology, 72, 636-645.

Guy, L. S., \& Edens, J. F. (2003). Juror decision making in a mock sexually violent predator trial: Gender differences in the impact of divergent types of expert testimony. Behavioural Sciences and the Law, 21, 215-237.

Guy, L. S., \& Edens, J. F. (2006). Gender differences in attitudes toward psychopathic sexual offenders. Behavioural Sciences and the Law, 24, 65-85.

Hamburger, M. E., Lilienfeld, S. O., \& Hogben, M. (1996). Psychopathy, gender, and gender roles: Implications for antisocial and histrionic personality disorders. Journal of Personality Disorders, 10, 41-55.

Hankin, B. L., \& Abramson, L. Y. (2001). Development of gender differences in depression: An elaborated cognitive vulnerability-transactional stress theory. Psychological Bulletin, 127, 773-796.

Hare, R. D. (1970). Psychopathy: Theory and research. New York: Wiley.

Hare, R. D. (1980). A research scale for the assessment of psychopathy in criminal populations. Personality and Individual Differences, 1, 111-119. 
Hare, R. D. (1991). The Hare Psychopathy Checklist-Revised. Toronto, Ontario: MultiHealth Systems.

Hare, R. D. (1998). Psychopathy, affect, and behavior. In D. J. Cooke, A. E. Forth, \& R. D. Hare (Eds.), Psychopathy: Theory, research, and implications for society (pp.105-137). Dordrecht, Netherlands: Kluwer.

Hare, R. D. (2003). The Hare Psychopathy Checklist-Revised, $2^{\text {nd }}$ edition. Toronto, ON, Canada: Multi-Health Systems.

Hare, R. D., Clark, D., Grann, M., \& Thornton, D. (2000). Psychopathy and the predictive validity of the PCL-R: An international perspective. Behavioural Sciences and the Law, 18, 623-645.

Hare, R. D., Harpur, T. J., Hakstian, A. R., Forth, A. E., Hart, S. D., \& Newman, J. P. (1990). The revised psychopathy checklist: Reliability and factor structure. Psychological Assessment, 2, 338-341.

Hare, R. D., Hart, S. D., \& Harpur, T. J. (1991). Psychopathy and the DSM-IV criteria for antisocial personality disorder. Journal of Abnormal Psychology, 100, 391-398.

Hare, R. D., \& Jutai, J. (1983). Criminal history of the male psychopath: Some preliminary data. In K. T. Van Dusen \& S. A. Mednick (Eds.), Prospective studies of crime and delinquency (pp. 225-236).

Harpur, T. J., Hakstian, A. R., \& Hare, R. D. (1988). Factor structure of the Psychopathy Checklist. Journal of Consulting and Clinical Psychology, 56, 741-747.

Harpur, T. J., Hare, R. D., \& Hakstian, A. (1989). Two-factor conceptualization of psychopathy: Construct validity and assessment implications. Psychological Assessment: A Journal of Consulting and Clinical Psychology, 1, 6-17. 
Harris, G. T., Rice, M. E., \& Quinsey, V. L. (1994). Psychopathy as a taxon: Evidence that psychopaths are a discrete class. Journal of Consulting and Clinical Psychology, 62, 387-397.

Harris, G. T., Skilling, T., \& Rice, M. E. (2001). The construct of psychopathy. Crime and Justice, 28, 197-264.

Hart, S. D., Watt, K. A., \& Vincent, G. M. (2002). Commentary on Seagrave and Grisso: Impressions of the state of the art. Law and Human Behavior, 26, 241-245.

Hemphill, J. F., Hare, R. D., \& Wong, S. (1998). Psychopathy and recidivism: A review. Legal and Criminological Psychology, 3, 139-170.

Higgins, P. L., Heath, W. P., \& Grannemann, B. D. (2007). How type of excuse defense, mock juror age, and defendant age affect mock juror's decisions. The Journal of Social Psychology, 147, 371-392.

Hobson, J., Shine, J., \& Roberts, R. (2000). How do psychopaths behave in a prison therapeutic community? Psychology, Crime and Law, 6, 139-154.

Horn, R., \& Hollin, C. R. (1997). Police beliefs about women who offend. Legal and Criminological Psychology, 2, 193-204.

Horowitz, R., \& Pottieger, A. E. (1991). Gender bias in juvenile justice handling of seriously crime-involved youths. Journal of Research in Crime and Delinquency, $28,75-100$.

Huffine, C., \& Clausen, J. (1979). Madness and work: Short- and long-term effects of mental illness on occupational careers. Social Forces, 57, 1049-1062.

Hyde, J. S. (Ed.). (2004). Half the human experience: The psychology of women $\left(6^{\text {th }}\right.$ Edition). Houghton Mifflin Company. 
Innes, C. A. (1997). Patterns of misconduct in the federal system. Criminal Justice Review, 22, 157-174.

Jackson, J. (2004). Experience and expression: Social and Cultural significance in the fear of crime. The British Journal of Criminology, 44, 946-966.

Jones, S., \& Cauffman, E. (2008). Juvenile psychopathy and judicial decision making: An empirical analysis of an ethical dilemma. Behavioural Sciences and the Law, 26, $151-165$.

Kaplan, M. F., \& Kemmerick, G. D. (1974). Juror judgment as information integration: Combining evidential and nonevidential information. Journal of Personality and Social Psychology, 30, 493-499.

Kaplan, M. F., \& Miller, L. E. (1978). Reducing the effects of juror bias. Journal of Personality and Social Psychology, 36, 1443-1455.

Kendall, K. (1998). Evaluation of programs for female offenders. In R. Zaplin (Ed.), Female offenders: Critical perspectives and effective interventions (pp. 361-379). Gaithersburg, Maryland: Aspen.

Kerr, N. L., MacCoun, R., \& Kramer, G. P. (1996). Bias in judgment: Comparing individuals and groups. Psychological Review, 103, 687-719.

Kerr, N. L., Niedermeier, K. E., \& Kaplan, M. F. (1999). Bias in jurors vs. bias in juries: New evidence from the SDS perspective. Organizational Behavior and Human Decision Processes, 80, 70-86.

Kerwin, J., \& Shaffer, D. R. (1994). Mock jurors versus mock juries: The role of deliberations in reactions to inadmissible testimony. Personality and Social Psychology Bulletin, 20, 153-162. 
Koons, B. A., Burrows, J. D., Morash, M., \& Bynum, T. (1997) Expert and offender perceptions of program elements linked to successful outcomes for incarcerated women. Crime and Delinquency, 43, 512-532.

Kruh, I. P., Frick, P. J., \& Clements, C. B. (2005). Historical and personality correlates to the violence patterns of juveniles tried as adults. Criminal Justice and Behavior, 92, 69-96.

Laird, R. D., Jordan, K. Y., Dodge, K. A., Petit, G. S., \& Bates, J. E. (2001). Peer rejection in childhood, involvement with antisocial peers in early adolescence, and the development of externalizing behavior problems. Development and Psychopathology, 13, 337-354.

Langton, C. M., Barbaree, H. E., Harkins, L., \& Peacock, E. J. (2006). Sex offenders' response to treatment and its association with recidivism as a function of psychopathy. Sexual Abuse: A Journal of Research and Treatment, 18, 99-120.

Larsson, H., Viding, E., Plomin, R. (2008). Callous-unemotional traits and antisocial behavior: Genetic, environmental, and early parenting characteristics. Criminal Justice and Behavior, 35, 197-211.

Leistico, A.-M. R., Salekin, R. T., DeCoster, J., \& Rogers, R. (2008). A large-scale metaanalysis relating the Hare measures of psychopathy to antisocial conduct. Law and Human Behavior, 32, 28-45.

Lenney, E. (1977). Women's self-confidence in achievement settings. Psychological Bulletin, 84, 1-13/ 
Lenney, E. (1981). What's fine for the gander isn't always good for the goose: Sex differences in self-confidence as a function of ability area and comparison with others. Sex Roles, 7, 904-924.

Lilienfeld, S. O. (1992). The association between antisocial personality and somatization disorders: A review and integration of theoretical models. Clinical Psychology Review, 12, 641-662.

Lilienfeld, S. O. (1994). Conceptual problems in the assessment of psychopathy. Clinical Psychology Review, 14, 17-38.

Lilienfeld, S. O., \& Andrews, B. P. (1996). Development and preliminary validation of a self-report measure of psychopathic personality traits in noncriminal populations. Journal of Personality Assessment, 66, 488-524.

Lilienfeld, S. O., \& Fowler, K. A. (2006). The self-report assessment of psychopathy: Pitfalls, problems, and promises. In C. Patrick (Ed.), Handbook of psychopathy (pp. 107-132). New York: Guilford Press.

Link, B. G. (1987). Understanding labeling effects in the area of mental disorders: An assessment of the effects of expectations of rejection. American Sociological Review, 52, 96-112.

Link, B. G., \& Cullen, F. T. (1986). Contact with the mentally ill and perceptions of how dangerous they are. Journal of Health and Social Behavior, 27, 289-302.

Link, B. G., Cullen, F. T, Frank, J., \& Wozniak, J. (1987). The social rejection of former mental patients: Understanding why labels matter. American Journal of Sociology, 92, 1461-1500.

Lipsey, M. W. (1995). What do we learn from 400 research studies on the effectiveness of treatment with juvenile delinquents? In J. McGuire (Ed.), What works: 
Reducing reoffending: Guidelines from research and practice (pp. 63-78).

Oxford, England: John Wiley \& Sons.

Lipsey, M. W., \& Wilson, D. B. (2001). Practical meta-analysis. (Applied Social Research Methods Series, Vol. 49). Thousand Oaks, CA: Sage.

Loeber, R., \& Farrington, D. P. (2000). Young children who commit crime:

Epidemiology, developmental origins, risk factors, early interventions, and policy implications. Development and Psychopathology, 12, 737-762.

Loney, B. R., Taylor, J., Butler, M. A., \& Iacono, W. G. (2007). Adolescent psychopathy features: 6-year temporal stability and the prediction of externalizing symptoms during the transition to adulthood. Aggressive Behavior, 33, 242-252.

Lösel, F. (1996). Effective correctional programming: What empirical research tells us and what it doesn't. Forum of Corrections Research, 8, 33-36.

Loucks, A. D., \& Zamble, E. (2000). Predictors of criminal behavior and prison misconduct in serious female offenders. Empirical and Applied Criminal Justice Review, 1, 1-47.

Louth, S. M., Hare, R. D., \& Linden, W. (1998). Psychopathy and alexithymia in female offenders. Canadian Journal of Behavioural Science, 30, 91-98.

Lynam, D. R. (1996). Early identification of chronic offenders: Who is the fledgling psychopath? Psychological Bulletin, 120, 209-234.

Lynam, D. R. (1998). Early identification of the fledgling psychopath: Locating the psychopathic child in the current nomenclature. Journal of Abnormal Psychology, $107,566-575$. 
Lynam, D. R. (2002). Fledgling psychopathy: A view from personality theory. Law and Human Behavior, 26, 255-259.

Lynam, D. R., Caspi, A., Moffitt, T. E., Loeber, R., \& Stouthamer-Loeber, M. S. (2007). Longitudinal evidence that psychopathy scores in early adolescence predict adult psychopathy. Journal of Abnormal Psychology, 116, 155-165.

Lynam, D. R., Loeber, R., \& Stouthamer-Loeber, M. S. (2008). The stability of psychopathy from adolescence into adulthood: The search for moderators. Criminal Justice and Behavior, 35, 228-243.

MacDonald, P. (1995). Crime rates and crime fear: Portraying crime out of control. In C. McCormick (Ed.), Constructing danger: The misrepresentation of crime in the news (pp. 138-159). Halifax, NS: Fernwood Publishing.

MacDonald, J. M., \& Chesney-Lind, M. (2001). Gender bias and juvenile justice revisited: A multiyear analysis. Crime and Delinquency, 47, 173-195.

Mechanic, D., McAlpine, D., Rosenfield, S., \&. Davis, D. (1994). Effects of illness attribution and depression on the quality of life among persons with serious mental illness. Social Science \& Medicine, 39, 155-164.

Mednick, M. T., \& Thomas, V. G. (1993). Women and the psychology of achievement: A view from the eighties. In F. L. Denmark \& M. A. Paludi (Eds.), Psychology of women: A handbook of issues and theories. Westport, CT: Greenwood.

Moffitt, T. (1993). Life-course-persistent and adolescent-limited antisocial behavior: A developmental taxonomy. Psychological Review, 100, 674-701. 
Moffitt, T., Caspi, A., Rutter, M., \& Silva, P. (2002). Review of sex differences in antisocial behavior: Conduct disorder, delinquency and violence in the Dunedin longitudinal study. Psychological Medicine, 32, 1475-1476.

Muncie, J. (1999). Youth and crime. London, Sage.

Murrie, D. C., Boccaccini, M. T., Johnson, J. T., \& Janke, C. (2008). Does interrater (dis)agreement on Psychopathy Checklist scores in sexually violent predator trials suggest partisan allegiance in forensic evaluations? Law and Human Behavior, $32,352-362$.

Murrie, D. C., Boccaccini, M. T., McCoy, W., \& Cornell, D. G. (2007). Diagnostic labeling in juvenile court: How do descriptions of psychopathy and conduct disorder influence judges? Journal of Clinical Child and Adolescent Psychology, 36, 228-246.

Murrie, D. C., Cornell, D. G., \& McCoy, W. K. (2005). Psychopathy, conduct disorder, and stigma: Does diagnostic labeling influence juvenile probation officer recommendations? Law and Human Behavior, 29, 323-342.

Nagel, I. H., \& Johnson, B. L. (1994). The role of gender in a structured sentencing system: Equal treatment, policy choices and the sentencing of female offenders under the United States sentencing guidelines. Journal of Criminal Law \& Criminology, 85, 181-221.

Narby, D. J., \& Cutler, B. L. (1994). Effectiveness of voir dire as a safeguard in eyewitness cases. Journal of Applied Psychology, 79, 724-729. 
Neumann, C. S., Kosson, D. S., Forth, A. E., \& Hare, R. D. (2006). Factor structure of the Hare Psychopathy Checklist: Youth Version (PCL: YV) in incarcerated adolescents. Psychological Assessment, 18, 142-154.

Neumann, C. S., Kosson, D., \& Salekin, R. T. (2007). Exploratory and confirmatory factor analysis of the psychopathy construct: Methodological and conceptual issues. In H. Hervé \& J. Yuille (Eds.), Psychopathy: Theory, research, and social implications (pp. 79-104). New York: Erlbaum.

O'Connor, D. A. (2001). The female psychopath: Validity and factor structure of the revised Psychopathy Checklist (PCL-R) in women inmates. Unpublished doctoral dissertation, Florida State University, Tallahassee.

Ogloff, J., Wong, S., \& Greenwood, A. (1990). Treating criminal psychopaths in a therapeutic community program. Behavioural Schiences and the Law, 8, 81-90.

O’Neil, M. E. (1999). The gender gap argument: Exploring the disparity of sentencing women to death. New England Journal on Criminal and Civil Confinement, 25 , 213-244.

O’Neill, M. L., Lidz, V., \& Heilbrun, K. (2003). Adolescents with psychopathic characteristics in a substance abusing cohort: Treatment and process outcomes. Law and Human Behavior, 27, 299-313.

Patterson, G. R., Reid, J. B., \& Dishion, T. J. (1998). Antisocial boys. In J. M. Jenkins, K. Oatley, \& N. L. Stein (Eds.), Human emotions: A reader (pp. 330-336). Malden, MA, US: Blackwell Publishing.

Patrick, C. J. (1994). Emotion and psychopathy: Startling new insights. Psychophysiology, 31, 319-330. 
Pennington, N., \& Hastie, R. (1981). Juror decision making models: The generalization gap. Psychological Bulletin, 89, 246-287.

Pennington, N., \& Hastie, R. (1986). Evidence evaluation in complex decision making. Journal of Personality and Social Psychology, 51, 242-258.

Pennington, N., \& Hastie, R. (1988). Explanation-based decision making: Effects of memory structure on judgment. Journal of Experimental Psychology: Learning, Memory, and Cognition, 14, 521-533.

Petrila, J., \& Skeem, J. L. (2003). An introduction to the special issues on juvenile psychopathy and some reflections on the current debate: Juvenile psychopathy: The debate. Behavioural Sciences \& the Law, 21, 689-694.

Porporino, F. J., \& Motiuk, L. L. (1995). The prison careers of mentally disordered offenders. International Journal of Law and Psychiatry, 18, 29-44.

Porter, S., Birt, A. R., \& Boer, D. (2001). Investigation of the criminal and conditional release profiles of Canadian federal offenders as a function of psychopathy and age. Law and Human Behavior, 25, 647-661.

Public Safety Canada (2007). Retrieved July 31, 2008 from http://www.publicsafety.gc.ca/res/cor/rep/ fl/CCRSO 2007-eng.pdf

Quas, J. A., Goodman, G. S., \& Jones, D. P. H. (2003). Predictors of attributions of selfblame and internalizing behavior problems in sexually abused children. Journal of Child Psychology and Psychiatry, 44, 723-736.

Rice, M. E., Harris, G. T., \& Cormier, C. (1992). A follow-up of rapists assessed in a maximum security psychiatric facility. Journal of Interpersonal Violence, 5, 435448. 
Richards, H. J., Casey, J. O., \& Lucente, S. W. (2003). Psychopathy and treatment response in incarcerated female substance abusers. Criminal Justice and Behavior, 30, 251-276.

Robins, L. N., \& Regier, D. A. (1991). Psychiatric disorders in America: The Epidemiological Catchment Area study. New York: Free Press.

Rockett, J. L., Murrie, D. C., \& Boccaccini, M. T. (2007). Diagnostic labeling in juvenile justice settings: Do psychopathy and conduct disorder findings influence clinicians? Psychological Services, 4, 107-122.

Rogers, R., Salekin, R. T., Sewell, K. W., \& Cruise, K. R. (2000). Prototypical analysis of antisocial personality disorder: A study of inmate samples. Criminal Justice and Behavior, 27, 234-255.

Rogers, R., Vitacco, M. J., Cruise, K. R., Sewell, K. W., \& Neumann, C. S. (2002). Screening for adolescent psychopathy among at-risk youth: Initial validation of the survey of attitudes and life experiences. Assessment, 9, 343-350.

Rudolph, K. D., \& Asher, S. R. (2000). Adaptation and maladaptation in the peer system: Developmental processes and outcomes. In A. J. Sameroff, M. Lewis, \& S. M. Miller (Eds.), Handbook of developmental psychopathology (2 ${ }^{\text {nd }}$ ed.) (pp. 157175). Dordrecht, Netherlands: Kluwer Academic Publishers.

Rutherford, M. J., Cacciola, J. S., Alterman, A. I., \& McKay, J. R. (1996). Reliability and validity of the Revised Psychopathy Checklist in women methadone patients. Assessment, 3, 145-156.

R. v. C.-T. (J.A.). (29 April 1991), No. 936 (Ont. Ct. Gen. Div.).

R. v. G. R. (10 June 1994), No. 286 (Nfld. Yuv. Ct.). 
R. v. Kasparek (8 March 1994), No. 945 (Ont. Ct. Gen. Div.).

R. v. L.M.T. (15 April 1996), No. 9203-4559-C2 (Alta. Q.B.).

R. v. Newman (1989), 77 Nfld. \& P.E.I.R. 313 (Nfld. S.C.).

R. v. Schultz (7 October 1987), No. 1970 (B.C.C.A).

Salekin, R. T. (2002). Psychopathy and therapeutic pessimism: Clinical lore or clinical reality? Clinical Psychology Review, 22, 79-112.

Salekin, R. T. (2008). Psychopathy and recidivism from mid-adolescence to young adulthood: Cumulating legal problems and limiting life opportunities. Journal of Abnormal Psychology, 117, 386-395.

Salekin, R., Rogers, R., \& Sewell, K. (1996). A review and meta-analysis of the Psychopathy Checklist and Psychopathy Checklist-Revised: Predictive validity of dangerousness. Clinical Psychology: Science and Practice, 3, 203-215.

Salekin, R., Rogers, R., \& Sewell, K. (1997). Construct validity of psychopathy in a female offender sample: A multitrait-multimethod evaluation. Journal of Abnormal Psychology, 106, 576-585.

Salekin, R., Rogers, R., Ustad, K. L., \& Sewell, K. (1998). Psychopathy and recidivism among female inmates. Law and Human Behavior, 22, 109-128.

Scheff, T. J. (1966). Being mentally ill: A sociology theory. Chicago: Aldine.

Scheff, T. J. (1972). On reason and sanity: Political dimensions of psychiatric thought. In W. P. Lebra (Ed.), Transcultural research in mental health. Honolulu: University Press of Hawaii. 
Schrum, C. L., \& Salekin, R. D. (2006). Psychopathy in adolescent female offenders: An item response theory analysis of the Psychopathy Checklist: Youth Version. Behavioural Sciences and the Law, 24, 39-63.

Schuller, R. A., \& Hastings, R A. (1996). Trials of battered women who kill: The impact of alternative forms of expert evidence. Law and Human Behavior, 20, 167-187.

Schuller, R. A., Terry, D., \& McKimmie, B. (2005). The impact of expert testimony on jurors' decisions: Gender of the expert and testimony complexity. Journal of Applied Social Psychology, 35, 1266-1280.

Schutte, J. W., \& Hosch, H. M. (1997). Gender differences in sexual assault verdicts: A meta-analysis. Journal of Social Behavior \& Personality, 12, 759-772.

Serin, R. C. (1993). Diagnosis of psychopathy with and without an interview. Journal of Clinical Psychology, 48, 367-372.

Serin, R. C. (1996). Violent recidivism in criminal psychopaths. Law and Human Behavior, 20, 207-217.

Serin, R. C., \& Kuriychuk, M. (1994). Social and cognitive processing deficits in violent offenders: Implications for treatment. International Journal of Law and Psychiatry, 17, 431-441.

Seto, M. C., \& Barbaree, H. (1999). Psychopathy, treatment behavior, and sex offender recidivism. Journal of Interpersonal Violence, 14, 1235-1248.

Sheldon, R., \& Horvath, J. (1986 September). Processing offenders in a juvenile court: A comparison of males and females. Paper presented at the annual meeting of the Western Society of Criminology, Newport Beach, CA. 
Sherman, L. (1993). Defiance, deterrence, and irrelevance: A theory of the criminal sanction. Journal of Research in Crime and Delinquency, 30, 445-474.

Simon, R. J., \& Mahan, L. (1971). Quantifying burdens of proof: A view from the bench, the jury, and the classroom. Law and Society Review, 5, 319-330.

Simourd, D. J., \& Hoge, R. D. (2000). Criminal psychopathy: A risk-and-need perspective. Criminal Justice and Behavior, 27, 256-272.

Sims, B., \& Johnston, E. (2004). Examining public opinion about crime and justice: A Statewide study. Criminal Justice Policy Review, 15, 270-293.

Skeem, J. L., Monahan, J., \& Mulvey, E. P. (2002). Psychopathy, treatment involvement, and subsequent violence among civil psychiatric patients. Law and Human Behavior, 26, 577-603.

Skilling, T. A., Harris, G. T., Rice, M. E., \& Quinsey, V. L. (2002). Identifying persistently antisocial offenders using the Hare Psychopathy Checklist and DSM antisocial personality disorder criteria. Psychological Assessment, 14, 27-38.

Spain, S., Douglas, K., Poythress, N. G., \& Epstein, M. (2004). The relationship between psychopathic features, violence and treatment outcome: The comparison of three youth measures of psychopathic features. Behavioural Science and the Law, 22, 85-102.

Sprott, J. B. (1999). Are members of the public tough on crime? The dimensions of public "punitiveness". Journal of Criminal Justice, 27, 467-474.

Stahl, A. L. (1998). Offenders in juvenile court, 1996. Washington, DC: Department of Justice, Office of Juvenile Justice and Delinquency Prevention.

Statistics Canada (2006). Persons charged by type of offence. Retrieved December $4^{\text {th }}$, 2007 from http://www40.statcan.ca/101/cst01/legal14b.htm?sdi=youth\%20crime. 
Steinberg, L. (2002). The juvenile psychopath: Fads, fictions, and facts. National Institutes of Justice Perspectives on Crime and Justice: 2001 Lecture Series, 5, $35-64$.

Stevens, A. (2008). Psychopathy in the media: A content analysis. Unpublished master's thesis, Carleton University, Ottawa, ON.

Strachan, C. E. (1993). The assessment of psychopathy in female offenders. Unpublished doctoral dissertation, University of British Columbia, Vancouver, BC.

Teilmann, K. S., \& Landry, P. H. (1981). Gender bias in juvenile justice. Journal of Research Crime and Delinquency, 18, 47-80.

Tengström, A., Grann, M., Långström, N., \& Kullgren, G. (2000). Psychopathy (PCL-R) as a predictor of violent recidivism among criminal offenders with schizophrenia. Law and Human Behavior, 24, 45-58.

Teplin, L. A. (1984). Criminalizing mental disorders: The comparative arrest rate of the mentally ill. American Psychologist, 39, 794-803.

Teplin, L. A., Abram, K. M., \& McClelland, G. M. (1994). Does psychiatric disorder predict violent crime among released jail detainees? A six-year longitudinal study. American Psychologist, 94, 335-342.

Verona, E., Patrick, C. J., \& Joiner, T. T. (2001). Psychopathy, antisocial personality, and suicide attempt history risk. Journal of Abnormal Psychology, 110, 462-470.

Vidal, S., \& Skeem, J. L. (2007). Effect of psychopathy, abuse, and ethnicity on juvenile probation officers' decision making and supervision strategies. Law and Human Behavior, 31, 479-498. 
Viding, E., Blair, R. J. R., Moffitt, T. E., \& Plomin, R. (2005). Evidence for substantial genetic risk for psychopathy in 7-year olds. Journal of Child Psychology and Psychiatry, 46, 592-597.

Vitale, J. E., Smith, S. S., Brinkley, C. A., \& Newman, J. P. (2002). The reliability and validity of the Psychopathy Checklist-Revised in a sample of female offenders. Criminal Justice and Behavior, 29, 202-231.

Walsh, Z., \& Kosson, D. S. (2008). Psychopathy and violence: The importance of factor level interactions. Psychological Assessment, 20, 114-120.

Walsh, T., \& Walsh, Z. (2006). The evidentiary introduction of psychopathy. ChecklistRevised assessed psychopathy in U.S. courts: Extent and appropriateness. Law and Human Behavior, 30, 493-507.

Walters, G. D. (2003a). Predicting criminal justice outcomes with the Psychopathy Checklist and Lifestyle Criminality Screening Form: A meta-analytic comparison. Behavioural Sciences and the Law, 21, 89-102.

Walters, G. D. (2003b). Predicting institutional adjustment and recidivism with the psychopathy checklist factor scores: A meta-analysis. Law and Human Behavior, $27,541-558$.

Walters, G. D. (2006). Risk-appraisal versus self-report in the prediction of criminal justice outcomes: A meta-analysis. Criminal Justice and Behavior, 33, 279-304.

Warren, J. L., Burnette, M. L., South, S. C., Preeti, C., Bale, R., Friend, R., \& Van Patten, I. (2003). Psychopathy in women: Structural modeling and comorbidity. International Journal of Law and Psychiatry, 26, 223-242.

Weiler, B. L., \& Widom, C. S. (1996). Psychopathy and violent behavior in abused and 
neglected young adults. Criminal Behavior and Mental Health, 6, 253-271.

Widiger, T., Corbitt, E., \& Millon, T. (1992). Antisocial personality disorder. In A. Tasman \& M. Riba (Eds.), Review of psychiatry (Vol. 11, pp. 63-79). Washington, DC: American Psychiatric Press.

Wilson, D. L., Frick, P. J., \& Clements, C. B. (1999). Gender, somatization, and psychopathic traits in a college sample. Journal of Psychopathology and Behavioural Assessment, 21, 221-235.

Wormith, J. S., Olver, M. E., Stevenson, H. E., \& Girard, L. (2008). The long-term prediction of offender recidivism using diagnostic, personality, and risk/need approaches to offender assessment. Psychological Services, 4, 287-305.

Young, M. (1991). An inside job. Oxford, England: Clarendon Press.

Youth Criminal Justice Act. (2002). Retrieved December 3, 2007, from http://laws.justice.gc.ca/en/Y-1.5/index.html.

Zinger, I., \& Forth, A. E. (1998). Psychopathy and Canadian criminal proceedings: The potential for human rights abuses. Canadian Journal of Criminology, 40, $237-$ 276. 


\section{Appendix A}

Beliefs Questionnaire

Please indicate how strongly you agree or disagree with each statement below.

1. Individuals who are diagnosed as psychopaths are more likely to commit crimes.

$\begin{array}{ccccccc}1 \quad 2 & 3 & 4 & 5 & 6 & 7 \\ \begin{array}{c}\text { Strongly } \\ \text { Disagree }\end{array} & & & & & \begin{array}{c}\text { Strongly } \\ \text { Agree }\end{array}\end{array}$

2. Individuals who are diagnosed as psychopaths are more likely to be violent.

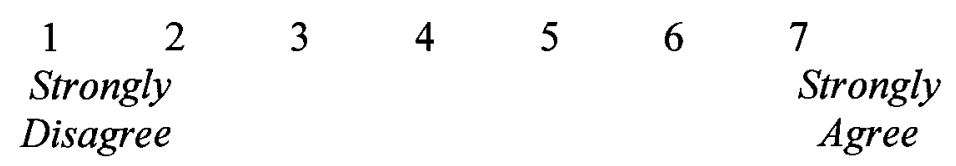

3. Individuals who are diagnosed as psychopaths do not benefit from treatment.

$\begin{array}{ccccccc}1 \quad 2 & 3 & 4 & 5 & 6 & 7 \\ \begin{array}{c}\text { Strongly } \\ \text { Disagree }\end{array} & & & & & \begin{array}{c}\text { Strongly } \\ \text { Agree }\end{array}\end{array}$

6. Adolescents diagnosed as psychopaths will maintain that diagnosis into adulthood.

$\begin{array}{ccccccc}1 \quad 2 & 3 & 4 & 5 & 6 & 7 \\ \text { Strongly } & & & & & \begin{array}{c}\text { Strongly } \\ \text { Agree }\end{array}\end{array}$

7. Psychopaths released from prison will likely reoffend again.

$\begin{array}{ccccccc}1 \quad 2 & 3 & 4 & 5 & 6 & 7 \\ \text { Strongly } & & & & & \begin{array}{c}\text { Strongly } \\ \text { Agree }\end{array} \\ \text { Disagree } & & & & & & \text { Agres }\end{array}$

8. Men are more likely to commit crimes than women.

$\begin{array}{ccccccc}1 \quad 2 & 3 & 4 & 5 & 6 & 7 \\ \text { Strongly } & & & & & \begin{array}{c}\text { Strongly } \\ \text { Agree }\end{array} \\ \text { Disagree } & & & & & & \end{array}$

9. Men are more likely to be violent than women.

$\begin{array}{ccccccc}1 \quad 2 & 3 & 4 & 5 & 6 & 7 \\ \text { Strongly } & & & & & \begin{array}{c}\text { Strongly } \\ \text { Agree }\end{array} \\ \text { Disagree } & & & & & & \text { A }\end{array}$


10. Male offenders are less likely to benefit from treatment than female offenders.

$\begin{array}{ccccccc}1 \quad 2 & 3 & 4 & 5 & 6 & 7 \\ \text { Strongly } & & & & & \begin{array}{c}\text { Strongly } \\ \text { Agree }\end{array} \\ \text { Disagree } & & & & & & \text { Arse }\end{array}$

11. Adolescent male offenders are more likely to continue offending into adulthood than female adolescent offenders.

$\begin{array}{ccccccc}1 \quad 2 & 3 & 4 & 5 & 6 & \begin{array}{c}7 \\ \text { Strongly } \\ \text { Agree }\end{array} \\ \text { Disagree } & & & & & & \text { Agry }\end{array}$

12. Male offenders released from prison are more likely to reoffend than female offenders released from prison.

$\begin{array}{ccccccc}1 \quad 2 & 3 & 4 & 5 & 6 & 7 \\ \text { Strongly } & & & & & \begin{array}{c}\text { Strongly } \\ \text { Agree }\end{array} \\ \text { Disagree } & & & & & & \text { Agre }\end{array}$

13. Youth offenders are more violent than adult offenders.

$\begin{array}{ccccccc}1 \quad 2 & 3 & 4 & 5 & 6 & 7 \\ \text { Strongly } & & & & & \begin{array}{c}\text { Strongly } \\ \text { Agree }\end{array} \\ \text { Disagree } & & & & & & \text { A }\end{array}$

14. Youth offenders do not benefit from treatment.

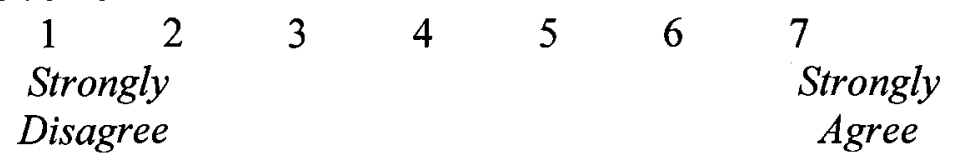

15. Youth offenders in general will continue offending into adulthood.

$\begin{array}{ccccccc}1 \quad 2 & 3 & 4 & 5 & 6 & 7 \\ \text { Strongly } & & & & & \begin{array}{c}\text { Strongly } \\ \text { Agree }\end{array}\end{array}$

16. Youth offenders released from custody pose a significant risk to society.

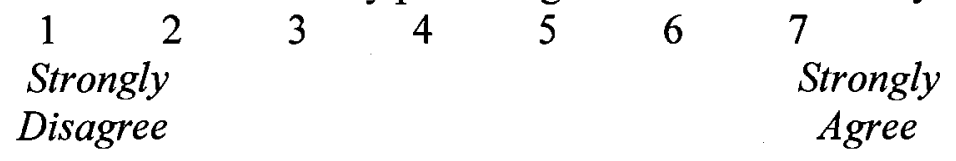




\section{Appendix B}

\section{Court Summary}

Judge: Mr./Mrs. Pullman is 15/30 years old and has been charged with section 268 of the Criminal Code, aggravated assault. The Crown has the burden of proving that charge beyond a reasonable doubt. It is your responsibility to listen to all the evidence and then to apply the law that I will give you at the end of the trial. The trial will begin with opening statements by the Crown and Defence attorneys. These statements are not evidence, yet summaries of what will be presented in the trial. Following these statements, the Crown and Defence will present and question the parties involved, who will subsequently be cross-examined. You will also hear testimony from the court appointed clinical psychologist, Dr. Richards who interviewed the defendant after his/her arrest. Please listen to the following arguments carefully. Following the testimonies, you will be asked to make a decision as to whether you find the defendant, Mr./Mrs. Pullman, guilty or not guilty of the charge.

The Crown makes their opening statements.

Crown: Mr./Mrs. Philip/Diane Pullman is the acquaintance of the victim, Mr./Mrs. Samuel/Samantha Marlowe. On October $15^{\text {th }}, 2007$, an altercation occurred between the accused and the victim. Mr./Mrs. Marlowe questioned the accused concerning his/her behavior towards Mr./Mrs. Marlowe's girlfriend/boyfriend. At this time, the altercation began and Mr./Mrs. Pullman puHe/Shed Mr./Mrs. Marlowe to the ground. When Mr./Mrs. Marlowe tried to defend himself/herself, Mr./Mrs. Pullman grabbed a piece of glass from the sidewalk and stabbed Mr./Mrs. Marlowe in the chest several times. Mr./Mrs. Marlowe was ruHe/Shed to the hospital where the doctors were able to stop the bleeding and save his/her life. Mr./Mrs. Pullman is charged with aggravated assault and it is your duty, as representatives of our community, to seek justice by finding Mr./Mrs. Pullman guilty.

The Defence makes their opening statement.

Defence: Mr./Mrs. Pullman is not guilty of this charge. Although the altercation between Mr./Mrs. Pullman and Mr./Mrs. Marlowe did occur, the details are as follows. Mr./Mrs. Marlowe approached Mr./Mrs. Pullman and insisted that Mr./Mrs. Pullman had been intimate with $\mathbf{M r}$./Mrs. Marlowe's girlfriend/girlfriend/boyfriend. $\mathbf{M r}$./Mrs. Pullman tried to explain that this was not true. Mr./Mrs. Marlowe became very angry and puHe/Shed Mr./Mrs. Pullman to the ground. Mr./Mrs. Marlowe hit Mr./Mrs. Pullman in the face and then began choking him/her. Mr./Mrs. Pullman, fearing for his/her life, grabbed the only thing that was within reach, a piece of glass and stabbed Mr./Mrs. Marlowe. Mr./Mrs. Pullman was being choked and acted in self-defence. $\mathrm{He} / \mathrm{She}$ is not guilty of this charge. I trust that you will consider all the information accordingly and find that my client is indeed innocent.

The Crown calls their witness, Mr./Mrs. Marlowe.

Crown: Please state your name for the Court?

Witness: My name is Samuel/Samantha Marlowe.

Crown: And how do you know the defendant, Mr./Mrs. Pullman? 
Witness: We met through mutual friends. I don't know him/her that well.

Crown: Please tell the court what happened when you went to talk to Mr./Mrs. Pullman. Witness: Philip/Diane said he/she would meet me in the alley behind this convenience store near my place. I went there, and he/she was already waiting. I asked him/her if he/she had slept with my girlfriend/boyfriend. He/She said he/she didn't know what I was talking about. But I told him/her that I knew it was true and that I was going to tell his/her girlfriend/boyfriend that he/she had cheated on her/him. That's when he/she came at me with his/her fists raised. I put my hands up to block him/her but he/she knocked me down.

Crown: And what happened next?

Witness: He/She got on top of me and when I tried to get him/her off, he/she grabbed a piece of broken glass and stabbed me in the chest.

Crown: And then what?

Witness: I don't know, I blacked out. When I woke up I was already in the hospital.

Crown: Was there anyone else in the alley with you?

Witness: No, not that I could see.

Crown: Thank you Mr./Mrs. Marlowe. I have no further questions your honour.

The Defence cross examines the witness.

Defence: Hello, Mr./Mrs. Marlowe.

Witness: Hello.

Defence: You said in your statement that Mr./Mrs. Pullman claimed that he/she had not been intimate with your partner?

Witness: Yes that's right.

Defence: Isn't it true that your partner also denied being with the defendant?

Witness: People saw them together; I know that they were together.

Defence: Isn't it true that you started yelling at Mr./Mrs. Pullman in the alley?

Witness: Well ya I guess I did. I was pretty pissed off.

Defence: I see. Isn't it true that you hit Mr./Mrs. Pullman several times in the face during the altercation?

Witness: Only when I was defending myself. I'm telling the truth damnit!!!

Defence: Did you choke Mr./Mrs. Pullman?

Witness: If I did, it was only because he/she started it!

Defence: No further questions.

The witness is excused.

The Defence calls the defendant, Mr./Mrs. Pullman.

Defence: Please state your name and age for the Court.

Witness: My name is Philip/Diane Pullman and I am 15/30 years old.

Defence: Please tell the court what happened on October $15^{\text {th }}$.

Witness: Sam called me and said he/she wanted to talk about some issues he/she was having. I had no reason to believe that anything was wrong so I met with him/her.

Defence: You didn't know that Mr./Mrs. Marlowe believed that you had been with his/her girlfriend/boyfriend?

Witness: No I didn't because it never happened.

Defence: What happened next? 
Witness: I told him/her I'd meet him/her in this alley near his/her house. I got there early and waited for him/her. When he/she showed up, he/she looked pretty upset about something. He/She started yelling at me, saying he/she'd kill me for sleeping with his/her girlfriend/boyfriend. I said I didn't know what he/she was talking about. Defence: And what did Mr./Mrs. Marlowe do next?

Witness: After I said that I didn't know what he/she was talking about, he/she came at me and pushed me to the ground. He/She started punching me in the face. I put my hands up to block him/her and tried to get up. That's when he/she started choking me. I couldn't breathe; I didn't know what to do. I grabbed for whatever I could. I got hold of a piece of glass and stabbed at him/her until he/she got off me.

Defence: Thank you Mr./Mrs. Pullman. No further questions.

The Crown cross examines the witness.

Crown: So after you stabbed Mr./Mrs. Marlowe, what happened?

Witness: What do you mean?

Crown: Did you call the police?

Witness: I was scared that he/she'd get up so I ran away.

Crown: You left him/her there, and it didn't occur to you to call an ambulance?

Witness: Like I said, I was scared. I wasn't really thinking.

Crown: Isn't it true that you told one of your friends that you hoped Mr./Mrs. Marlowe would die?

Witness: I was really pissed off when I said that. People say stuff like that all the time when they're angry...it doesn't mean that I actually wanted him/her dead. I was defending myself!! Why can't you people see that!!

Crown: No further questions your honour.

The witness is excused.

Testimony from the court appointed clinical psychologist, Dr. Richards.

Judge: Dr. Richards, you had the opportunity to interview Mr. / Mrs. Pullman, is that correct?

Dr. Richards: Yes that's correct. I spent several hours with Phillip / Diane.

Judge: And what were your primary findings?

(PSYCHOPATH)

Dr. Richards: During the interview I found Phillip / Diane to be superficial and insincere. Phillip / Diane consistently tries to charm, con, and manipulate others to obtain what he / she wants. He / She has no empathy for Mr. / Mrs. Marlowe and refuses to take responsibility for his / her actions. I find him / her to be both impulsive and irresponsible in his / her behaviours lacking any realistic long-term goals. In my professional opinion, Phillip / Diane is a psychopath.

Or

(ANTISOCIAL PERSONALITY DISORDER)

Dr. Richards: During the interview I found Phillip / Diane to be aggressive and agitated. He / She seemed to get bored with the interview and respond with anger. Phillip 
/ Diane has had recurring difficulties with the law and has a tendency of violating the rights and boundaries of others. He / She has no remorse for Mr. / Mrs. Marlowe or others that he / she may hurt. In my professional opinion, Phillip / Diane has an antisocial personality disorder.

Or

(CONDUCT DISORDER)

Dr. Richards: During the interview, I discovered that Phillip / Diane has a persistent pattern of behavior in which he /she violates societal norms. Phillip / Diane has a history of bullying. He / She often threatens to harm or intimidate others. He / She initiates fights at school and has been caught destroying public property. He / She also lies in order to get what he / she wants. This behavior has caused clinically significant impairment in Phillip / Diane's social and academic functioning. In my professional opinion, Phillip / Diane has a conduct disorder.

Or

(NO DIAGNOSIS)

Dr. Richards: During the interview, I found Phillip / Diane to be an earnest young man / woman. He / She was forthright and candid, providing careful and thorough answers. He / She was visibly upset about the incident and clearly showed empathy for Mr. / Mrs. Marlowe. In my professional opinion, Phillip / Diane does not have any signs of a clinical diagnosis.

Judge: Thank you Dr. Richards.

The Judge provides the law and instructions for the jury.

Judge: Members of the jury, you have heard the testimony from the both parties involved and the court appointed clinical psychologist. It is now my responsibility to provide you with the law. Mr. / Mrs. Pullman is been charged with the following:

\section{AGGRAVATED ASSAULT}

(1) Every one commits an aggravated assault who wounds, maims, disfigures or endangers the life of the complainant.

(2) Every one who commits an aggravated assault is guilty of an indictable offence and liable to imprisonment for a term not exceeding fourteen years.

Judge: Mr. / Mrs. Pullman's defence is as follows:

\section{SELF-DEFENCE AGAINST UNPROVOKED ASSAULT}

(1) Every one who is unlawfully assaulted without having provoked the assault is justified in repelling force by force if the force he uses is not intended to cause death or grievous bodily harm and is no more than is necessary to enable him to defend himself.

Extent of justification 
(2) Every one who is unlawfully assaulted and who causes death or grievous bodily harm in repelling the assault is justified if

(a) he causes it under reasonable apprehension of death or grievous bodily harm from the violence with which the assault was originally made or with which the assailant pursues his purposes; and

(b) he believes, on reasonable grounds, that he cannot otherwise preserve himself from death or grievous bodily harm.

Please take into consideration all the information you have heard today, and do not let any biases you may have come into your decision making process. 


\section{Appendix C}

Demographic Questionnaire

Please answer the following questions about yourself.

1. Age:

2. Gender (Please circle): Male Female

3. Level of completed education (check one):

__ Some high school

High school diploma

Undergraduate degree

Professional degree

Some graduate studies

Masters diploma

Ph.D.

Other: please specify

4. Language Fluency (Check all that apply to you):

\section{English:}

Oral; __ Written

French:

Oral; __ Written

Other (specify):

Oral; ___ Written
5. Ethnicity: (check one) Caucasian Black Aboriginal Indian Asian Other:

6. Occupation status (check one):

Student
Working
Unemployed
Retired
Other:

7. Country of citizenship: Canada Other: 


\section{Appendix D}

\section{Credibility Ratings Form}

Please answer each question by circling a number for each scale provided below.

1. In your opinion, how convincing was the testimony of the victim, Samuel / Samantha Marlowe?

$\begin{array}{ccccccc}1 & 2 & 3 & 4 & 5 & 6 & \begin{array}{c}7 \\ \text { Extremely }\end{array} \\ \text { Not atl } & & & & & & \end{array}$

2. In your opinion, how convincing was the testimony of the defendant, Phillip / Diane Pullman?

$\begin{array}{ccccccc}1 & 2 & 3 & 4 & 5 & 6 & \begin{array}{c}7 \\ \text { Extremely }\end{array} \\ \text { Not at all } & & & & & & \end{array}$

3. In your opinion, how convincing was the testimony by Dr. Richards?

$\begin{array}{lllllll}1 & 2 & 3 & 4 & 5 & 6 & 7\end{array}$

Not at all

Extremely 


\section{Appendix E}

Verdict and Verdict Confidence Form

Please answer the following questions regarding your verdict.

With respect to the aggravated assault charge, please rate the degree to which you find the defendant, Philip/Diane Pullman, guilty.

Please circle one value on the scale below.

$\begin{array}{ccccccc}1 & 2 & 3 & 4 & 5 & 6 & \begin{array}{c}7 \\ \text { Definitely } \\ \text { Guilty } \\ \text { Guilty }\end{array}\end{array}$

Please check one of the boxes below.

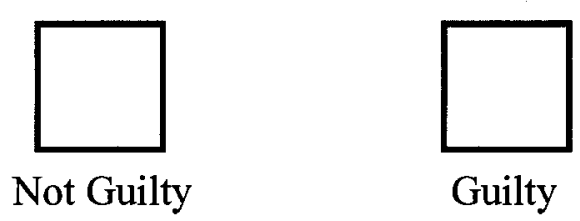

How confident are you regarding your verdict decision (i.e., Guilty or Not Guilty)?

$\begin{array}{ccccccc}1 & 2 & 3 & 4 & 5 & 6 & 7 \\ \begin{array}{c}\text { Not } \text { Confident } \\ \text { at all }\end{array} & & & & & & \\ \text { Extremely } \\ \text { Confident }\end{array}$

In your own words, please describe in the space below how you made your final verdict decision (i.e., what factors did you consider in reaching your verdict of guilty or not guilty?) 
Appendix F

Proposed Sentence Form

If you have found the defendant NOT GUILTY, please turn this page over now to answer the next set of questions on treatment and risk for violence.

If you found the defendant GUILTY, please answer the questions below with regards to sentence recommendations for aggravated assault.

In accordance with section 268 of the Criminal Code of Canada, a sentence of imprisonment not exceeding fourteen years follows the conviction of a person accused of aggravated assault. According to the Youth Criminal Justice Act, the court can impose an adult sentence on any youth that is 15 years or older OR an alternate sentence can be imposed. Please decide whether the defendant should be sentenced as a youth or an adult and choose ONE option below (DO NOT CHOOSE BOTH AN ADULT AND A YOUTH SENTENCE).

ADULT SENTENCES:

Please check one.

$$
\begin{gathered}
1-2 \text { years } \\
3-4 \text { years } \\
5-6 \text { years } \\
\\
7-8 \text { years } \\
10-14 \text { years }
\end{gathered}
$$

$\underline{\text { OR }}$

\section{YOUTH SENTENCES:}

Please check one.

Order an absolute discharge (defendant is free to go)

Discharge with conditions (e.g., defendant must be supervised by the provincial director)

Impose a fine (not to exceed $\$ 1,000$ )

Community service

Probation (not exceeding two years)

Order to attend non-residential

program (maximum two hundred and forty hours

Custody and supervision order (not to

exceed two years)

Finally, if you could give ANY sentence to the defendant, what would it be? 


\section{Appendix G \\ Treatment and Risk for Violence Questionnaire}

Please answer each question by circling a number for each scale provided below.

1. How likely are you to recommend treatment for the defendant, Mr. / Mrs. Pullman?

$\begin{array}{ccccccc}1 & 2 & 3 & 4 & 5 & 6 & 7 \\ \text { Not at all } & & & & & & \text { Extremely }\end{array}$

2. How much would Mr. / Mrs. Pullman benefit from treatment?

$\begin{array}{ccccccc}1 & 2 & 3 & 4 & 5 & 6 & 7 \\ \text { Not at all } & & & & & & \text { Extremely }\end{array}$

3. How useful would a treatment program aimed at reducing violence be for Mr. / Mrs. Pullman?

$\begin{array}{ccccccc}1 & 2 & 3 & 4 & 5 & 6 & 7 \\ \text { Not at all } & & & & & & \text { Extremely }\end{array}$

4. How useful would any treatment program aimed at reducing criminal behavior be for Mr. / Mrs. Pullman?

$\begin{array}{ccccccc}1 & 2 & 3 & 4 & 5 & 6 & 7 \\ \text { Not at all } & & & & & & \text { Extremely }\end{array}$

5. How high is Mr. / Mrs. Pullman's risk for future violence?

$\begin{array}{ccccccc}1 & 2 & 3 & 4 & 5 & 6 & 7 \\ \text { Not at all } & & & & & & \text { Extremely }\end{array}$

6. How high is Mr. / Mrs. Pullman's risk for future criminal acts?

$\begin{array}{ccccccc}1 & 2 & 3 & 4 & 5 & 6 & 7 \\ \text { Not at all } & & & & & & \text { Extremely }\end{array}$

7. How likely is it that Mr. / Mrs. Pullman poses a threat to society?

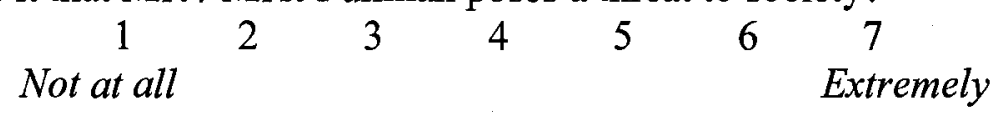

8. How likely is it that Mr. / Mrs. Pullman will become a criminal as an adult?

$\begin{array}{ccccccc}1 & 2 & 3 & 4 & 5 & 6 & 7 \\ \text { Not at all } & & & & & & \text { Extremely }\end{array}$




\section{Appendix $\mathrm{H}$}

Manipulation Check

Please answer the following questions. Circle the letter that corresponds to your answer.

1. How old is the defendant, Philip/Diane Pullman?
a. 12 years old
b. 15 years old
c. 30 years old
d. 32 years old

2. What diagnosis did Dr. Richards provide for Mr./Mrs. Pullman?
a. Psychopath
b. Antisocial personality disorder
c. Conduct disorder
d. No disorder

3. Where did the altercation take place?
a. In an alley
b. At Marlowe's house
c. At Pullman's house
d. At a party

4. What did Philip/Diane Pullman use to stab Samuel/Samantha Marlowe?
a. A knife
b. A piece of glass
c. A sword
d. A fork

5. What was the accused, Mr./Mrs. Pullman charged with?
a. Attempted murder
b. Assault with a deadly weapon
c. Aggravated assault
d. Parole violation 
Appendix I

\section{Informed Consent Form}

The purpose of an informed consent form is to ensure that you, as the participant, understand the purpose of the study as well as the nature of your involvement. The informed consent form should provide sufficient information such that you have the opportunity to determine whether or not you wish to participate in the study.

Purpose: In conducting this study, we hope to gain a better understanding of the effect of different variables on jury decision making.

Task requirements: You will be required to read a description of a court case as well as the testimony of an expert witness. Using this information you will be asked to fill in a questionnaire concerning the verdict you would choose, whether you would recommend treatment and whether you believe the defendant is at risk for future violence and criminality. You will also answer a questionnaire concerning your beliefs about certain types of offenders and questions concerning facts from the case.

Research personnel If you have any research questions or concerns regarding the study, the principal investigator, Julie Blais, can be reached by phone at 613-520-2600 ext. 1408 or emailed at jblais2@connect.carleton.ca. The Faculty Sponsor, Adelle Forth, can be reached by phone at 613-520-2600, ext. 1267 or emailed at adelle_forth@carleton.ca. If you have any ethical questions or concerns regarding the study, the departmental chair, Anne Bowker can be reached by phone at (613) 520-2600 ext 2648, or by email at psychchair@carleton.ca. As well, the Chair of the Carleton University Ethics Committee for Psychological Research, Avi Parush, can be reached by phone at (613) 520-2600 ext. 6026, or by email at avi_parush@carleton.ca.

Duration and location: The entire session should take approximately 30-45 minutes and will take place in a classroom that will be booked in advance.

Potential risk and discomfort: The subject matter of the court case involves a description of a serious assault which could be upsetting to some individuals. Please be reminded that your participation is entirely voluntary, that you may choose not to answer any question, and that you may withdraw from the study at any time without penalty.

Anonymity and confidentiality: The data collected will be coded with numbers instead of names to ensure anonymity of information. As well, confidentiality will be upheld, as information will only be shared with research personnel for the purpose of research publications, conference presentations or teaching material. Also, the informed consent forms will be kept separate from your questionnaires once returned.

Right to withdraw: Your participation in this study is entirely voluntary. You have the right to withdraw from the experiment at any time, and omit specific questions, both without academic penalty. You will receive your credit, regardless of withdrawing from the experiment, even if you fail to complete the study. 
Signatures: I have read the above description of the study and I understand that the data in this study will be used in research publications, conference presentations, or for teaching purposes. My signature indicates that I agree to participate in this study.

Participant's Name:

Researcher's Name:

Participant's Signature: Researcher's Signature:

Date: 
Appendix J

Debriefing Form

I would like to thank you for your participation in this study. However, before you go, I would briefly like to tell you a bit more about our study and why we are interested in examining these sorts of issues.

What are we trying to learn in this research?

We are trying to learn about the potential biasing effects of psychopathy, while exploring what effects factors such as age and gender of the offender have on jury decision making. The goal is to discover what mock jurors believe concerning sentencing, treatment, and risk for future violence when offenders are diagnosed with psychopathy, antisocial personality or conduct disorder and no disorder at all. Also, we are interested in the potential interaction effects between diagnostic criteria and offender age and gender. For example, do people have less negative views towards an offender who is diagnosed as a psychopath if that person is also a female?

Why is this important to scientists or the general public?

Findings from this study will help to determine if laypersons' beliefs about how different types of offenders should be treated by the Criminal Justice System (CJS) are consistent with the findings available on actual violence risk and treatment outcomes. This is important because there is a possibility that a self-fulfilling prophecy is occurring with the CJS. More specifically, offenders assumed to be at greater risk are given harsher sanctions which may result in a more dangerous offender. There is also a gap in the literature concerning the potential biasing effect of offender age; therefore this study will be able to make preliminary conclusions concerning how young offenders are viewed by potential jurors. Finally, this will be the first Canadian study exploring what effect information about psychopathic traits will have on potential jurors' perceptions of psychopathic offenders.

\section{What are our hypotheses and predictions?}

Our first hypothesis is that jurors will be harsher in terms of sentencing, beliefs about treatment and future violence for psychopathic offenders compared to nonpsychopathic offenders. Our second hypothesis is that jurors will be less harsh in terms of sentencing, treatment and future violence when the offender is a female. Finally, we believe that jurors will be less harsh with psychopathic offenders when they are also described as young adolescents.

Where can I learn more?

There is information about the potential biasing effects of psychopathy at the following references: 
Edens, J. F., Colwell, L. H., Desforges, D. M., \& Fernandez, K. (2005). The impact of mental

health evidence on support for capital punishment: Are defendants labeled psychopathic considered more deserving of death? Behavioural Sciences and the Law, 23, 603625.

Murrie, D. C., Cornell, D. G., \& McCoy, W. K. (2005). Psychopathy, conduct disorder, and

stigma: Does diagnostic labeling influence juvenile probation officer recommendations?

Law and Human Behavior, 29, 323-342.

Vidal, S., \& Skeem, J. L. (2007). Effect of psychopathy, abuse, and ethnicity on juvenile probation officers' decision making and supervision strategies. Law and Human Behavior, 31, 479-498.

To find out more about psychopathy go to: www.hare.org

What if I have questions later?

For research concerns, participants can contact the Faculty Sponsor, Adelle Forth, who can be reached by phone at 613-520-2600, ext. 1267 or emailed at adelle_forth@carleton.ca. The Principle Investigator, Julie Blais, can also be reached by phone at 613-520-2600, ext. 1408, or emailed at jblais2@connect.carleton.ca.

For ethical concerns, participants can contact the Chair of the Carleton University Ethics Committee for Psychological Research, Avi Parush, who can be reached by phone at ext 6026 or by email at avi_parush@carleton.ca. The Chair of the Department, Anne Bowker, can also be reached by phone at ext. 2648 , or by email at psychchair@carleton.ca.

Is there anything that I can do if I found this experiment to be emotionally draining?

If you should feel upset please, contact the Carleton University Health and Counseling Services by phone at (613) 520-6674, for follow-up consultation for distress.

Thank you again for participating in our study 


\section{Appendix K}

Reasons for Verdict Decision

1. Disbelief for victim's statement

2. Belief of defendant's statement

3. Doctor's testimony

4. Not enough evidence

5. Self-defence

6. Disliked victim

7. Level of force used

8. Victim initiated confrontation

9. Defendant was set-up

10. No remorse

11. Disbelief of defendant's statement

12. No doubt about stabbing

13. Defendant was an aggressive person

14. Defendant's history of violence

15. Psychological disorder makes defendant violent and antisocial

16. Not sure who to believe

17. Not enough time with doctor

18. Didn't call ambulance

19. Crime of Passion

20. No evidence of alleged choking

21. Anger of the Victim

22. Girlfriend denies sexual allegations

23. Doctor's testimony didn't fit

24. Age of defendant 
25. Victim was too aggressive during testimony

26. Defendant is a psychopath

27. Victim took no responsibility for the altercation

28. Victim seemed ready to fight

29. Defendant set up meeting

30. Requirements of aggravated assault clearly met

31. Not proven beyond a reasonable doubt

32. Defendant left the scene of the crime

33. Defendant showed remorse

34. Psychologist is biased

35. Psychologist's testimony not complete

36. Defendant hoped the victim would die

37. Victim was defending himself 